Cochrane Database of Systematic Reviews

\title{
Ivabradine as adjuvant treatment for chronic heart failure (Review)
}

Benstoem C, Kalvelage C, Breuer T, Heussen N, Marx G, Stoppe C, Brandenburg V

Benstoem C, Kalvelage C, Breuer T, Heussen N, Marx G, Stoppe C, Brandenburg V. Ivabradine as adjuvant treatment for chronic heart failure.

Cochrane Database of Systematic Reviews 2020, Issue 11. Art. No.: CD013004.

DOI: 10.1002/14651858.CD013004.pub2.

www.cochranelibrary.com 
TABLE OF CONTENTS

HEADER 1

ABSTRACT

PLAIN LANGUAGE SUMMARY

SUMMARY OF FINDINGS

BACKGROUND

OBJECTIVES

METHODS

Figure 1.

Figure 2.

Figure 3.

Figure 4.

RESULTS

DISCUSSION

AUTHORS' CONCLUSIONS

ACKNOWLEDGEMENTS

REFERENCES

CHARACTERISTICS OF STUDIES

DATA AND ANALYSES

Analysis 1.1. Comparison 1: Usual care with ivabradine compared to placebo, usual care, or no treatment in participants with

HFrEF (long-term treatment ( $\geq 6$ months) with ivabradine), Outcome 1: Mortality from cardiovascular causes (follow-up range 19 months to 23 months)

Analysis 1.2. Comparison 1: Usual care with ivabradine compared to placebo, usual care, or no treatment in participants with

HFrEF (long-term treatment ( $\geq 6$ months) with ivabradine), Outcome 2: Rate of serious adverse events

ADDITIONAL TABLES

APPENDICES

HISTORY

CONTRIBUTIONS OF AUTHORS

DECLARATIONS OF INTEREST

SOURCES OF SUPPORT

DIFFERENCES BETWEEN PROTOCOL AND REVIEW

INDEX TERMS 
[Intervention Review]

\title{
Ivabradine as adjuvant treatment for chronic heart failure
}

\author{
Carina Benstoem ${ }^{1}$, Christina Kalvelage ${ }^{1}$, Thomas Breuer ${ }^{1}$, Nicole Heussen²,3, Gernot Marx ${ }^{1}$, Christian Stoppe ${ }^{1}$, Vincent Brandenburg 4
}

1Department of Intensive Care Medicine, Medical Faculty, RWTH Aachen University, Aachen, Germany. 2Department of Medical Statistics, Medical Faculty RWTH Aachen University, Aachen, Germany. ${ }^{3}$ Center of Biostatistic and Epidemiology, Medical School, Sigmund Freud Private University, Vienna, Austria. ${ }^{4}$ Department of Cardiology, Medical Faculty, University Hospital RWTH Aachen, Aachen, Germany

Contact address: Carina Benstoem, cbenstoem@ukaachen.de.

Editorial group: Cochrane Heart Group.

Publication status and date: New, published in Issue 11, 2020.

Citation: Benstoem C, Kalvelage C, Breuer T, Heussen N, Marx G, Stoppe C, Brandenburg V. Ivabradine as adjuvant treatment for chronic heart failure. Cochrane Database of Systematic Reviews 2020, Issue 11. Art. No.: CD013004. DOI: 10.1002/14651858.CD013004.pub2.

Copyright ( 2020 The Cochrane Collaboration. Published by John Wiley \& Sons, Ltd.

\section{A B S T R A C T}

\section{Background}

Chronic heart failure is one of the most common medical conditions, affecting more than 23 million people worldwide. Despite established guideline-based, multidrug pharmacotherapy, chronic heart failure is still the cause of frequent hospitalisation, and about $50 \%$ die within five years of diagnosis.

\section{Objectives}

To assess the effectiveness and safety of ivabradine in individuals with chronic heart failure.

\section{Search methods}

We searched CENTRAL, MEDLINE, Embase, and CPCI-S Web of Science in March 2020. We also searched ClinicalTrials.gov and the WHO ICTRP. We checked reference lists of included studies. We did not apply any time or language restrictions.

\section{Selection criteria}

We included randomised controlled trials in which adult participants diagnosed with chronic heart failure were randomly assigned to receive either ivabradine or placebo/usual care/no treatment. We distinguished between type of heart failure (heart failure with a reduced ejection fraction or heart failure with a preserved ejection fraction) as well as between duration of ivabradine treatment (short term ( 6 months) or long term ( $\geq 6$ months)).

\section{Data collection and analysis}

Two review authors independently assessed trials for inclusion, extracted data, and checked data for accuracy. We calculated risk ratios (RR) using a random-effects model. We completed a comprehensive 'Risk of bias' assessment for all studies. We contacted authors for missing data. Our primary endpoints were: mortality from cardiovascular causes; quality of life; time to first hospitalisation for heart failure during follow-up; and number of days spent in hospital due to heart failure during follow-up. Our secondary endpoints were: rate of serious adverse events; exercise capacity; and economic costs (narrative report). We assessed the certainty of the evidence applying the GRADE methodology.

\section{Main results}

We included 19 studies (76 reports) involving a total of 19,628 participants (mean age 60.76 years, $69 \%$ male). However, few studies contributed data to meta-analyses due to inconsistency in trial design (type of heart failure) and outcome reporting and measurement. In general, risk of bias varied from low to high across the included studies, with insufficient detail provided to inform judgement in several cases. 
We were able to perform two meta-analyses focusing on participants with heart failure with a reduced ejection fraction (HFrEF) and longterm ivabradine treatment. There was evidence of no difference between ivabradine and placebo/usual care/no treatment for mortality from cardiovascular causes (RR 0.99, 95\% confidence interval ( $\mathrm{Cl}$ ) 0.88 to $1.11 ; 3$ studies; 17,676 participants; $12=33 \%$; moderate-certainty evidence). Furthermore, we found evidence of no difference in rate of serious adverse events amongst HFrEF participants randomised to receive long-term ivabradine compared with those randomised to placebo, usual care, or no treatment ( $\mathrm{RR} 0.96,95 \% \mathrm{Cl} 0.92 \mathrm{to} 1.00 ; 2$ studies; 17,399 participants; $1^{2}=12 \%$; moderate-certainty evidence). We were not able to perform meta-analysis for all other outcomes, and have low confidence in the findings based on the individual studies.

\section{Authors' conclusions}

We found evidence of no difference in cardiovascular mortality and serious adverse events between long-term treatment with ivabradine and placebo/usual care/no treatment in participants with heart failure with HFrEF. Nevertheless, due to indirectness (male predominance), the certainty of the available evidence is rated as moderate.

\section{PLAIN LANGUAGE SUMMARY}

\section{Ivabradine as adjuvant treatment for chronic heart failure}

\section{What is the aim of this review?}

We investigated the effects of ivabradine (either as short-term treatment ( $<6$ months) or long-term treatment ( $\geq 6$ months) in people with heart failure and preserved (HFpEF, left ventricular ejection fraction is $50 \%$ or higher) or reduced ejection fraction (HFrEF, left ventricular ejection fraction is less than $40 \%)$.

\section{Key messages}

We found that long-term ivabradine has no effect on death from cardiovascular causes in people with HFrEF. We also found that there is no difference between long-term ivabradine and placebo (dummy treatment), usual care, or no treatment in the rate of serious adverse events in people with HFrEF.

\section{What was studied in this review?}

Heart failure is a common condition that occurs when the heart muscle is too weak to pump blood sufficiently to the body, which leads to symptoms like shortness of breath, tiredness, swelling of the legs, and a limited ability to exercise. About half of people who suffer from heart failure die within five years of diagnosis. Several medications are known to be effective in treating heart failure; however, we wanted to know if ivabradine could improve survival. Seven studies focused on short-term treatment ( 6 months) with ivabradine, and eleven studies focused on a long-term treatment ( $\geq 6$ months) with ivabradine. One study provided no information on duration of ivabradine administration.

\section{What are the main results of this review?}

We found 19 randomised controlled trials (a type of study in which participants are assigned to one of two or more treatment groups using a random method) with a total of 19,628 participants investigating ivabradine. Eleven studies focused on HFrEF, three studies on HFpEF, and one study on heart failure with mid-range ejection fraction (HFmrEF); no details were provided on heart failure in the remaining studies.

\section{How up-to-date is this review?}

We searched for studies that had been published up to March 2020. 
SUMMARY OF FINDINGS

Summary of findings 1. Usual care with ivabradine compared to placebo, usual care, or no treatment in participants with HFrEF (long-term treatment ( $\geq 6$ months) with ivabradine)

Usual care with ivabradine compared to placebo, usual care, or no treatment in participants with HFrEF (long-term treatment ( $\geq 6$ months) with ivabradine)

Patient or population: adults ( $\geq 18$ years of age) with a diagnosis of chronic heart failure with reduced ejection fraction (HFrEF)

Setting: hospital or outpatient care

Intervention: long-term treatment ( $\geq 6$ months) with ivabradine

Comparison: placebo, usual care, or no treatment

\begin{tabular}{|c|c|c|c|c|c|c|}
\hline \multirow[t]{2}{*}{ Outcomes } & \multicolumn{2}{|c|}{ Anticipated absolute effects ${ }^{*}(95 \% \mathrm{Cl})$} & \multirow{2}{*}{$\begin{array}{l}\text { Relative effect } \\
(95 \% \mathrm{Cl})\end{array}$} & \multirow{2}{*}{$\begin{array}{l}\text { № of partici- } \\
\text { pants } \\
\text { (studies) }\end{array}$} & \multirow{2}{*}{$\begin{array}{l}\text { Certainty of } \\
\text { the evidence } \\
\text { (GRADE) }\end{array}$} & \multirow[t]{2}{*}{ Comments } \\
\hline & Risk with placebo & $\begin{array}{l}\text { Risk with usual care with } \\
\text { ivabradine compared to place- } \\
\text { bo, usual care, or no treatment } \\
\text { in participants with HFrEF } \\
\text { (long-term treatment ( } \geq 6 \\
\text { months) with ivabradine) }\end{array}$ & & & & \\
\hline $\begin{array}{l}\text { Mortality from } \\
\text { cardiovascu- } \\
\text { lar causes (fol- } \\
\text { low-up range } 19 \\
\text { to } 23 \text { months) }\end{array}$ & 106 per 1000 & 105 per 1000 (93 to 117 ) & $\begin{array}{l}\text { RR } 0.99 \\
\text { (0.88 to } 1.11 \text { ) }\end{array}$ & $\begin{array}{l}17,676 \\
\text { (3 RCTs) }\end{array}$ & $\begin{array}{l}\oplus \oplus \oplus \ominus \\
\text { MODERATE } 1\end{array}$ & $\begin{array}{l}\text { Evidence of no } \\
\text { difference as the } \\
\text { effect is close to } 1 \\
\text { and the } \mathrm{Cl} \text { is nar- } \\
\text { row. }\end{array}$ \\
\hline
\end{tabular}

Quality of life Swedberg 2010: Treatment with ivabradine improved Kansas City Cardiomyopathy Questionnaire (KCCQ) by 1.8 (95\% Cl 0.30 to 3.24) for clinical summary score (CSS) and by $2.4(95 \% \mathrm{Cl}$

0.91 to 3.85 ) for overall summary score (OSS) (placebo-corrected, $P=0.018$ and $P<0.001$, re-

(2 RCTs)

$\oplus \oplus \ominus \ominus$

spectively)

Chaudhari 2014: Significant improvement $(P=0.004$, no further details available $)$

Time to first Not reported in studies that met the inclusion criteria for this comparison

hospitalisation

for heart fail-

ure during fol-

low-up

Number of days Not reported in studies that met the inclusion criteria for this comparison

spent in hospi-

tal due to heart 


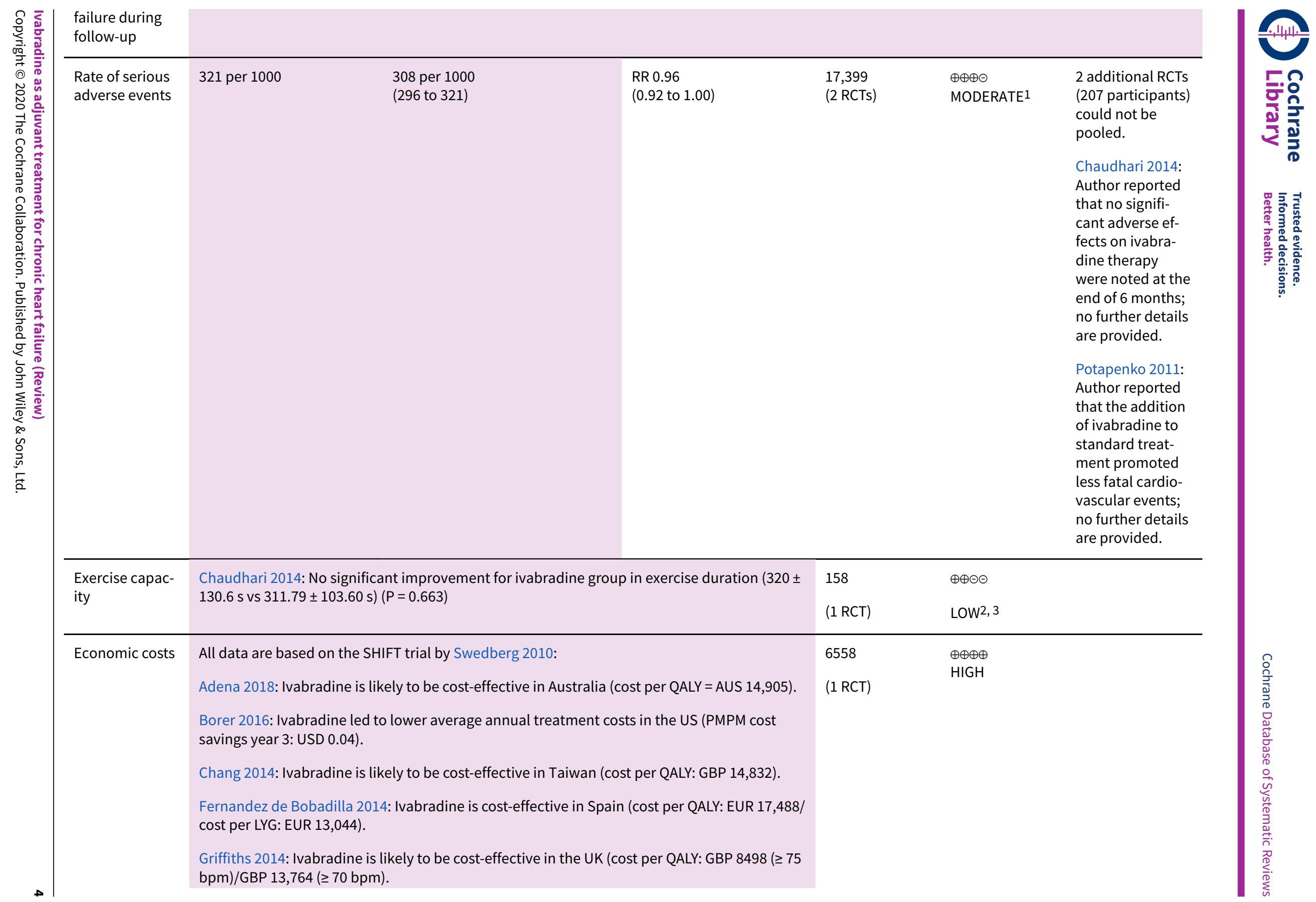


Kourlaba 2014: Ivabradine is a cost-effective option in Greece (cumulative lifetime total cost per patient EUR 8665 vs EUR 5837/ICER per QALY: EUR 9986).

Krittayaphong 2019: The addition of ivabradine to standard treatment is a cost-effective treatment strategy in HFrEF patients in Thailand with a heart rate $\geq 77$ bpm (USD 6515.16/ QALY).

Polistena 2014: Results show social acceptability of ivabradine in Italy (cost per QALY: EUR 17,435/cost per LYG: EUR 15,557/HOS costs avoided: EUR 3420).

Taheri 2018: From an Iranian healthcare system, the analysis indicates that the clinical benefit of ivabradine can be achieved at a reasonable cost in eligible hear failure patients (cost per QALY: USD 5437).

${ }^{\star}$ The risk in the intervention group (and its 95\% confidence interval) is based on the assumed risk in the comparison group and the relative effect of the intervention (and its $95 \% \mathrm{Cl}$ ).

bpm: beats per minute; Cl: confidence interval; HFrEF: heart failure with reduced ejection fraction; HOS: hospitalization; ICER: Incremental cost-effectiveness ratio; LYG: life years gained;PMPM: per member per month; QALY: quality-adjusted life year; RCT: randomised controlled trial; RR: risk ratio

\section{GRADE Working Group grades of evidence}

High certainty: We are very confident that the true effect lies close to that of the estimate of the effect.

Moderate certainty: We are moderately confident in the effect estimate: the true effect is likely to be close to the estimate of the effect, but there is a possibility that it is substantially different.

Low certainty: Our confidence in the effect estimate is limited: the true effect may be substantially different from the estimate of the effect.

Very low certainty: We have very little confidence in the effect estimate: the true effect is likely to be substantially different from the estimate of effect.

1Downgraded by one level due to indirectness (male predominance).

2Downgraded by one level due to risk of bias (allocation, blinding).

3Downgraded by one level due to imprecision (low number of participants).

${ }^{4}$ Downgraded by one level due to attrition bias (only around $30 \%$ of the overall trial participants contributed data).

\section{Summary of findings 2. Usual care with ivabradine compared to placebo, usual care, or no treatment in participants with HFrEF (short-term treatment ( $<6$ months) with ivabradine)}

Usual care with ivabradine compared to placebo, usual care, or no treatment in participants with HFrEF (short-term treatment (< 6 months) with ivabradine)

Patient or population: adults ( $\geq 18$ years of age) with a diagnosis of chronic heart failure with reduced ejection fraction (HFrEF)

Setting: hospital or outpatient care

Intervention: short-term treatment ( $<6$ months) with ivabradine 
Comparison: placebo, usual care, or no treatment

\begin{tabular}{|c|c|c|c|c|c|}
\hline \multirow[t]{2}{*}{ Outcomes } & \multicolumn{2}{|c|}{ Anticipated absolute effects* $(95 \% \mathrm{Cl})$} & \multirow{2}{*}{$\begin{array}{l}\text { Relative effect } \\
(95 \% \mathrm{Cl})\end{array}$} & \multirow{2}{*}{$\begin{array}{l}\text { № of participants } \\
\text { (studies) }\end{array}$} & \multirow{2}{*}{$\begin{array}{l}\text { Certainty of the } \\
\text { evidence } \\
\text { (GRADE) }\end{array}$} \\
\hline & Risk with placebo & $\begin{array}{l}\text { Risk with usual care with ivabradine } \\
\text { compared to placebo, usual care, or } \\
\text { no treatment in participants with } \\
\text { HFrEF (short-term treatment ( }<6 \\
\text { months) with ivabradine) }\end{array}$ & & & \\
\hline $\begin{array}{l}\text { Mortality from car- } \\
\text { diovascular causes } \\
\text { (follow-up range } 19 \\
\text { to } 23 \text { months) }\end{array}$ & \multicolumn{5}{|c|}{ Not reported in studies that met the inclusion criteria for this comparison } \\
\hline Quality of life & \multicolumn{3}{|c|}{$\begin{array}{l}\text { Sarullo 2010: Minnesota Living with Heart Failure Questionnaire } \\
\text { Significant improvement for ivabradine at } 3 \text { months vs baseline }(37.5+1.9 \text { vs } 30.9+2.3)(P<0.001) \text {; no } \\
\text { significant difference for control at } 3 \text { months vs baseline }(31.2+2.6 \text { vs } 30.6+2.1)(P=\text { n.s. })\end{array}$} & $\begin{array}{l}60 \\
(1 \mathrm{RCT})\end{array}$ & $\begin{array}{l}\oplus \oplus \ominus \ominus \\
\text { LOW1, } 2\end{array}$ \\
\hline $\begin{array}{l}\text { Time to first hospital- } \\
\text { isation for heart fail- } \\
\text { ure during follow-up }\end{array}$ & \multicolumn{5}{|c|}{ Not reported in studies that met the inclusion criteria for this comparison } \\
\hline $\begin{array}{l}\text { Number of days } \\
\text { spent in hospital due } \\
\text { to heart failure dur- } \\
\text { ing follow-up }\end{array}$ & \multicolumn{5}{|c|}{ Not reported in studies that met the inclusion criteria for this comparison } \\
\hline $\begin{array}{l}\text { Rate of serious ad- } \\
\text { verse events }\end{array}$ & \multicolumn{3}{|c|}{$\begin{array}{l}\text { Tsutsui 2016: Significant worsening of adverse events (heart failure, phosphenes, diarrhoea, na- } \\
\text { sopharyngitis): } 54.8 \% \text { (2.5 mg ivabradine); } 64.3 \% \text { (5 mg ivabradine) vs } 29.3 \% \text { (control) }(P=0.004) \\
\text { Adamyan 2008: Noticeable side effects requiring the withdrawal of drugs were not observed. }\end{array}$} & $\begin{array}{l}270 \\
\text { (2 RCTs) }\end{array}$ & $\begin{array}{l}\oplus \oplus \oplus \odot \\
\text { LOW } 1,3\end{array}$ \\
\hline Exercise capacity & \multicolumn{3}{|c|}{$\begin{array}{l}\text { Abdel 2011: Significant improvement for ivabradine group in exercise duration at } 3 \text { months ( } 497 \mathrm{~s} \text { vs } \\
328 \mathrm{~s})(P=0.024) \\
\text { Adamyan } 2008 \text { : Significant improvement for ivabradine group in exercise duration at } 90 \text { days }(495 \pm \\
147 \mathrm{~s} \text { vs } 416 \pm 128 \mathrm{~s})(P<0.05) \\
\text { Sarullo } 2010 \text { : Significant improvement for ivabradine group in exercise duration at } 3 \text { months }(28.2 \pm \\
3.5 \text { min vs } 14.8 \pm 2.5 \mathrm{~min})(P<0.001)\end{array}$} & $\begin{array}{l}305 \\
\text { (3 RCTs) }\end{array}$ & $\begin{array}{l}\oplus \oplus \ominus \ominus \\
\text { LOW } 1,2\end{array}$ \\
\hline
\end{tabular}


${ }^{*}$ The risk in the intervention group (and its 95\% confidence interval) is based on the assumed risk in the comparison group and the relative effect of the intervention (and its $95 \% \mathrm{Cl})$.

Cl: confidence interval; HFrEF: heart failure with reduced ejection fraction;RCT: randomised controlled trial; RR: risk ratio

\section{GRADE Working Group grades of evidence}

High certainty: We are very confident that the true effect lies close to that of the estimate of the effect.

Moderate certainty: We are moderately confident in the effect estimate: the true effect is likely to be close to the estimate of the effect, but there is a possibility that it is substantially different.

Low certainty: Our confidence in the effect estimate is limited: the true effect may be substantially different from the estimate of the effect.

Very low certainty: We have very little confidence in the effect estimate: the true effect is likely to be substantially different from the estimate of effect.

1Downgraded by one level due to imprecision (low number of participants).

2Downgraded by one level due to risk of bias (blinding).

${ }^{3}$ Downgraded by one level due to publication bias (low number of studies reporting on this outcome)

Summary of findings 3. Usual care with ivabradine compared to placebo, usual care, or no treatment in participants with HFpEF (long-term treatment ( $\geq 6$ months) with ivabradine)

Usual care with ivabradine compared to placebo, usual care, or no treatment in participants with HFpEF (long-term treatment ( $\geq 6$ months) with ivabradine)

Patient or population: adults ( $\geq 18$ years of age) with a diagnosis of chronic heart failure with a preserved ejection fraction (HFpEF)

Setting: hospital or outpatient care

Intervention: long-term treatment ( $\geq 6$ months) with ivabradine

Comparison: placebo, usual care, or no treatment

\begin{tabular}{|c|c|c|c|c|c|}
\hline \multirow[t]{2}{*}{ Outcomes } & \multicolumn{2}{|c|}{ Anticipated absolute effects ${ }^{\star}(95 \% \mathrm{Cl})$} & \multirow{2}{*}{$\begin{array}{l}\text { Relative effect } \\
(95 \% \mathrm{CI})\end{array}$} & \multirow{2}{*}{$\begin{array}{l}\text { № of participants } \\
\text { (studies) }\end{array}$} & \multirow{2}{*}{$\begin{array}{l}\text { Certainty of the } \\
\text { evidence } \\
\text { (GRADE) }\end{array}$} \\
\hline & Risk with placebo & $\begin{array}{l}\text { Risk with usual care with ivabradine } \\
\text { compared to placebo, usual care, or } \\
\text { no treatment in patients with HFpEF } \\
\text { (long-term treatment ( } \geq 6 \text { months) } \\
\text { with ivabradine) }\end{array}$ & & & \\
\hline $\begin{array}{l}\text { Mortality from cardiovas- } \\
\text { cular causes }\end{array}$ & \multicolumn{3}{|c|}{$\begin{array}{l}\text { Komajda 2017: } 1 \text { death from cardiovascular cause occurred in the ivabradine group (ischaemic } \\
\text { stroke); no deaths occurred in the control group. }\end{array}$} & $178(1 \mathrm{RCT})$ & $\begin{array}{l}\oplus \oplus \oplus \odot \\
\text { LOW } 1,2\end{array}$ \\
\hline Quality of life & \multicolumn{3}{|c|}{ No significant improvement (no further details available) } & $\begin{array}{l}179 \\
(1 \mathrm{RCT})\end{array}$ & $\begin{array}{l}\oplus \oplus \odot \ominus \\
\text { LOW } 1,2\end{array}$ \\
\hline
\end{tabular}


Number of days spent in hospital due to heart failure during follow-up

\section{Rate of serious adverse}

events

Not reported in studies that met the inclusion criteria for this comparison

Komajda 2017: No significant difference in improvement $(35.1 \%$ vs $25.0 \%)(P=0.191)$

179

$(1 \mathrm{RCT})$

$\oplus \oplus \Theta \Theta$

Exercise capacity

Komajda 2017: No significant improvement for ivabradine group in 6-minute walk test (change of last postbaseline value from baseline: $+0.0 \mathrm{~m}$ vs $+11.0 \mathrm{~m})(P=0.882)$

179

$(1 \mathrm{RCT})$

$\oplus \oplus \ominus \ominus$

Not reported in studies that met the inclusion criteria for this comparison

Economic costs

Not reported in studies that met the inclusion criteria for this comparison

*The risk in the intervention group (and its $95 \%$ confidence interval) is based on the assumed risk in the comparison group and the relative effect of the intervention (and its $95 \% \mathrm{Cl}$ ).

Cl: confidence interval; HFpEF: heart failure with a preserved ejection fraction; $\mathbf{R C T}$ : randomised controlled trial

\section{GRADE Working Group grades of evidence}

High certainty: We are very confident that the true effect lies close to that of the estimate of the effect.

Moderate certainty: We are moderately confident in the effect estimate: the true effect is likely to be close to the estimate of the effect, but there is a possibility that it is substantially different.

Low certainty: Our confidence in the effect estimate is limited: the true effect may be substantially different from the estimate of the effect.

Very low certainty: We have very little confidence in the effect estimate: the true effect is likely to be substantially different from the estimate of effect.

1Downgraded by one level for imprecision (low number of participants).

2Downgraded by one level due to risk of bias (serious methodological limitations due to insufficient information on random sequence generation, allocation concealment, blinding of participants and personnel, blinding of outcome assessment, incomplete outcome data, and selective reporting).

\section{Summary of findings 4. Usual care with ivabradine compared to placebo, usual care, or no treatment in participants with HFpEF (short-term} treatment ( 6 months) with ivabradine)

\section{Usual care with ivabradine compared to placebo, usual care, or no treatment in participants with HFpEF (short-term treatment (< 6 months) with ivabradine)}

Patient or population: adults ( $\geq 18$ years of age) with a diagnosis of chronic heart failure with a preserved ejection fraction (HFpEF)

Setting: hospital or outpatient care

Intervention: short-term treatment (<6 months) with ivabradine

Comparison: placebo, usual care, or no treatment 


\begin{tabular}{|c|c|c|c|c|c|}
\hline \multirow[t]{2}{*}{ Outcomes } & \multicolumn{2}{|c|}{ Anticipated absolute effects* $(95 \% \mathrm{Cl})$} & \multirow{2}{*}{$\begin{array}{l}\text { Relative effect } \\
(95 \% \mathrm{CI})\end{array}$} & \multirow{2}{*}{$\begin{array}{l}\text { № of participants } \\
\text { (studies) }\end{array}$} & \multirow{2}{*}{$\begin{array}{l}\text { Certainty of the } \\
\text { evidence } \\
\text { (GRADE) }\end{array}$} \\
\hline & Risk with placebo & $\begin{array}{l}\text { Risk with usual care with ivabradine } \\
\text { compared to placebo, usual care, or } \\
\text { no treatment in participants with } \\
\text { HFpEF (short-term treatment ( }<6 \\
\text { months) with ivabradine) }\end{array}$ & & & \\
\hline $\begin{array}{l}\text { Mortality from cardiovascu- } \\
\text { lar causes (follow-up range } \\
19 \text { to } 23 \text { months) }\end{array}$ & \multicolumn{5}{|c|}{ Not reported in studies that met the inclusion criteria for this comparison } \\
\hline Quality of life & \multicolumn{5}{|c|}{ Not reported in studies that met the inclusion criteria for this comparison } \\
\hline $\begin{array}{l}\text { Time to first hospitalisation } \\
\text { for heart failure during fol- } \\
\text { low-up }\end{array}$ & \multicolumn{5}{|c|}{ Not reported in studies that met the inclusion criteria for this comparison } \\
\hline $\begin{array}{l}\text { Number of days spent in } \\
\text { hospital due to heart failure } \\
\text { during follow-up }\end{array}$ & \multicolumn{5}{|c|}{ Not reported in studies that met the inclusion criteria for this comparison } \\
\hline $\begin{array}{l}\text { Rate of serious adverse } \\
\text { events }\end{array}$ & \multicolumn{5}{|c|}{ Not reported in studies that met the inclusion criteria for this comparison } \\
\hline Exercise capacity & \multicolumn{3}{|c|}{$\begin{array}{l}\text { De Masi De Luca 2013: Significant improvement for ivabradine in exercise duration (baseline: } \\
5.4 \pm 2.1 \text { min vs follow-up at month 3: } 6.9 \pm 2.9 \mathrm{~min})(P<0.05) \text {. No data for placebo group. } \\
\text { Kosmala 2013: Significant improvement for ivabradine group (baseline: } 4.2 \pm 1.8 \text { metabolic } \\
\text { equivalents vs follow-up at day } 7: 5.7 \pm 1.9 \text { metabolic equivalents) }(P=0.001) \text {. "No change in } \\
\text { the control subjects." }\end{array}$} & $\begin{array}{l}171 \\
\text { (2 RCTs) }\end{array}$ & $\begin{array}{l}\oplus \oplus \ominus \ominus \\
\text { LOW 1, } 2\end{array}$ \\
\hline Economic costs & \multicolumn{5}{|c|}{ Not reported in studies that met the inclusion criteria for this comparison } \\
\hline
\end{tabular}

${ }^{\star}$ The risk in the intervention group (and its $95 \%$ confidence interval) is based on the assumed risk in the comparison group and the relative effect of the intervention (and its $95 \% \mathrm{Cl})$.

CI: confidence interval; HFpEF: heart failure with a preserved ejection fraction; $\mathbf{R C T}$ : randomised controlled trial

High certainty: We are very confident that the true effect lies close to that of the estimate of the effect.

Moderate certainty: We are moderately confident in the effect estimate: the true effect is likely to be close to the estimate of the effect, but there is a possibility that it is substantially different.

Low certainty: Our confidence in the effect estimate is limited: the true effect may be substantially different from the estimate of the effect.

Very low certainty: We have very little confidence in the effect estimate: the true effect is likely to be substantially different from the estimate of effect. 

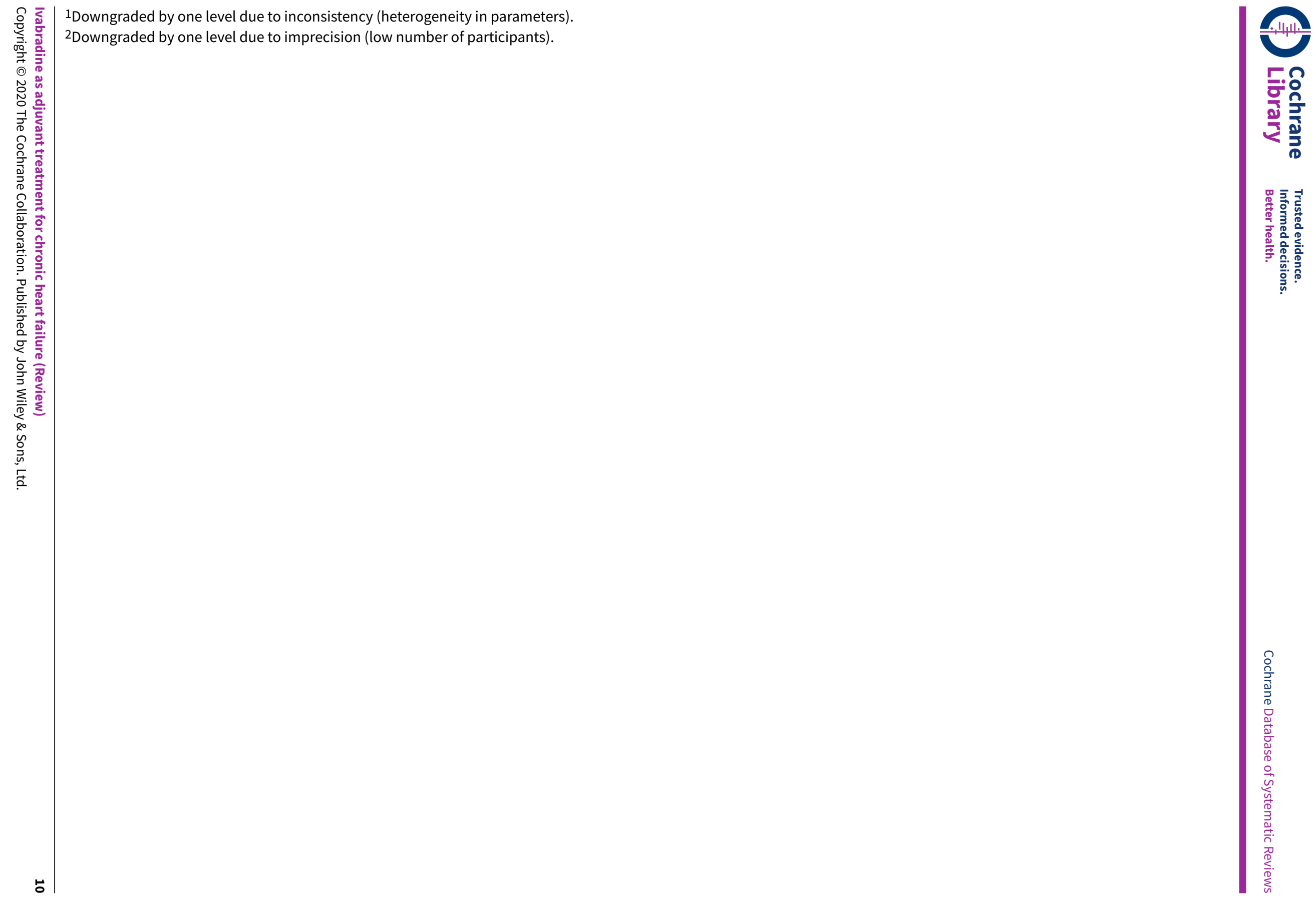


\section{B A C K G R O U N D}

\section{Description of the condition}

\section{Definition of heart failure}

Heart failure is defined as a complex clinical syndrome in which abnormal heart function results in, or increases the subsequent risk of, clinical symptoms and signs of reduced cardiac output, pulmonary or systemic congestion, or a combination, at rest or with stress (Ponikowski 2016). Individuals who have had heart failure for some time are said to have chronic heart failure (Ponikowski 2016). This subsequently leads to peripheral vasoconstriction, the increase of extracellular fluid volume accompanied by an increase in the end-diastolic preload of the heart, and thus the inadequate adaptation of the cardiac output and inadequate systemic perfusion. Chronic heart failure, with its age-dependent prevalence and incidence, is one of the most common medical conditions (Roger 2013).

\section{Type and severity of heart failure}

One commonly used method to classify the severity of heart failure is the New York Heart Association (NYHA) classification, which describes the functional status and symptoms of patients (Table 1) (Ezekowitz 2017; German Society for Cardiology 2013; Ponikowski 2016). The terminology used to describe type and severity of heart failure is based on measurements of the left ventricular ejection fraction (LVEF) (Ponikowski 2016):

1. heart failure with a reduced ejection fraction (HFrEF) applies to patients with an LVEF less than $40 \%$;

2. heart failure with a preserved ejection fraction (HFpEF) applies to patients with an LVEF 50\% or higher; and

3. heart failure with a mid-range ejection fraction (HFmrEF) applies to patients with an LVEF between $40 \%$ and $49 \%$.

Individuals with HFrEF and those with HFpEF have different clinical characteristics, are administered different treatment regimens, and might react differently to similar heart failure drugs (Ponikowski 2016). In HFpEF, also known as diastolic heart failure, the diagnosis is more complex than in HFrEF. Individuals with HFpEF generally do not have a dilated left ventricle; however, they often have an increase in thickness of the wall of the left ventricle and/or an increased left atrial size as a sign of increased filling pressures, therefore although the heart's LVEF may still appear to be in the normal range, its pumping capacity is inadequate (Ponikowski 2016). In HFrEF, also known as systolic heart failure, the heart muscle is not able to contract adequately and therefore ejects oxygen-rich blood only insufficiently into the body (Ponikowski 2016).

\section{Epidemiology of heart failure}

Demographic changes and medical progress have contributed significantly to an increased prevalence of chronic heart failure, therefore heart failure is a first-rate medical, social, and economic problem of our society. By 2013, more than 23 million individuals were diagnosed with heart failure worldwide (Roger 2013). The prevalence of heart failure depends on the definition applied, but approximately $1 \%$ to $2 \%$ of the population in high-income countries suffers from chronic heart failure, with the prevalence increasing to $10 \%$ or higher of the population aged over 70 years (Laribi 2012; Mozaffarian 2016). The lifetime risk of heart failure at age 55 years is $33 \%$ for men and $28 \%$ for women (Bleumink 2004). Nearly threequarters $(74 \%)$ of heart failure patients suffer from at least one accompanying morbidity, which is most likely to worsen patients' overall health status (van Deursen 2014). Over the last 50 years, age-specific cardiovascular disease-related mortality has fallen by about two-thirds in industrialised countries. However, heart failure is a notable exception in this respect: in the USA, the rate of hospitalisation has increased steadily since 1975 , up to 1.9 million cases per year (CDC 2017). Heart failure is the fourth most frequent cause of death in Germany today (Statistisches Bundesamt 2017), and about half of people with heart failure die within five years of diagnosis (Mozaffarian 2016). By 2030, the number of people with heart failure is expected to rise by $46 \%$ (Benjamin 2017); reasons for this include an aging population and a growing number of heart attack survivors, who are at increased risk for heart failure.

\section{Therapy of heart failure}

Therapy goals for chronic HFrEF are the improvement of individual quality of life, prolonged survival, a reduction of signs and symptoms, and the prevention of hospitalisation (German Society for Cardiology 2013). In principle, therapeutic approaches (operative or medicinal) specific to the cause should be sought. According to the European Society of Cardiology (ESC) Clinical Practice Guideline on Acute and Chronic Heart Failure, optimal medical pharmacotherapy for chronic HFrEF involves the use of angiotensin-converting-enzyme inhibitors (ACE inhibitors) and beta-blockers (Ponikowski 2016). Individuals with persistent symptoms should also receive a mineralocorticoid receptor antagonist (MRA) if the ejection fraction is 35\% or less. The additional therapeutic value of selective MRAs like eplerenone has been shown by the reduction of morbidity and mortality in individuals after acute myocardial infarction, systolic heart failure, and left ventricular systolic dysfunction (Pitt 2005; Zannad 2011). In summary, optimal medical pharmacotherapy for HFrEF includes ACE inhibitors plus beta-blockers plus MRA. These therapy recommendations are in line with the recommendations made by the American Heart Association, Yancy 2013, and the Canadian Cardiovascular Society, Ezekowitz 2017. These drugs have a decisive influence on morbidity and mortality, as they have a positive effect on left ventricular function. This benefit appears to be partly due to a negative chronotropic effect (Lechat 2001; McAlister 2009). However, even with the best medical treatment, the prognosis of HFrEF is still poor, especially in individuals with an increased resting pulse (70 to 75 beats per minute or higher).

Heart failure adds significantly to the overall socioeconomic burden of disease, and will continue to do so in the future. In the USA, costs are quantified at USD 30,700 million each year, which includes the cost of healthcare services, medications to treat heart failure, and missed days of work (Heidenreich 2011). The annual global economic cost of heart failure in 2012 was estimated at USD 108,000 million (Cook 2014). Heart failure costs are especially driven by repeated and prolonged hospitalisation, which accounts for $1 \%$ to $3 \%$ (approximately 1 million in total) of all USA and European hospital admissions per year (Ambrosy 2014). Global registries on hospitalised heart failure show that the median length of stay ranges from 4 days to 20 days (Ambrosy 2014). In addition, almost one out of four hospitalised individuals $(24 \%)$ is rehospitalised for heart failure within the 30-day postdischarge period, and nearly one out of two individuals (46\%) is rehospitalised for heart failure within 60 days after discharge (O'Connor 2010). 


\section{Description of the intervention}

Ivabradine, which is also known by the trade names Bradia (India), Coralan (Hong Kong, Singapore), Coraxan (Russia, Serbia), Corlanor (USA), Corlentor (Armenia, Spain, Italy, Romania), Ivabid (India), Lancora (Canada), Procoralan (worldwide), is used as an adjuvant oral medication for the symptomatic treatment of chronic heart failure. One film-coated tablet contains $5 \mathrm{mg}$ (equivalent to 5.390 $\mathrm{mg}$ ) or $7.5 \mathrm{mg}$ (equivalent to $8.085 \mathrm{mg}$ ) ivabradine as hydrochloride. Ivabradine is approved for the symptomatic treatment of chronic heart failure in NYHA class II to IV with systolic dysfunction, and in individuals with sinus rhythm with heart rate 75 beats per minute or higher, in combination with optimal medical pharmacotherapy (ACE inhibitors plus beta-blockers plus MRA), or when betablocker therapy is contraindicated or not tolerated. The European Medicines Agency states: "The usual recommended starting dose of ivabradine is $5 \mathrm{mg}$ twice daily. After two weeks of treatment, the dose can be increased to $7.5 \mathrm{mg}$ twice daily if the resting heart rate is persistently above 60 beats per minute, or decreased to $2.5 \mathrm{mg}$ twice daily (one half $5 \mathrm{mg}$ tablet twice daily) if the resting heart rate is persistently below 50 beats per minute, or in case of symptoms related to bradycardia, such as dizziness, fatigue, or hypotension. If the heart rate is between 50 and 60 beats per minute, the dose of $5 \mathrm{mg}$ twice daily should be maintained. If, during treatment, the heart rate decreases and remains below 50 beats per minute at rest, or the patient experiences symptoms related to bradycardia, the dose must be titrated down to the next dose in persons receiving $7.5 \mathrm{mg}$ twice daily or $5 \mathrm{mg}$ twice daily. If the heart rate increases and remains above 60 beats per minute at rest, the dose can be titrated up to the next dose in persons receiving $2.5 \mathrm{mg}$ twice daily or $5 \mathrm{mg}$ twice daily. Treatment must be discontinued if heart rate remains below 50 beats per minute, or symptoms of bradycardia persist" (EMA 2017). These dosage and administration instructions are in line with the instructions of the US Food and Drug Administration (FDA 2020).

\section{How the intervention might work}

The cardiac effects of ivabradine are sinus node-specific, and have no influence on the intra-atrial, atrioventricular, or intraventricular stimulus conduction. Myocardial contractility and ventricular repolarisation remain unchanged. Ivabradine reduces the myocardial oxygen demand by reducing the heart rate, which makes the use of ivabradine interesting in individuals with chronic heart failure. Ivabradine is an active substance with heart rate-lowering effects, which lead to a reduction of the effective arterial elastance (Ea) representing pulsatile and mean load of the left ventricle. The reduction of total afterload is mostly the result of a lower vascular pulsatile load. Ivabradine acts as an $\mathrm{I}_{\mathrm{f}}$-channel inhibitor to the heart, selectively inhibiting the $\mathrm{I}_{\mathrm{f}}$-ionic current, which controls the spontaneous diastolic depolarisation in the sinus node, thereby regulating the heart rate. As a result, the haemodynamic parameters remain constant, whilst at the same time the myocardial oxygen demand is reduced. The main pharmacodynamic property of ivabradine is a specific dose-dependent reduction in heart rate. At the recommended dosage, the heart rate is lowered by about 10 beats per minute, both at rest and under load. Randomised controlled trials showed that when added to standard treatment, ivabradine significantly reduced the rate of a combined endpoint consisting of cardiovascular death and hospitalisation due to acute myocardial infarction, or hospitalisation due to new or worsening heart failure. It also reduced the incidence of death due to cardiac insufficiency, hospitalisation for any reason, or cardiovascularbased hospitalisation (Servier Deutschland GmbH 2016). These aspects make the use of ivabradine very promising in individuals with chronic HFrEF.

\section{Why it is important to do this review}

Despite current intensive multidrug therapy, people with heart failure are frequently admitted to hospital. Even with the best medical treatment, the prognosis of heart failure remains poor. Individuals with NYHA stages II and III under therapy with ACE inhibitors have a one-year mortality of $9 \%$ to $12 \%$; those with endstage heart failure without therapy have a one-year mortality of $52 \%$ (Bauriedel 2005). The continuous development of therapeutic approaches for the treatment of the disease - in particular with regard to drugs with heart rate-lowering properties - is of crucial importance.

Although there are obvious promising characteristics, we want to highlight that the relevant national and international experts only rated the quality of the evidence as IIa (B) for the therapeutic use of ivabradine in corresponding guidelines (Ponikowski 2016). It is also important to note that to date, the effects of ivabradine have been based mainly on results from industry-initiated studies (Fox 2008; Swedberg 2010); the review of these results in science-initiated studies is still pending. In summary, considering all aspects raised, it is anticipated that this Cochrane Review will have an impact on future clinical trials in this area.

Two systematic reviews on this topic are available; however, both reviews have several limitations, with a significant impact on the conclusions (Fox 2013; Mizzaci 2017). Fox 2013 only considered two industry-sponsored trials, one of which he was the principal investigator for (Fox 2008; Swedberg 2010). Mizzaci 2017 was retracted in January 2017 on the request of several editors, as it contained numerous data inaccuracies (e.g. cited incorrect death rates), which made the conclusions unreliable (International Journal of Cardiology 2017). There is a need to assess this evidence systematically and combine results across trials. This Cochrane Review will close this gap in research, providing the basis for future randomised controlled trials and clinical guidelines on the management of heart failure.

\section{O B JECTIVES}

To assess the effectiveness and safety of ivabradine in individuals with chronic heart failure.

\section{METHODS}

\section{Criteria for considering studies for this review Types of studies}

We considered randomised clinical trials (RCTs) (individual, crossover, and cluster-randomised trials) irrespective of publication type, publication status, publication date, and language for this review. For multi-arm trials, we used only those treatment arms relevant to our review.

\section{Types of participants}

We included adults ( $\geq 18$ years of age) with a diagnosis of chronic heart failure. We contacted trialists if the age of participants was 
not stated clearly, or to obtain data for a subgroup of participants; the latter was not required in this review. If needed in future updates of the review, we will contact the study authors to ask for data concerning this subgroup. If no data for the corresponding subgroup can be provided, the publication will be excluded from quantitative analysis.

\section{Types of interventions}

We included trials comparing:

Usual care with ivabradine compared to placebo, usual care, or no treatment

1. usual care with placebo versus usual care with ivabradine; or

2. usual care versus usual care with ivabradine; or

3. no treatment versus usual care with ivabradine

for the management of chronic heart failure. We combined the possible comparators into a single comparison.

We distinguished between participants suffering from HFpEF, $\mathrm{HFrEF}$, and $\mathrm{HFmrEF}$, as well as duration of ivabradine treatment:

1. participants with HFPEF with short-term treatment ( $<6$ months) with ivabradine;

2. participants with HFpEF with long-term treatment ( $\geq 6$ months) with ivabradine;

3. participants with HFrEF with short-term treatment ( $<6$ months) with ivabradine;

4. participants with HFrEF with long-term treatment ( $\geq 6$ months) with ivabradine;

5. participants with HFmrEF with short-term treatment $1<6$ months) with ivabradine;

6. participants with HFmrEF with long-term treatment ( $\geq 6$ months) with ivabradine.

Studies also including participants with $\mathrm{HFmrEF}$ were assigned to HFpEF or HFrEF, depending on the main characteristics.

\section{Types of outcome measures}

As no core outcome set for clinical studies investigating interventions in chronic heart failure participants is available, the list of outcomes chosen was based on outcome measures from studies potentially eligible for inclusion in our review that appeared to be most meaningful to patients, clinicians, and policymakers.

\section{Primary outcomes}

1. Mortality from cardiovascular causes (as defined by trial authors).

2. Quality of life $(\mathrm{Q} o \mathrm{~L})$ measured using validated scales, e.g. the Short Form Health Survey (SF-36) (Ware 1992).

3. Time to first hospitalisation for heart failure during follow-up.

4. Number of days spent in hospital due to heart failure during follow-up.

\section{Secondary outcomes}

1. Rate of serious adverse events (as defined by trial authors).

2. Exercise capacity measured using validated scales, e.g. the 6minute walk test (6MWT) (American Thoracic Society 2002).

3. Economic costs (narrative report).
Reporting one or more of these outcomes in the trial was not an inclusion criteria for the review. Where a published report did not report one of these outcomes, we accessed the trial protocol and contacted the trial authors to ascertain whether the outcomes were measured but not reported. We included relevant trials that measured these outcomes but did not report the data at all, or reported data in an unuseable format, as part of the narrative. To maintain stringency we decided to report all outcomes in a 'Summary of findings' table, even though exercise capacity and economic costs were initially planned only for assessment and not for the 'Summary of findings' table.

\section{Search methods for identification of studies}

\section{Electronic searches}

We identified trials through systematic searches of the following bibliographic databases on 20 March 2020:

1. Cochrane Central Register of Controlled Trials (CENTRAL) in the Cochrane Library (Issue 3 of 12, 2020);

2. Epub Ahead of Print, In-Process \& Other Non-Indexed Citations, MEDLINE Daily and MEDLINE (Ovid, 1946 to 19 March 2020);

3. Embase (Ovid, 1980 to 2020 week 11);

4. Conference Proceedings Citation Index-Science (CPCI-S) Web of Science (Clarivate Analytics, 1990 to 20 March 2020).

We adapted the preliminary search strategy for identifying trials in MEDLINE Ovid for use in the other databases (Appendix 1). We applied the Cochrane sensitivity-maximising randomised controlled trial filter to MEDLINE Ovid and adapted it for the other databases, except CENTRAL (Lefebvre 2011).

We searched the US National Institutes of Health Ongoing Trials Register ClinicalTrials.gov (www.clinicaltrials.gov) and the World Health Organization International Clinical Trials Registry Platform (WHO ICTRP) (apps.who.int/trialsearch/) for ongoing or unpublished trials on 11 June 2020.

We searched all databases from their inception to the present, and imposed no restriction on language of publication or publication status.

We did not perform a separate search for adverse effects of interventions used for the treatment of chronic heart failure, considering adverse effects described in the included studies only.

We identified economic evaluation studies through systematic searches of the following bibliographic databases on 20 March 2020:

1. NHS Economic Evaluation Database (inception to 31 March 2015, when it stopped being updated);

2. Epub Ahead of Print, In-Process \& Other Non-Indexed Citations, MEDLINE Daily and MEDLINE (Ovid, 2015 to 19 March 2020);

3. Embase (Ovid, 2015 to 2020 week 11).

We adapted the preliminary search strategy for identifying economic evaluation studies in MEDLINE Ovid for use in the other databases (Appendix 2). We applied the NHS EED filter to MEDLINE Ovid and Embase Ovid (Centre for Reviews and Dissemination 2017). 


\section{Searching other resources}

We checked the reference lists of all included studies and any relevant systematic reviews identified for additional references to trials. We also examined any relevant retraction statements and errata for included studies. We contacted authors for missing data and ongoing trials.

\section{Data collection and analysis}

\section{Selection of studies}

Four review authors ( $C B, C K, T B, V B)$ independently screened titles and abstracts of all the studies identified as a result of the search, coding them as 'retrieve' (eligible, potentially eligible, or unclear), or 'do not retrieve'. We retrieved the full-text study reports or publications. Four review authors (CB, CK, TB, VB) independently screened the full texts, identified studies for inclusion, and identified and recorded reasons for exclusion of the ineligible studies. Any disagreements were resolved through discussion. We identified and excluded duplicates and collated multiple reports of the same study so that each study, rather than each report, was the unit of interest in the review. We recorded the selection process in sufficient detail to complete PRISMA flow diagrams (Figure 1; Figure 2) and Characteristics of excluded studies tables. 
Figure 1. Study flow diagram for selection of randomised controlled trials.

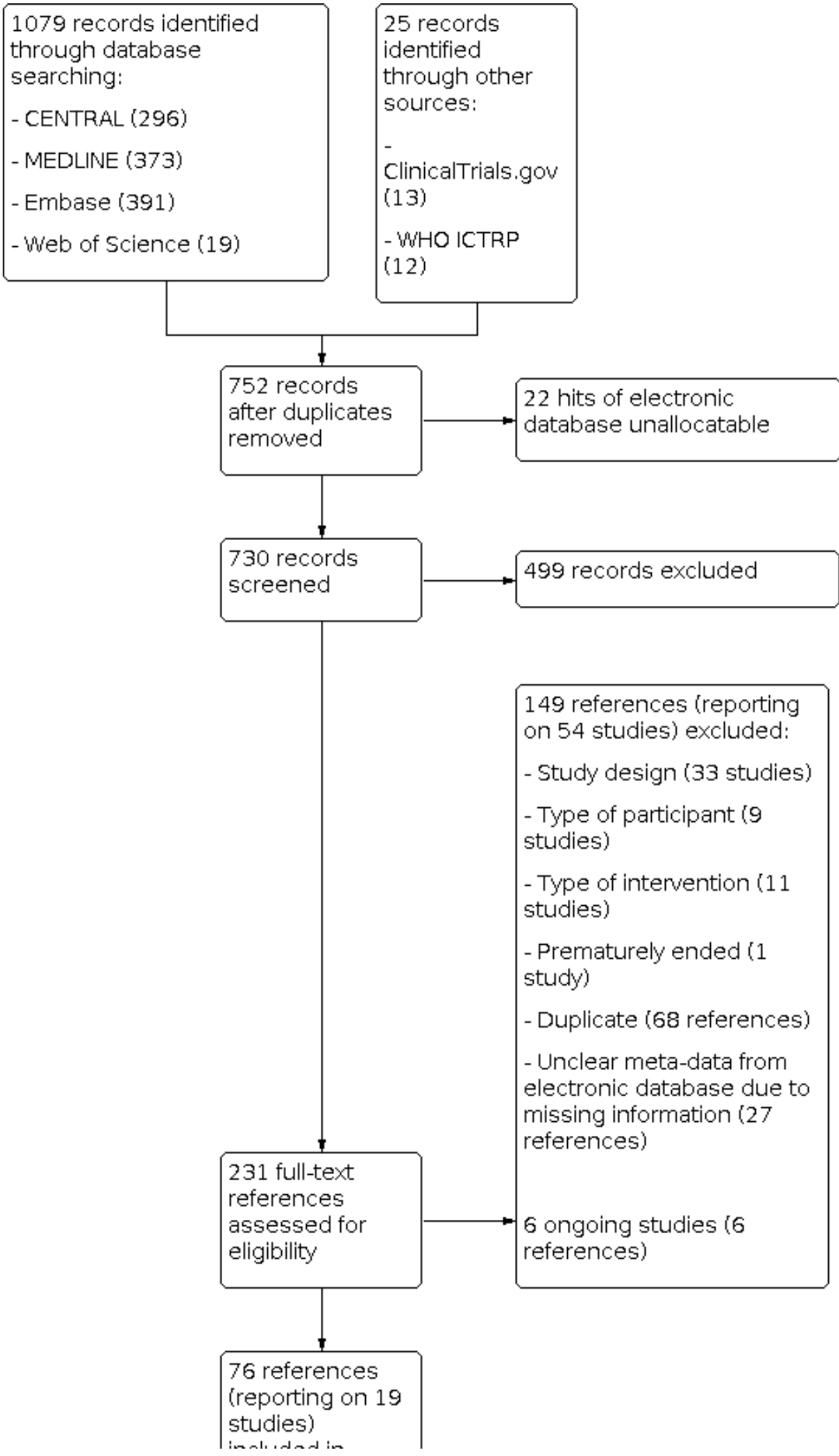


Figure 1. (Continued)

\begin{tabular}{l}
$\begin{array}{l}\text { ludies) } \\
\text { included in } \\
\text { qualitative } \\
\text { synthesis }\end{array}$ \\
\hline $\begin{array}{l}76 \text { references } \\
\text { (reporting on } 19 \\
\text { studies) } \\
\text { included in } \\
\text { quantitative } \\
\text { synthesis } \\
\text { (meta-analysis) }\end{array}$
\end{tabular}


Figure 2. Study flow diagram for selection of economic evaluations.

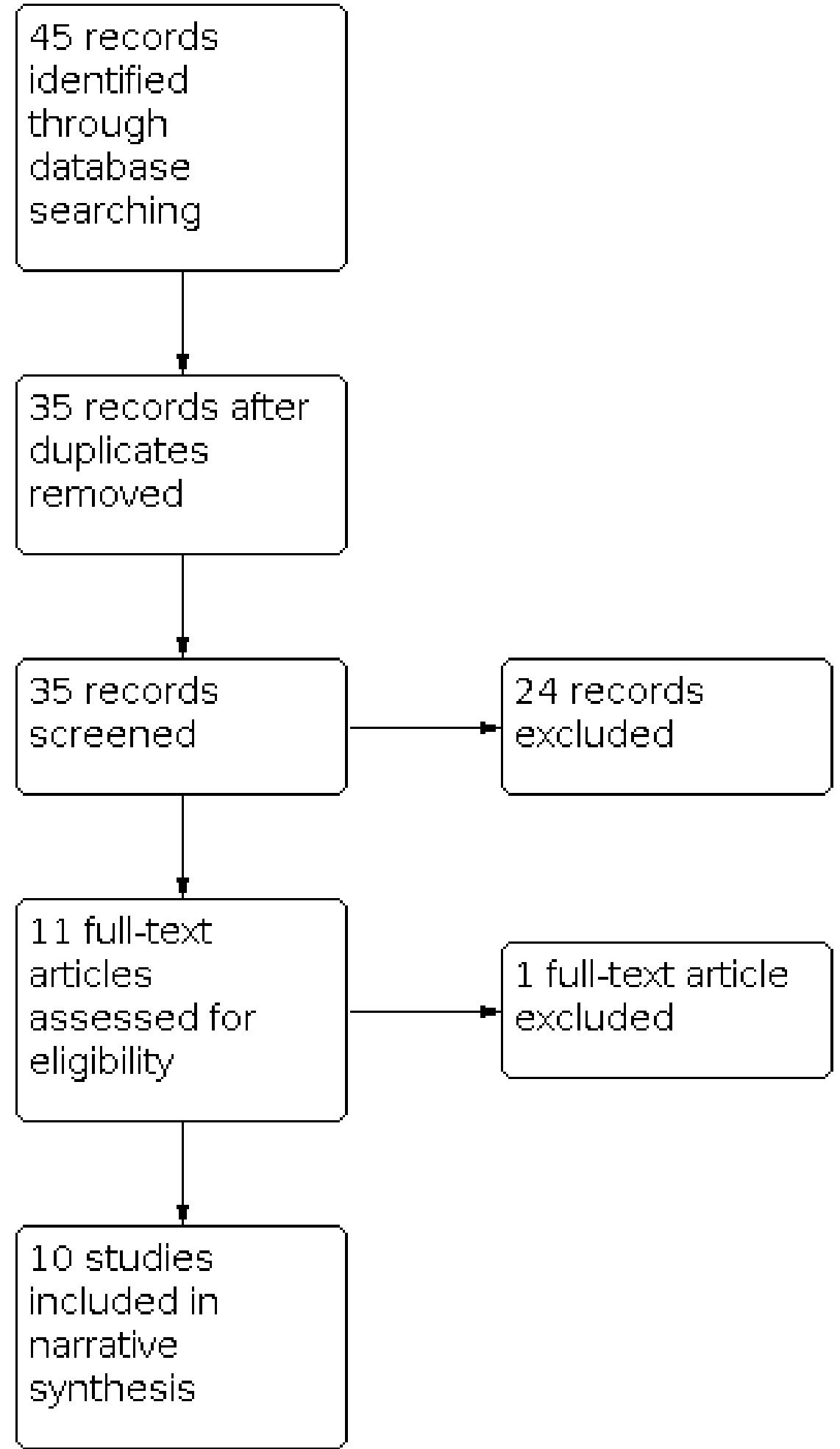

\section{Data extraction and management}

We used a purposely developed data collection form for study characteristics and outcome data that had been piloted on one study in the review. Five review authors (CB, CK, TB, CS, VB) extracted the following study characteristics from the included studies.
1. Methods: study design, total duration of study, details of any runin period, number of study centres and location, study setting, withdrawals, and date of study.

2. Participants: $\mathrm{N}$ randomised, $\mathrm{N}$ lost to follow-up or withdrawn, $\mathrm{N}$ analysed, mean age, age range, gender, severity of condition (NYHA class), ejection fraction, pre-existing heart-disease, 
optimal medical pharmacotherapy according to guideline recommendations, inclusion and exclusion criteria, reported differences between intervention and comparison groups.

3. Interventions: intervention, comparison, concomitant medications, and excluded medications.

4. Outcomes: primary and secondary outcomes specified and collected, and time points reported.

5. Notes: funding for trial, and notable conflicts of interest of trial authors.

Two review authors ( $C B, C K$ ) independently extracted outcome data from the included studies to check each other's work. Any disagreements were resolved by consensus. Two review authors (CB, VB) transferred data into the Review Manager 5 file (Review Manager 2014). We double-checked that data were entered correctly by comparing the data presented in the systematic review with the data extraction form (CB or CK orTB). A second review author (CK) spot-checked study characteristics for accuracy against the trial report.

We also included a commentary on economic aspects of the use of ivabradine. This information is of special interest to policymakers and end-users of this systematic review. We intended to address the economic burden of chronic heart failure, resource inputs, resource consequences, and issues of cost-effectiveness. This narrative summary reports on the main characteristics and results of included economic studies, including resource use measures, cost, and cost-effectiveness. We followed the recommendations in Chapter 15 of the Cochrane Handbook for Systematic Reviews of Interventions (Higgins 2011).

\section{Assessment of risk of bias in included studies}

Four review authors (CB, CK, TB, VB) independently assessed risk of bias for each study using the criteria outlined in the Cochrane Handbook for Systematic Reviews of Interventions (Higgins 2011). Any disagreements were resolved by discussion. We assessed risk of bias according to the following domains.

1. Random sequence generation.

2. Allocation concealment.

3. Blinding of participants and personnel.

4. Blinding of outcome assessment.

5. Incomplete outcome data.

6. Selective outcome reporting.

7. Other bias.

We graded each potential source of bias as high, low, or unclear, and provided a quote from the study report, together with a justification for our judgement, in the 'Risk of bias' table. We summarised the 'Risk of bias' judgements across different studies for each of the domains listed (Figure 3; Figure 4). Where information on risk of bias related to unpublished data or correspondence with a trialist, we noted this in the 'Risk of bias' table.

\section{Figure 3. Risk of bias graph: review authors' judgements about each risk of bias item presented as percentages across all included studies.}

Random sequence generation (selection bias)

Allocation concealment (selection bias)

Blinding of participants and personnel (performance bias): All outcomes

Blinding of outcome assessment (detection bias): All outcomes Incomplete outcome data (attrition bias): All outcomes

Selective reporting (reporting bias)

Other bias

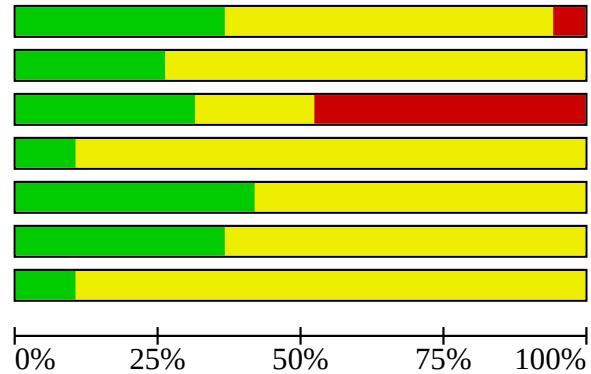

Low risk of bias

Unclear risk of bias

High risk of bias 
Figure 4. Risk of bias summary: review authors' judgements about each risk of bias item for each included study.

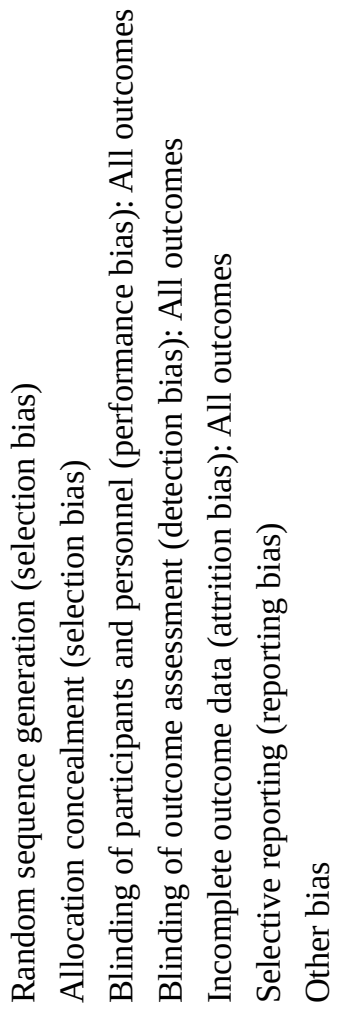

Abdel 2011

Adamyan 2008

Adamyan 2015a

Bansal 2019

Chaudhari 2014

De Masi De Luca 2013

Fox 2008

Komajda 2017

Kosmala 2013

Potapenko 2011

Sarullo 2010

Sisakian 2016

Swedberg 2010

Tatarchenko 2008

Tsutsui 2016

Tsutsui 2019

Tumasyan 2016

Tumasyan 2017

Tumasyan 2018

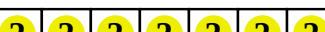

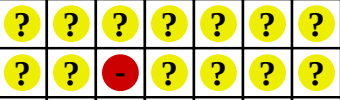

\begin{tabular}{|llllllllll}
\hline$?$ & $?$ & - & $?$ & $?$ & $?$ & $?$ \\
\hline & $?$ & & $?$ & & & $?$ & $?$ \\
\hline
\end{tabular}

\begin{tabular}{|llllllllll}
\hline$?$ & $?$ & $?$ & $?$ & + & $?$ & ? \\
\hline
\end{tabular}

\begin{tabular}{llllllllll}
\hline & $?$ & - & $?$ & $?$ & $?$ & $?$ \\
\hline
\end{tabular}

\begin{tabular}{|l|l|l|l|l|l|l|}
\hline$?$ & $?$ & $?$ & $?$ & $?$ & $?$ & $?$ \\
\hline
\end{tabular}

\begin{tabular}{|l|l|l|l|l|l|l|}
\hline$?$ & $?$ & - & $?$ & $?$ & $?$ & $?$ \\
\hline$?$ & $?$ & - & $?$ & $?$ & $?$ & $?$ \\
\hline
\end{tabular}


When considering treatment effects, we took into account the risk of bias for the studies that contributed to that outcome.

\section{Assessment of bias in conducting the systematic review}

We conducted the review according to our published protocol, and reported any deviations from it in the Differences between protocol and review section of the systematic review.

\section{Measures of treatment effect}

We analysed dichotomous data as risk ratios (RR) with 95\% confidence intervals $(\mathrm{Cl})$.

We did not pool any continuous data, but we plan to use the mean difference with $95 \% \mathrm{Cl}$ for outcomes measured in the same way between trials and enter data as a scale with a consistent direction of effect where applicable in any future updates of this review.

We reported the economic aspects of the use of ivabradine narratively.

\section{Unit of analysis issues}

No studies with a cross-over design or cluster-randomised trials were included in the review, so there were no unit of analysis issues. For multi-arm studies, we analysed only those arms which met our inclusion criteria, but described any additional arms in the Characteristics of included studies tables.

\section{Dealing with missing data}

We contacted investigators to verify key study characteristics and to obtain missing numerical outcome data where possible (e.g. when a study was identified as abstract only). A detailed description of author feedback is provided in the Characteristics of included studies tables.

\section{Dichotomous outcomes}

We did not impute missing values for any outcomes in our primary analyses.

\section{Continuous datc}

We did not impute missing values for any outcomes in our primary analyses. If studies did not include standard deviations in their report, we calculated them using data from the trial if possible.

\section{Assessment of heterogeneity}

We started by inspecting forest plots visually to gauge likely levels of heterogeneity, and then used the $\mathrm{I}^{2}$ statistic to measure heterogeneity amongst the trials in each analysis. When we identified substantial heterogeneity, we reported it and explored possible causes by prespecified subgroup analysis. We regarded heterogeneity as substantial if:

1. the $\mathrm{I}^{2}$ value was high (exceeding $30 \%$ ); and

2. there was inconsistency between trials in the direction or magnitude of effects (judged visually), or $\mathrm{P}<0.10$ in the $\mathrm{Chi}^{2}$ test for heterogeneity.

We interpreted the $1^{2}$ taking into consideration the magnitude and direction of the treatment effects and the strength of the evidence for heterogeneity.

\section{Assessment of reporting biases}

We were not able to pool more than 10 trials, therefore we did not create a funnel plot to explore possible small-study biases for the primary outcomes. We assessed reporting bias qualitatively, based on the characteristics of the included studies.

\section{Data synthesis}

We undertook meta-analyses only when this was meaningful, that is if the treatments, participants, and the underlying clinical question were similar enough for pooling to make sense.

Given the clinical heterogeneity across trials on chronic heart failure patients and their differences in comorbidities and comedications, we used a random-effects model to produce an overall summary of average treatment effect across trials. We treated the random-effects summary as the average range of possible treatment effects. We presented results as the average treatment effect with its $95 \% \mathrm{Cl}$, and the estimates of $\mathrm{Tau}^{2}$ and $\mathrm{I}^{2}$.

\section{'Summary of findings' table}

We created a 'Summary of findings' table for each of our four comparisons (Summary of findings 1; Summary of findings 2; Summary of findings 3; Summary of findings 4). We used the five GRADE considerations (study limitations, consistency of effect, imprecision, indirectness, and publication bias) to assess the certainty of a body of evidence as it relates to the studies which contribute data to the meta-analyses for the prespecified outcomes. We used the methods and recommendations described in Section 8.5 and Chapter 12 of the Cochrane Handbook for Systematic Reviews of Interventions (Higgins 2011), employing GRADEpro GDT software (GRADEpro GDT). We justified all decisions to downgrade the certainty of evidence using footnotes, and made comments to aid the reader's understanding of the review where necessary. Two review authors (CB, VB) independently assessed the certaintyof the evidence; any disagreements were resolved by discussion or by involving a third review author (CK). We justified, documented, and incorporated our judgements into the reporting of results for each outcome. We extracted study data, formatted them into data tables, and prepared the 'Summary of findings' tables before writing the results and conclusions of our review.

\section{Subgroup analysis and investigation of heterogeneity}

Due to heterogeneity in participant characteristics (e.g. mean age), differences in the underlying condition (HFpEF and HFrEF), and heterogeneity in outcome definition and reporting in the included studies, we were not able to perform subgroup analysis.

\section{Sensitivity analysis}

Based on the limited evidence available for this Cochrane Review, sensitivity analysis was not feasible.

\section{RESULTS}

\section{Description of studies}

See Characteristics of included studies, Characteristics of excluded studies, and Characteristics of ongoing studies tables. 


\section{Results of the search}

For the identification of RCTs, we performed the database searches in March 2020 and identified 752 citations with potential for inclusion after removal of duplicates. We excluded 499 citations during the initial screening of titles and abstracts. Overall, we assessed 231 full-text references. A total of 149 references (reporting on 54 studies) failed to meet the inclusion criteria for this review. We assessed six references as ongoing studies (see Characteristics of ongoing studies). We included 19 studies (reported in 76 separate publications) in the review (the PRISMA study flow diagram for identification of RCTs is shown in Figure 1).

For the identification of economic evaluations, we performed the database searches in March 2020 and identified 35 publications with potential for inclusion after removal of duplicates. During screening, we excluded 25 publications that did not focus on the scope of our economic evaluation. We included 10 studies (reported in 10 publications) in the review (the PRISMA study flow diagram for identification of economic evaluations is shown in Figure 2).

We searched ClinicalTrials.gov and the WHO ICTRP to identify additional and ongoing trials that met the inclusion criteria of our systematic review. Details of our search strategy are provided in Appendix 1.

\section{Included studies}

We included 19 RCTs in the review (Abdel 2011; Adamyan 2008; Adamyan 2015a; Bansal 2019; Chaudhari 2014; De Masi De Luca 2013; Fox 2008; Komajda 2017; Kosmala 2013; Potapenko 2011; Sarullo 2010; Sisakian 2016; Swedberg 2010; Tatarchenko 2008; Tsutsui 2016; Tsutsui 2019; Tumasyan 2016; Tumasyan 2017; Tumasyan 2018). Detailed descriptions of the included studies are provided in the Characteristics of included studies tables.

The included studies involved a total of 19,628 participants (mean age 60.76 years, $69 \%$ male) randomly assigned to receive either ivabradine or usual care/usual care plus placebo. Nine studies compared ivabradine to placebo and usual care (Abdel 2011; Chaudhari 2014; De Masi De Luca 2013; Fox 2008; Komajda 2017; Kosmala 2013; Sarullo 2010; Swedberg 2010; Tsutsui 2019), whilst 10 studies compared ivabradine to usual care (Adamyan 2008; Adamyan 2015a; Bansal 2019; Potapenko 2011; Sisakian 2016; Tatarchenko 2008; Tsutsui 2016; Tumasyan 2016; Tumasyan 2017; Tumasyan 2018). All included trials used a standard parallel-group design. Nine citations referred only to an abstract (Abdel 2011; Adamyan 2008; Adamyan 2015a; Bansal 2019; De Masi De Luca 2013; Tatarchenko 2008; Tumasyan 2016; Tumasyan 2017; Tumasyan 2018). We contacted the study authors (if contact details were available) to obtain further information on these studies, and when authors responded, we highlighted this in the corresponding Characteristics of included studies table.

We identified six single-centre studies, Abdel 2011; Adamyan 2015a; Bansal 2019; Chaudhari 2014; Sisakian 2016; Tumasyan 2016, and six multicentre studies, Fox 2008; Komajda 2017; Kosmala 2013; Swedberg 2010; Tsutsui 2016; Tsutsui 2019; the number of centres ranged from 2 to 781 , located around the world. This information was not available for the remaining studies. Most studies ( $N=$ 10) did not report details on funding (e.g. institutional funding or funding by an independent health department or research foundation). One study was funded by university and departmental means (Sarullo 2010); one was funded by the government (Bansal 2019); and five studies received industrial funding/were funded by the pharmacological company that produced the investigational product (Fox 2008; Komajda 2017; Swedberg 2010; Tsutsui 2016; Tsutsui 2019).

The sample size ranged from 49 participants, in Potapenko 2011, to 10,917 participants, in Fox 2008. Most studies did not perform a power analysis. We noted a gender imbalance across all studies in favour of male participants (69\%).

Eleven studies focused on HFrEF (Abdel 2011; Adamyan 2008; Bansal 2019; Chaudhari 2014; Fox 2008; Potapenko 2011; Sarullo 2010; Sisakian 2016; Swedberg 2010; Tsutsui 2016; Tsutsui 2019); three studies on HFpEF (De Masi De Luca 2013; Komajda 2017; Kosmala 2013); and one study on HFmrEF (Tumasyan 2018). The remaining studies provided no details on type of heart failure respectively on LVEF (Adamyan 2015a; Tatarchenko 2008; Tumasyan 2016; Tumasyan 2017). Summaries of study characteristics are shown for studies focusing on HFrEF in Table 2 and for studies focusing on HFpEF in Table 3. There is no clear focus with respect to severity of heart failure in the included studies. NYHA classification included class 1 to 4 and various combinations of two or more NYHA classes.

The included studies also drew a heterogeneous picture with regard to duration of ivabradine administration and dosage of ivabradine. Seven studies focused on short-term treatment $(<6$ months) with ivabradine (Abdel 2011; Adamyan 2008; Bansal 2019; De Masi De Luca 2013; Kosmala 2013; Sarullo 2010; Tsutsui 2016), and 11 studies focused on long-term treatment ( $\geq 6$ months) with ivabradine (Adamyan 2015a; Chaudhari 2014; Fox 2008; Komajda 2017; Potapenko 2011; Sisakian 2016; Swedberg 2010; Tsutsui 2019; Tumasyan 2016; Tumasyan 2017; Tumasyan 2018). One study provided no information on duration of ivabradine administration (Tatarchenko 2008). The duration of interventional product (IP) administration varied significantly across studies, from one week, Kosmala 2013, to 36 months, Tumasyan 2016; Tumasyan 2018. For the majority of included studies, dosage of ivabradine was based on the participant's heart rate, and ranged from $2.5 \mathrm{mg}$ twice a day (often starting dose) to a maximum of $15 \mathrm{mg}$ twice a day.

Regarding adherence to guideline management of chronic heart failure, only four studies reported that all participants were treated with beta-blockers and ACE inhibitors (Adamyan 2015a; Tumasyan 2016; Tumasyan 2017; Tumasyan 2018). In eight studies, part of the included participants received beta-blockers (60.1\% to $95.3 \%)$ and ACE inhibitors (45.8\% to $96 \%$ ), or MRA (29.3\% to $77.6 \%$ ) (Fox 2008; Komajda 2017; Potapenko 2011; Sarullo 2010; Sisakian 2016; Swedberg 2010; Tsutsui 2016; Tsutsui 2019). Of note, six studies provided no information on whether participants were treated with beta-blockers, ACE inhibitors, angiotensin II receptor blockers (ARB), or MRA (Abdel 2011; Bansal 2019; Chaudhari 2014; De Masi De Luca 2013; Kosmala 2013; Tatarchenko 2008). One study focused on participants with an intolerance to beta-blockers (Adamyan 2008).

\section{Excluded studies}

Overall, we excluded 54 studies during the full-text screening process. Thirty-three studies used a study design other than RCT; nine studies focused on a different study population; 11 studies assessed a different study intervention; one study ended prematurely; 27 references corresponded to unclear meta-data 
from electronic databases due to missing information such as author or article name; six studies were not published at the time; and 68 studies were duplicates. For details, see Characteristics of excluded studies tables. Only the references of studies that might have been expected to meet the inclusion criteria but did not are listed.

\section{Risk of bias in included studies}

Risk of bias varied considerably across the included studies, and insufficient detail was provided to inform judgement in several cases (for an overview, see 'Risk of bias' graph in Figure 3 and 'Risk of bias' summary table in Figure 4).

\section{Allocation}

We judged seven studies as having a low risk of bias for random sequence generation (Fox 2008; Kosmala 2013; Sarullo 2010; Sisakian 2016; Swedberg 2010; Tsutsui 2016; Tsutsui 2019). Information was insufficient to permit a decision regarding 11 trials (Abdel 2011; Adamyan 2008; Adamyan 2015a; Bansal 2019; De Masi De Luca 2013; Komajda 2017; Potapenko 2011; Tatarchenko 2008; Tumasyan 2016; Tumasyan 2017; Tumasyan 2018). We rated one study as having a high risk of bias (Chaudhari 2014).

We judged five studies as having a low risk of bias for allocation concealment (Fox 2008; Potapenko 2011; Sarullo 2010; Sisakian 2016; Swedberg 2010). Information was insufficient to permit a decision regarding 14 trials (Abdel 2011; Adamyan 2008; Adamyan 2015a; Bansal 2019; Chaudhari 2014; De Masi De Luca 2013; Komajda 2017; Kosmala 2013; Tatarchenko 2008; Tsutsui 2016; Tsutsui 2019; Tumasyan 2016; Tumasyan 2017; Tumasyan 2018). No study was rated as having a high risk of bias.

\section{Blinding}

We judged six studies as having low risk of performance bias, as participants and personnel were blinded to group allocation (Fox 2008; Komajda 2017; Kosmala 2013; Swedberg 2010; Tsutsui 2016; Tsutsui 2019). Nine studies did not use blinding and were rated as having a high risk of performance bias (Adamyan 2008; Adamyan 2015a; Chaudhari 2014; Potapenko 2011; Sarullo 2010; Tatarchenko 2008; Tumasyan 2016; Tumasyan 2017; Tumasyan 2018). Information was insufficient to permit a decision regarding four trials (Abdel 2011; Bansal 2019; De Masi De Luca 2013; Sisakian 2016).

With regard to detection bias, only two studies reported blinding of outcome assessors (Sarullo 2010; Tsutsui 2019). For all other studies, information was insufficient to permit a decision.

\section{Incomplete outcome data}

We judged eight studies as having a low risk of attrition bias (Bansal 2019; Fox 2008; Kosmala 2013; Potapenko 2011; Sisakian 2016; Swedberg 2010; Tsutsui 2016; Tsutsui 2019). Information was insufficient to permit a decision regarding the remaining 11 trials.

\section{Selective reporting}

We found trial registration protocols for Fox 2008, Komajda 2017, and Swedberg 2010. We did not find a trial registration protocol for the remaining studies to confirm whether all prespecified outcomes were reported in the publication. For seven studies (Fox 2008; Kosmala 2013; Potapenko 2011; Sarullo 2010; Swedberg
2010; Tsutsui 2016; Tsutsui 2019), the outcomes listed in the methods section were adequately reported in the results section. Information was insufficient to permit a decision regarding the remaining 12 trials. As we were not able to pool more than 10 trials, we did not include funnel plots in this review.

\section{Other potential sources of bias}

For most studies (Abdel 2011; Adamyan 2008; Adamyan 2015a; Bansal 2019; Chaudhari 2014; De Masi De Luca 2013; Komajda 2017; Potapenko 2011; Sisakian 2016; Swedberg 2010; Tatarchenko 2008; Tumasyan 2016; Tumasyan 2017; Tumasyan 2018), information was insufficient on which to base a judgement of low risk of bias. However, we rated three studies as at unclear risk of other potential sources of bias (Fox 2008; Tsutsui 2016; Tsutsui 2019). Fox 2008 stated that "Representatives of the sponsor were non-voting members of the study executive committee and were involved with the executive committee in the study design, interpretation of the data, and the writing of the report". The influence of the sponsor (Servier), who also funded the trial, resulted in a judgement of unclear risk of other potential sources of bias. With regard to Tsutsui 2016, the authors stated that "The data were collected and analysed and the first draft manuscript was written by the sponsor. It was fully reviewed and revised by the authors". In this study, as well as in Tsutsui 2019, the sponsor was Ono Pharmaceutical, who also funded the trial, resulting in a judgement of unclear risk of other potential sources of bias. We judged two studies to be at low risk of other potential sources of bias due to sufficient information concerning funding (no funding or internal funds) (Kosmala 2013; Sarullo 2010).

\section{Effects of interventions}

See: Summary of findings 1 Usual care with ivabradine compared to placebo, usual care, or no treatment in participants with HFrEF (long-term treatment ( $\geq 6$ months) with ivabradine); Summary of findings 2 Usual care with ivabradine compared to placebo, usual care, or no treatment in participants with HFrEF (short-term treatment (< 6 months) with ivabradine); Summary of findings 3 Usual care with ivabradine compared to placebo, usual care, or no treatment in participants with HFpEF (long-term treatment $(\geq 6$ months) with ivabradine); Summary of findings $\mathbf{4}$ Usual care with ivabradine compared to placebo, usual care, or no treatment in participants with HFpEF (short-term treatment ( $<6$ months) with ivabradine)

For the analyses of effects of interventions, we distinguished between type of heart failure (HFrEF and HFpEF) and duration of treatment with ivabradine (long-term treatment ( $\geq 6$ months) and short-term treatment ( $<6$ months)). Tumasyan 2018 (HFmrEF) reported no outcomes of interest. Four studies provided no details on type of heart failure (Adamyan 2015a; Tatarchenko 2008; Tumasyan 2016; Tumasyan 2017), thus we did not include these studies in our analysis. See 'Summary of findings' tables for each comparison (Summary of findings 1; Summary of findings 2; Summary of findings 3; Summary of findings 4).

\section{Usual care with ivabradine compared to placebo, usual care, or no treatment in participants with HFrEF (long-term treatment ( $\geq 6$ months) with ivabradine)}

For this comparison, we assessed all trials that compared usual care with ivabradine compared to placebo, usual care, or no treatment in participants with HFrEF, and in which ivabradine was given as 
long-term treatment ( $\geq 6$ months). Six studies met the inclusion criteria for this comparison (Chaudhari 2014; Fox 2008; Potapenko 2011; Sisakian 2016; Swedberg 2010; Tsutsui 2019), five of which adhered partly to guideline recommendations for chronic heart failure management (Fox 2008; Potapenko 2011; Sisakian 2016; Swedberg 2010; Tsutsui 2019).

\section{Primary outcomes}

\section{Mortality from cardiovascular causes}

Three studies assessed mortality from cardiovascular causes (follow-up range 19 months to 23 months) (Fox 2008; Swedberg 2010; Tsutsui 2019). We found evidence of no difference (effect is close to 1 , and the $\mathrm{Cl}$ is narrow) between HFrEF participants randomised to receive ivabradine as a long-term treatment compared with those randomised to placebo, usual care, or no treatment (risk ratio (RR) $0.99,95 \%$ confidence interval $(\mathrm{Cl}) 0.88$ to 1.11; 3 studies; 17,676 participants; $1^{2}=33 \%$; Analysis 1.1).

Even though the $\mathrm{Cl}$ on the forest plots overlap and all studies have a null effect, the effect estimates are going in opposite directions: Fox 2008 favours placebo, whilst Swedberg 2010 favours ivabradine, leading to an $1^{2}$ of $33 \%$, which is suggestive of moderate heterogeneity. However, the mean heart rate at baseline as well as other demographics (age, sex, LVEF) and the dosage of ivabradine of Fox 2008 are similar to Swedberg 2010. The only main differences between Fox 2008 and Swedberg 2010 are the use of MRA (39.5\% versus $60.0 \%$ ) and the NYHA class (I-III versus II-IV). Participants with persistent symptoms should receive an MRA if the ejection fraction is $35 \%$ or less (Ponikowski 2016). The guideline adherence of Fox 2008 was thus probably lower than that of Swedberg 2010, which might have led to the tendency towards placebo. Additionally, the difference in NYHA classes is in line with the explanation of Fox 2008, who argues that the tendency towards advantages of placebo are a result of insufficient reductions in heart rate. GRADE was assessed as moderate certainty due to indirectness (male predominance).

\section{Quality of life}

Two studies reported on QoL (Chaudhari 2014; Swedberg 2010); the latter study was available as abstract only. QoL was assessed using the Kansas City Cardiomyopathy Questionnaire (KCCQ). Swedberg $2010(n=1944)$ reported that treatment with ivabradine improved KCCQ by 1.8 (95\% Cl 0.30 to 3.24) for clinical summary score (CSS) and by $2.4(95 \% \mathrm{Cl} 0.91$ to 3.85$)$ for overall summary score (OSS) (placebo-corrected, $\mathrm{P}=0.018$ and $\mathrm{P}<0.001$, respectively). Chaudhari 2014 reported a significant improvement in QoL score six months after ivabradine treatment was added to optimal medical care $(n=158)(P=0.004$, no further details available). GRADE was assessed as low certainty due to risk of bias (blinding) and attrition bias.

\section{Time to first hospitalisation for heart failure during follow-up}

This outcome was not reported in studies that met the inclusion criteria for this comparison.

\section{Number of days spent in hospital due to heart failure during follow-up}

This outcome was not reported in studies that met the inclusion criteria for this comparison.

\section{Secondary outcomes}

\section{Rate of serious adverse events}

Four studies included in this comparison reported on serious adverse events (Chaudhari 2014; Fox 2008; Potapenko 2011; Swedberg 2010), two of which provided data applicable for metaanalysis (Fox 2008; Swedberg 2010). Chaudhari 2014 did not define serious adverse events, but stated that no significant serious adverse effects on ivabradine therapy were noted at the end of six months. Fox 2008 and Swedberg 2010 did not define serious adverse events, thus it can be assumed that the standardised definition for clinical studies was applied (death, life-threatening, hospitalisation, disability or permanent damage, congenital anomaly or birth defect). Chaudhari 2014 reported on "serious adverse effects", and Potapenko 2011 reported on "cardiovascular events". We were able to report on the absolute number of participants experiencing at least one serious adverse event. We found no evidence of a difference in the rate of serious adverse events in HFrEF participants randomised to receive ivabradine as a long-term treatment compared with those randomised to placebo, usual care, or no treatment with (RR 0.96, $95 \% \mathrm{Cl} 0.92$ to $1.00 ; 2$ studies; 17,399 participants; $\left.\right|^{2}=12 \%$; Analysis 1.2). GRADE was assessed as moderate certainty due to indirectness (male predominance).

For those studies that could not be pooled, it was reported that there were no significant adverse effects on ivabradine therapy noted at the end of six months (Chaudhari 2014), and that the addition of ivabradine to standard treatment resulted in fewer fatal cardiovascular events (Potapenko 2011).

\section{Exercise capacity}

Only one study reported on the total exercise duration after six months (Chaudhari 2014), which was available as abstract only. The authors assessed "exercise duration (in seconds) by exercise test" and concluded that ivabradine failed to show significant improvement in exercise duration ( $320 \pm 130.6$ versus $311.79 \pm$ $103.60, P=0.663,158$ participants) when compared to standard of care. GRADE was downgraded two levels due to risk of bias (allocation, blinding) and imprecision (low number of participants) to low certainty.

\section{Usual care with ivabradine compared to placebo, usual care, or no treatment in participants with HFrEF (short-term treatment ( 6 months) with ivabradine)}

For this comparison, we assessed all trials that compared usual care with ivabradine compared to placebo, usual care, or no treatment in participants with $\mathrm{HFrEF}$, and in which ivabradine was given as short-term treatment ( $<6$ months). Five studies met the inclusion criteria for this comparison (Abdel 2011; Adamyan 2008; Bansal 2019; Sarullo 2010; Tsutsui 2016), of which only two trials adhered partly to guideline recommendations for chronic heart failure management (Sarullo 2010; Tsutsui 2016).

\section{Primary outcomes}

Mortality from cardiovascular causes

This outcome was not reported in studies that met the inclusion criteria for this comparison. 


\section{Quality of life}

Only one study reported on QoL after three months using the Minnesota Living with Heart Failure Questionnaire (MLHFQ) (Sarullo 2010). The authors concluded that ivabradine showed a significant improvement in QoL score at three months versus baseline (37.5 \pm 1.9 versus $30.9+2.3 ; P<0.001 ; 60$ participants) when compared to standard of care at three months versus baseline $(31.2+2.6$ versus $30.6+2.1)(P$ value not specified). Nevertheless, this 'significant improvement' shows no clinically meaningful difference, as the MLHFQ is of limited clinical relevance. GRADE was downgraded one level for imprecision (low number of participants) and one level for risk of bias (blinding) to low certainty.

\section{Time to first hospitalisation for heart failure during follow-up}

This outcome was not reported in studies that met the inclusion criteria for this comparison.

Number of days spent in hospital due to heart failure during follow-up

This outcome was not reported in studies that met the inclusion criteria for this comparison.

\section{Secondary outcomes}

\section{Rate of serious adverse events}

Two studies reported on serious adverse events (Adamyan 2008; Tsutsui 2016). Tsutsui 2016 reported that the incidence of adverse events (heart failure, phosphenes, diarrhoea, nasopharyngitis) was $54.8 \%$ in the $2.5 \mathrm{mg}$ ivabradine group and $64.3 \%$ in the 5 $\mathrm{mg}$ ivabradine group, which was significantly higher than in the placebo group (29.3\%) ( $P=0.004,125$ participants). Even though Tsutsui 2016 defines these events as adverse events and not as serious adverse events, we decided to document these results due to the strong similarity with the definitions of the other publications. Adamyan $2008(n=145)$ reported that noticeable side effects requiring the withdrawal of drugs were not observed. GRADE was downgraded one level for imprecision (low number of participants) and one level for publication bias (low number of studies reporting on this outcome) to low certainty.

\section{Exercise capacity}

Three studies reported on exercise capacity (Abdel 2011; Adamyan 2008; Sarullo 2010). Abdel 2011 measured mean exercise duration in seconds after three months; Adamyan 2008 measured exercise capacity in total duration in seconds at day 90; and Sarullo 2010 reported on exercise duration at submaximal load in minutes as well as maximal workload in watt. Pooling of data was not feasible due to the missing standard deviation of Abdel 2011 and the differences in the exercise test protocol between Adamyan 2008 (Bruce protocol) and Sarullo 2010 (specific protocol); the latter led to exercise duration differences of more than twice as large values, thus we decided not to pool those data. Abdel 2011 reported that after 12 weeks of ivabradine therapy, the mean exercise duration time increased significantly from 328 seconds to 497 seconds ( $P=0.024,100$ participants). Adamyan 2008 noted significant improvement at 90 days ( $495 \pm 147 \mathrm{~s}$ versus $416 \pm 128 \mathrm{~s}$ ) in exercise time or maximal workload ( $P<0.05,145$ participants). Sarullo 2010 reported that the exercise capacity increased from $14.8 \pm 2.5 \mathrm{~min}$ to $28.2 \pm 3.5 \mathrm{~min}$ in the ivabradine group when compared to placebo ( $P$ $<0.001,60$ participants). GRADE was downgraded two levels due to risk of bias (blinding) and imprecision (low number of participants) to low certainty.

\section{Usual care with ivabradine compared to placebo, usual care, or no treatment in participants with HFpEF (long-term treatment ( $\geq 6$ months) with ivabradine)}

For this comparison, we assessed all trials that compared usual care with ivabradine compared to placebo, usual care, or no treatment in participants with $\mathrm{HFpEF}$, in which ivabradine was given as longterm treatment ( $\geq 6$ months). Only one study met the inclusion criteria for this comparison. As Komajda 2017 included participants with an LVEF $\geq 45 \%$, it could also have been assigned to the HFmrEF group. However, since they reported that mean LVEF at baseline was $60.5 \%$, we decided to analyse the results of this study in the group of participants with HFpEF.

\section{Primary outcomes}

\section{Mortality from cardiovascular causes}

Komajda 2017 reported on mortality from cardiovascular causes. One death from cardiovascular cause occurred in the ivabradine group (ischaemic stroke), and no deaths occurred in the control group. GRADE was downgraded one level for imprecision (low number of participants) and by one level due to risk of bias (serious methodological limitations due to insufficient information on random sequence generation, allocation concealment, blinding of participants and personnel, blinding of outcome assessment, incomplete outcome data, and selective reporting) to low certainty.

\section{Quality of life}

Komajda 2017 reported on QoL at baseline and after two, four, and eight months using the Kansas City Cardiomyopathy Questionnaire (KCCQ). Findings on the KCCQ changed minimally in both treatment groups. GRADE was downgraded one level for imprecision (low number of participants) and by one level due to risk of bias (serious methodological limitations due to insufficient information on random sequence generation, allocation concealment, blinding of participants and personnel, blinding of outcome assessment, incomplete outcome data, and selective reporting) to low certainty.

\section{Time to first hospitalisation for heart failure during follow-up}

This outcome was not reported in the study that met the inclusion criteria for this comparison.

\section{Number of days spent in hospital due to heart failure during follow-up}

This outcome was not reported in the study that met the inclusion criteria for this comparison.

\section{Secondary outcomes}

\section{Rate of serious adverse events}

Komajda 2017 reported on serious adverse events, but did not define serious adverse events, thus it can be assumed that the standardised definition for clinical studies was applied (death, life-threatening, hospitalisation, disability or permanent damage, congenital anomaly or birth defect). The authors reported that the incidence of serious adverse events was $35.1 \%$ in the ivabradine group and $25.0 \%$ in the placebo group $(P=0.191)$, showing no statistically significant differences between groups. GRADE was downgraded one level for imprecision (low number of participants) and one level due to risk of bias (serious methodological limitations due to insufficient information on random sequence generation, allocation concealment, blinding of participants and personnel, 
blinding of outcome assessment, incomplete outcome data, and selective reporting) to low certainty.

\section{Exercise capacity}

Komajda 2017 reported on exercise capacity by comparing the results of a 6-minute walk test (6MWT) at baseline and after two, six, and eight months. The distance covered during the 6MWT did not change in the active group $(P=0.882)$. GRADE was downgraded one level for imprecision (low number of participants) and one level due to risk of bias (serious methodological limitations due to insufficient information on random sequence generation, allocation concealment, blinding of participants and personnel, blinding of outcome assessment, incomplete outcome data, and selective reporting) to low certainty.

\section{Usual care with ivabradine compared to placebo, usual care, or no treatment in participants with HFpEF (short-term treatment ( 6 months) with ivabradine)}

For this comparison, we assessed all trials that compared usual care with ivabradine compared to placebo, usual care, or no treatment in participants with $\mathrm{HFpEF}$, in which ivabradine was given as shortterm treatment ( $<6$ months). Two studies met the inclusion criteria for this comparison (De Masi De Luca 2013; Kosmala 2013). For both studies, we had insufficient information to judge adherence to guideline recommendations for chronic heart failure management.

\section{Primary outcomes}

\section{Mortality from cardiovascular causes}

This outcome was not reported in studies that met the inclusion criteria for this comparison.

\section{Quality of life}

This outcome was not reported in studies that met the inclusion criteria for this comparison.

\section{Time to first hospitalisation for heart failure during follow-up}

This outcome was not reported in studies that met the inclusion criteria for this comparison.

\section{Number of days spent in hospital due to heart failure during follow-up}

This outcome was not reported in studies that met the inclusion criteria for this comparison.

\section{Secondary outcomes}

\section{Rate of serious adverse events}

This outcome was not reported in studies that met the inclusion criteria for this comparison.

\section{Exercise capacity}

Both studies included in this comparison focused on exercise capacity (De Masi De Luca 2013; Kosmala 2013); however, the definition and measurement tool were too heterogenous to allow pooling. De Masi De Luca 2013 documented significant improvement in exercise duration (baseline: $5.4 \pm 2.1$ min versus follow-up at month 3: $6.9 \pm 2.9 \mathrm{~min})(P<0.05)$. No data were provided for the placebo group. Kosmala 2013 reported significant improvement in metabolic equivalents (METs) (baseline: $4.2 \pm 1.8$ versus follow-up at day $7: 5.7 \pm 1.9 \mathrm{METs})(\mathrm{P}=0.001)$, and "no change in the control subjects". GRADE was downgraded two levels for inconsistency (heterogeneity in parameters) and for imprecision (low number of participants) to low certainty.

\section{Economic evaluation}

Database searches in March 2020 resulted in 35 citations, 25 of which were excluded as they were reviews or duplicates and thus missing the focus on the scope of our economic evaluation. A total of 10 studies were thus included in this narrative summary reporting on economic aspects of chronic heart failure therapy with ivabradine (Adena 2018; Borer 2016; Chang 2014; Fernandez de Bobadilla 2014; Griffiths 2014; Kansal 2016; Kourlaba 2014; Krittayaphong 2019; Polistena 2014; Taheri 2018). The studies were published between 2014 and 2019, and two studies were available as abstracts only (Chang 2014; Fernandez de Bobadilla 2014). Polistena 2014 was published in Italian only; the abstract was available in English. Notably, all analyses were based on data from the SHIFT trial reporting long-term treatment with ivabradine in participants with HFrEF (Swedberg 2010). Based on the reports, we want to acknowledge that all studies adapted the predeveloped Markov model to a certain population, which was purposely developed for "submission to national regulatory bodies" (Polistena 2014). Studies used the Markov model to assess the cost-effectiveness of ivabradine on top of standard care in heart failure therapy and compared it to data from Australia (Adena 2018), the USA (Borer 2016; Kansal 2016), Taiwan (Chang 2014), Spain (Fernandez de Bobadilla 2014), the UK (Griffiths 2014), Greece (Kourlaba 2014), Iran (Taheri 2018), Thailand (Krittayaphong 2019), and Italy (Polistena 2014).

For the studies available as abstracts only, no information on funding or conflict of interests was provided. Five studies reported that they were funded either by Servier Laboratories or by Amgen; both companies are known for their close collaboration with the authors (see Other potential sources of bias) (Adena 2018; Borer 2016; Griffiths 2014; Kansal 2016; Kourlaba 2014). Multiple authors of the five publications are employees of Servier or Amgen. In addition, various authors have accepted funds from companies (received honoraria, speaker fees, consultancy fees) or are members of advisory boards or have appeared on expert panels, for example for Servier.

Nevertheless, we assessed quality according to quality checklist of Drummond 1996 as good for all included studies that were present as full text. GRADE was downgraded one level to moderate due to risk of bias (influence of the sponsor) (Swedberg 2010).

Most of the studies focused on the economic question of the costeffectiveness of ivabradine, including its impact on survival and quality of life from a general healthcare analytic viewpoint (Adena 2018; Chang 2014; Fernandez de Bobadilla 2014; Griffiths 2014; Kourlaba 2014; Krittayaphong 2019; Polistena 2014; Taheri 2018). In contrast, Borer 2016 and Kansal 2016 aimed to estimate the budget impact of ivabradine from a US commercial payer perspective.

All studies used a Markov model to analyse the economic data except for Borer 2016, who analysed a budget impact model estimated the per-member-per month (PMPM) impact of introducing ivabradine to existing formularies by comparing standard of care with ivabradine plus standard of care in a hypothetical one million-member commercial and Medicare Advantage plans. 
Time horizons varied across included economic evaluations as three years (Borer 2016), 10 years (Adena 2018; Kansal 2016; Taheri 2018), and lifetime (all other studies).

Six studies reported the cost per quality-adjusted life-year (QALY) (Adena 2018; Chang 2014; Fernandez de Bobadilla 2014; Krittayaphong 2019; Polistena 2014; Taheri 2018). Further outcome measures were very heterogenous, ranging from PMPM cost savings, Borer 2016, to incremental cost per additional QALY for lifetime subgrouped by heart rate, Griffiths 2014, or the incremental cost-effectiveness ratio (ICER) per QALY, Kansal 2016; Kourlaba 2014.

All included studies concluded that ivabradine should be regarded as cost-effective in the respective country for heart failure therapy in long-term treatment of participants with HFrEF (see Summary of findings 1). As all data were from the same study (SHIFT), differences in cost values can be explained by different cost of ivabradine, hospital costs, and currencies. GRADE was assessed as high certainty.

Based on our findings, there is a need to verify this conclusion with independent data to raise the certainty of the evidence.

\section{DISCUSSION}

\section{Summary of main results}

This review summarised 19 studies involving 19,628 participants randomly assigned to receive either ivabradine or placebo/usual care/no treatment for chronic heart failure. Most studies compared ivabradine to placebo and usual care or to usual care only. All included studies used a standard parallel-group design. The sample size in the included studies ranged from 49 to 10,917 participants; most studies did not provide a power analysis. We noted a large gender imbalance across all studies to the detriment of female participants. Studies concentrated either on participants diagnosed with HFrEF or HFpEF; one study focused on HFmrEF, and in four studies the type of heart failure (or any other classifying determinant) was not provided. Regarding severity of heart failure, there was no clear focus in the included studies. NYHA classification included class 1 to 4 and various combinations of two or more NYHA classes, drawing a heterogenous picture of clinical presentation across studies. Regarding dosage of ivabradine, the majority of studies determined ivabradine dosage based on participant's heart rate; this ranged from $2.5 \mathrm{mg}$ twice a day (often starting dose) to maximum of $15 \mathrm{mg}$ twice a day.

Due to substantial clinical heterogeneity in type of heart failure, heterogeneity regarding ivabradine treatment, and substantial heterogeneity in definition and measurement of outcome parameters, pooling of data was rarely feasible. This was worsened due to poor reporting within study reports (e.g. type of heart failure was often not mentioned). Although we contacted corresponding authors multiple times, we were not able to obtain additional information. To enable meta-analysis, we distinguished between: 1) usual care with ivabradine compared to placebo, usual care, or no treatment in participants with HFrEF (long-term treatment $(\geq 6$ months) with ivabradine); 2) usual care with ivabradine compared to placebo, usual care, or no treatment in participants with HFrEF (short-term treatment ( $<6$ months) with ivabradine); 3 ) usual care with ivabradine compared to placebo, usual care, or no treatment in participants with HFpEF (long-term treatment ( $\geq 6$ months) with ivabradine); and 4) usual care with ivabradine compared to placebo, usual care, or no treatment in participants with HFpEF (short-term treatment ( $<6$ months) with ivabradine). Although 19 studies met the inclusion criteria for our review, few studies contributed data to our four comparisons.

We were able to perform two meta-analyses focusing on participants with HFrEF and long-term treatment of ivabradine. Regarding mortality from cardiovascular causes, we found evidence of no difference between ivabradine and placebo/ usual care/no treatment. Furthermore, we found no evidence of a difference on the rate of serious adverse events in HFrEF participants randomised to receive ivabradine as a long-term treatment compared with those randomised to placebo, usual care, or no treatment. For all other outcomes, we were not able to perform meta-analysis. Single studies showed significant improvement in quality of life in participants with HFrEF on longterm treatment ( $\geq 6$ months) as well as in short-term treatment ( $<6$ months) with ivabradine. The serious adverse event rate was significantly worse in one single study $(N=125)$, whilst exercise capacity improved significantly in two single studies $(N=160)$ in participants with HFrEF in short-term treatment ( $<6$ months) with ivabradine. There was no significance in any outcome for participants with HFpEF on long-term treatment ( $\geq 6$ months) with ivabradine. Exercise capacity improved significantly in two single studies $(\mathrm{N}=171)$ in participants with HFpEF on short-term treatment ( $<6$ months) with ivabradine. GRADE was assessed as high, moderate, or low due to high risk of bias, imprecision of data, or low number of participants.

One other aspect of our systematic review warrants comment. Although we were able to include large-scale randomised trials (Fox 2008; Swedberg 2010), each of which was performed at several hundred centres in nearly 40 countries around the globe including nearly 18,000 participants, patient-centred outcomes focusing on individual health-related quality of life and functional outcome parameters were rarely assessed, and pooling of data on patientcentred outcomes was not possible.

We also performed an economic evaluation of ivabradine and included a narrative analysis of eight matching studies in this review. All studies concluded that ivabradine was cost-effective in the respective country for heart failure therapy when provided as a long-term treatment in participants with HFrEF. We want to point out that all analyses are based on data from the SHIFT trial reporting on long-term treatment with ivabradine in participants with HFrEF, and all studies adapted the predeveloped Markov model to a certain population, which was purposely developed for submission to national regulatory bodies. Risk of bias in the included studies must be taken into account when interpreting the economic evaluation.

\section{Overall completeness and applicability of evidence}

Although the number of trials meeting our inclusion criteria was relatively large, most of the included studies did not report the outcomes planned for this review. Not including heart failure death as an outcome in the protocol or consequently in the analysis might be regarded by some as a limitation of this review. Nevertheless, only SHIFT studies (Swedberg 2010; Tsutsui 2019) reported this outcome. The results for such an analysis would be the same as the SHIFT studies. Significant heterogeneity in type of outcome and measurement tool prohibited pooling of data to a great extent. We 
believe it is of importance to highlight that this problem was of special concern for functional outcome parameters that focused on exercise capacity. Almost half of the included studies reported on exercise capacity; however, pooling was impossible due to massive inconsistency limiting the overall completeness of the available evidence.

Regarding adherence to guideline management of chronic heart failure, we believe that this is a second factor limiting the applicability of the available evidence. Only four of the 19 included studies reported that all participants were treated adequately with beta-blockers and ACE inhibitors (Adamyan 2015a; Tumasyan 2016; Tumasyan 2017; Tumasyan 2018). All other studies did not explicitly state that study participants were treated in accordance with current guidelines for heart failure management, nor did they state reasons why participants were not treated with beta-blockers, ACE inhibitors, or MRA. These circumstances limit how clinicians will rate the potential of ivabradine as an adjuvant oral medication for the symptomatic treatment of chronic heart failure.

\section{Quality of the evidence}

We assessed the certainty of evidence in the included studies using the criteria outlined in the Cochrane Handbook for Systematic Reviews of Interventions (Higgins 2011), and by employing the GRADE approach. Six studies that matched our inclusion criteria were only available abstracts with a minimum of information on which to base judgements regarding the certainty of the evidence. Although we contacted corresponding authors multiple times, we were not able to obtain more information. GRADEpro GDT allowed us to import data from Review Manager 5 to create a 'Summary of findings' table for two of our primary outcomes, which we were able to pool: mortality from cardiovascular causes and rate of serious adverse events (GRADEpro GDT; Review Manager 2014).

In participants with HFrEF (long-term treatment ( $\geq 6$ months) with ivabradine), we graded the certainty of the evidence for mortality from cardiovascular causes as moderate due to the high number of cases $(n=17,676)$ and the narrow confidence interval $(0.88$ to 1.11 ), but indirectness (male predominance). GRADE was assessed as low for quality of life due to risk of bias (blinding) and attrition bias, and as moderate due to indirectness (male predominance) for rate of serious adverse events, the data for which we were able to pool (Fox 2008; Swedberg 2010). For exercise capacity, GRADE was downgraded two levels to low due to risk of bias (allocation, blinding) and imprecision (low number of participants).

In participants with HFrEF (short-term treatment ( $<6$ months) with ivabradine), GRADE was assessed as low for quality of life due to imprecision (low number of participants) and risk of bias (blinding), and as low for rate of serious adverse events due to imprecision (low number of participants) and publication bias (low number of studies reporting on this outcome). For exercise capacity, GRADE was downgraded two levels to low due to risk of bias (blinding) and imprecision (low number of participants).

In participants with HFpEF (long-term treatment ( $\geq 6$ months) with ivabradine), GRADE was assessed as low for mortality from cardiovascular causes as well as for quality of life, rate of serious adverse events, and exercise capacity due to imprecision (low number of participants) and risk of bias (serious methodological limitations due to insufficient information on random sequence generation, allocation concealment, blinding of outcome assessment, incomplete outcome data, and selective reporting).

In participants with HFpEF (short-term treatment ( $<6$ months) with ivabradine), GRADE was downgraded two levels to low for exercise capacity due to inconsistency (heterogeneity in parameters) and imprecision (low number of participants).

\section{Potential biases in the review process}

We undertook this systematic review in accordance with the standards of Cochrane as outlined in the Cochrane Handbook for Systematic Reviews of Interventions (Higgins 2011). We carried out a comprehensive search across relevant databases and assessed reference lists of the included studies. The process of study selection is outlined comprehensively and in full detail (Figure 1). In addition, we screened reference lists of systematic reviews and contacted study authors for additional data or relevant details multiple times. We did not apply any language or date restrictions. Two review authors performed all levels of the selection process independently, and analyses were conducted by one review author and checked by a colleague. We provided reasons for the exclusion of studies from this systematic review. We described each included study in full detail and made explicit judgements on risk of bias (low, high, or unclear risk of bias). We identified no other potential sources of bias in our review process.

\section{Agreements and disagreements with other studies or reviews}

The effect sizes of treatments with ivabradine found in this article are similar to the findings of Fox 2013 and Thomsen 2016 concerning cardiovascular death. Both reviews found no significant effect of ivabradine on cardiovascular mortality in participants with reduced ejection fraction. However, Fox 2013 showed a significant risk reduction in heart failure hospitalisation (RR $0.87,95 \% \mathrm{Cl}$ 0.68 to $1.10 ; P<0.001$ ) and in the combined endpoint of heart failure hospitalisation and cardiovascular mortality (RR 0.87, 95\% $\mathrm{Cl} 0.80$ to $0.94 ; \mathrm{P}<0.01$ ). A systematic review and meta-analysis by Hartmann 2018 showed that ivabradine significantly reduced heart rate, but it also showed no significant effect for all-cause mortality, cardiovascular death, and hospitalisation due to heart failure. Narayanan 2017 agreed with Hartmann 2018 and further added the statement that the greater reduction in heart rate was coupled with improvement in combined endpoint of heart failure readmission and cardiovascular death. Pei 2019 stated that the RR of the composite endpoint cardiovascular death or worsening heart failure (RR $0.93,95 \% \mathrm{Cl} 0.87$ to $0.98 ; \mathrm{P}=0.01$ ) and the RRs of admission to hospital for heart failure (RR $0.86,95 \% \mathrm{Cl} 0.79$ to $0.93 ; \mathrm{P}<0.001$ ) decreased significantly in participants treated with ivabradine. Furthermore, the RR of participants who died from heart failure was significantly decreased in the group treated with added ivabradine compared to the standard anti-heart failure therapy group (RR $0.82,95 \% \mathrm{Cl} 0.69$ to $0.96 ; \mathrm{P}=0.02$ ). It should be noted that the author equates cardiac death (Fox 2008: "Death from myocardial infarction, heart failure, or cardiac procedures") with death from heart failure (Swedberg 2010), and also uses an incorrect number of events in the placebo group of Fox 2008 ( $n=151$ instead of $n=154$ ) to calculate the RR. The current European Society of Cardiology guidelines recommend to consider ivabradine to reduce the risk of heart failure hospitalisation and cardiovascular death in symptomatic individuals with LVEF $\leq 35 \%$ in sinus rhythm and a resting heart rate of $\geq 70$ beats per minute despite treatment 
with beta-blockers, ACE-I (or ARB), and an MRA (or ARB) (class of recommendation Ila, level of evidence B) (Ponikowski 2016). Furthermore, ivabradine should be considered in individuals of this subgroup with contraindications for beta-blockers in combination with ACE-I (or ARB) and an MRA (or ARB) (class of recommendation Ila, level of evidence $C$ ). Overall, recently published studies are showing similar findings as our review, however, our findings are not in line with the evidence cited by the ESC Guideline that ivabradine reduces mortality in this population (Ponikowski 2016, p. 2151: "Ivabradine should be considered to reduce the risk of HF hospitalization and cardiovascular death in symptomatic patients with $\mathrm{LVEF} \leq 35 \%$, in sinus rhythm and a resting heart rate $\geq 70 \mathrm{bpm}$ who are unable to tolerate or have contra-indications for a betablocker. Patients should also receive an ACE-I (or ARB) and an MRA (or ARB)."). The findings of the present work may also have an impact on NICE guidance as it is also based on the assumption of a reduction of hard outcomes by ivabradine.

\section{AUTHORS' CONCLUSIONS}

\section{Implications for practice}

Our found evidence suggests that long-term treatment with ivabradine does not reduce mortality from cardiovascular causes or rate of serious adverse events in participants with HFrEF compared to placebo/usual care/no treatment. Nevertheless, due to significant differences across matching studies in trial design (type of heart failure, duration and dosage of ivabradine treatment), outcome reporting and measurement, the available evidence is uncertain.

\section{Implications for research}

Our results show the importance of a standardised approach regarding outcome definition and reporting in randomised controlled trials of similar scope (e.g. the implementation of minimum core outcome set) to assure the comparability of results across trials. In addition, we believe that clinical trials should follow guideline recommendations if the guideline management itself is not the focus of the investigation to assure the external applicability of research findings.

\section{ACKN OWLEDGEMENTS}

We would very much like to acknowledge the authors of primary studies who have kindly provided additional data and information. We would also like to thank the team from the Cochrane Heart Group for their support and for providing assistance during the editorial process. Our thanks also go to Edoardo Sciatti, Fran Hidalgo, and Thomas A. Marciniak for their valuable feedback during the peer review process. We also thank the Sign-off Editor, Rui Providencia, and the Senior Editor, Mike Brown from the Cochrane Circulation \& Breathing Network who helped sharpen our review with regard to current clinical guidelines. We want to acknowledge that the Methods section of this review is based on a standard template used by the Cochrane Heart Group. 


\section{REFERE N CE S}

\section{References to studies included in this review}

\section{Abdel 2011 \{published data only\}}

Abdel HY. Effects of adding ivabradine to optimal medical therapy in symptomatic patients with left ventricular systolic dysfunction secondary to ischemic or idiopathic dilated cardiomyopathy. ESC Heart Failure 2011;10:107.

\section{Adamyan 2008 \{published data only\}}

Adamyan KG, Chilingarian AL, Astvacatryan AV. Addition of ivabradin further improves clinical status in patients with end stage heart failure and intolerance to ss-blockers. Circulation 2008;118:341-2.

\section{Adamyan 2015a \{published data only\}}

Adamyan K, Tumasyan L, Chilingaryan A, Tunyan L. Efficacy of long-term ivabradine therapy on prognosis, left and right heart functional parameters in patients with chronic heart failure and preserved left ventricular systolic function. European Heart Journal 2015;36:666-7.

\section{Bansal 2019 \{published data only\}}

Bansal S, Chaudhary M. Importance of serum sodium in ischemic heart failure with systolic dysfunction. European Journal of Heart Failure 2019;21(Suppl S1):5-592.

\section{Chaudhari 2014 \{published and unpublished data\}}

Chaudhari M, Chakraborty P, Pathak S, Isser H, Bansal S. Effects of ivabradine on left ventricular function in patients with ischemic heart failure. Indian Heart Journal 2014;66:83-4.

\section{De Masi De Luca 2013 \{published data only\}}

* De Masi De Luca G, Accogli M, Palmisano P, De Masi De Luca A, Palumbo F, Giuncato G, et al. Ivabradine improves physical performance and neurohormonal parameters in patients with diastolic heart failure. Circulation 2013;A16580:128.

De Masi De Luca G, Capulzini L, Accogli M, De Masi De Luca A, Mangia R, Palumbo F, et al. Ivabradine and diastolic heart failure. JACC 2012;59(13):E1009.

\section{Fox 2008 \{published and unpublished data\}}

Beautiful Study Group. The BEAUTIFUL study: randomized trial of ivabradine in patients with stable coronary artery disease and left ventricular systolic dysfunction - baseline characteristics of the study population. Cardiology 2008;110:271-82.

* Fox K, Ford I, Steg PG, Tendera M, Ferrari R, on behalf of the BEAUTIFUL Investigators. Ivabradine for patients with stable coronary artery disease and left-ventricular systolic dysfunction (BEAUTIFUL): a randomised, double-blind, placebo-controlled trial. Lancet 2008;372(9641):807-16.

Fox K, Ford I, Steg PG, Tendera M, Robertson M, Ferrari R, et al. Heart rate as a prognostic risk factor in patients with coronary artery disease and left-ventricular systolic dysfunction (BEAUTIFUL): a subgroup analysis of a randomised controlled trial. Lancet 2008;372(9641):817-21.
NCT00143507. The BEAUTIFUL Study: effects of ivabradine in patients with stable coronary artery disease and left ventricular systolic dysfunction. clinicaltrials.gov/ct2/show/NCT00143507 (first received 21 November 2018).

Tendera M, Talajic M, Robertson M, Tardif JC, Ferrari R, Ford I, et al. Safety of ivabradine in patients with coronary artery disease and left ventricular systolic dysfunction (from the BEAUTIFUL Holter substudy). American Journal of Cardiology 2011;107(6):805-11.

\section{Komajda 2017 \{published data only\}}

EUCTR2012-002742-20-HU. Effect of ivabradine versus placebo on cardiac function, exercise capacity, and neuroendocrine activation in patients with chronic heart failure with preserved left ventricular ejection fraction an 8-month, randomised double-blind, placebo controlled, international, multicentre study - EDIFY. clinicaltrialsregister.eu/ctr-search/search? query=eudract_number:2012-002742-20 (first received 21 November 2018).

* Komajda M, Isnard R, Cohen-Solal A, Metra M, Pieske B, Ponikowski $P$, et al. Effect of ivabradine in patients with heart failure with preserved ejection fraction: the EDIFY randomized placebo-controlled trial. ESC Heart Failure 2017;19:1495-503.

Kosmala 2013 \{published and unpublished data\}

Kosmala W, Holland D, Rojek A, Wright L, PrzewlockaKosmala M, Marwick T. Effect of If-channel inhibition on hemodynamic status and exercise tolerance in heart failure with preserved ejection fraction: a randomized trial. JACC 2013;62:1330-8.

\section{Potapenko 2011 \{published data only\}}

Potapenko AV, Abdulazizov O, Diachuk LI, Kiiakbaev GK, Kobalava Z, Moiseev VS. Efficacy of Ivabradine in combined treatment of patients with postinfarction systolic chronic cardiac failure. Terapevticheskii Arkhiv 2011;83(12):19-26.

Sarullo 2010 \{published and unpublished data\}

* Sarullo FM, Fazio G, Puccio D, Fasullo S, Paterna S, Novo S, et al. Impact of "off-label" use of ivabradine on exercise capacity, gas exchange, functional class, quality of life, and neurohormonal modulation in patients with ischemic chronic heart failure. Journal of Cardiovascular Pharmacology and Therapeutics 2010;15(4):349-55.

Sarullo FM, Guttilla D, Fazio G, Paterna S, Di Pasquale P, Castello A. Impact of off-label utilization of Ivabradine on exercise capacity and gas exchange in patients with ischaemic chronic heart failure. European Heart Journal 2009;30:866.

\section{Sisakian 2016 \{published data only\}}

Sisakian HH, Sargsyan T, Khachatryan A. Effect of selective heart rate reduction through sinus node $\mathrm{I}_{\mathrm{f}}$ current inhibition on severely impaired left ventricular diastolic dysfunction in patients with chronic heart failure. Acta Cardiologica 2016;71(3):317-22. 


\section{Swedberg 2010 \{published data only\}}

Böhm M, Komajda M, Borer JS, Ford I, Maack C, Tavazzi L, et al. Duration of chronic heart failure affects outcomes with preserved effects of heart rate reduction with ivabradine: findings from SHIFT. European Journal of Heart Failure 2018;20:373-81.

Bocchi EA, Guimaraes G. Efficacy and safety profile of ivabradine in heart failure due to chagaś heart disease: a post-hoc analysis of the SHIFT trial. Journal of the American College of Cardiology 2017;69(11):922.

Bocchi EA, Rassi S, Guimarães GV and Argentina, Chile, and Brazil SHIFT Investigators. Efficacy and safety profile of ivabradine in heart failure due to chagaś heart disease: a posthoc analysis of the SHIFT trial. ESC Heart Failure 2018;5:249-56.

Boehm M, Borer J, Ford I, Gonzalez-Juanatey JR, Komajda M, Lopez-Sendon J, et al. Heart rate at baseline influences the effect of ivabradine on cardiovascular outcomes in chronic heart failure: analysis from the SHIFT study. Clinical Research in Cardiology 2013;102:11-22.

Boehm M, Borer JS, Camm J, Ford I, Lloyd SM, Komajda M, et al. Twenty-four-hour heart rate lowering with ivabradine in chronic heart failure: insights from the SHIFT Holter substudy. ESC Heart Failure 2015;17:518-26.

Boehm M, Borer JS, Ford I, Komajda M, Robertson M, Tavazzi L, et al. Effect of comorbidities and risk factors on outcomes and ivabradine's effects in patients with chronic systolic heart failure in the SHIFT trial. Journal of Cardiac Failure 2015;21(8S):S46.

Boehm M, Borer JS, Ford I, Lainscak M, Komajda M, Robertson M, et al. Effect of comorbidities on outcomes and ivabradine effects in patients with chronic systolic heart failure in the SHIFT trial. ESC Heart Failure 2015;17 Suppl 1:266.

Boehm M, Komajda M, Borer JS, Ford I, Maack C, Tavazzi L, et al. Duration of chronic heart failure affects outcomes with preserved effects of heart rate reduction with ivabradine: findings from SHIFT. ESC Heart Failure 2018;20:373-81.

Boehm M, Lloyd SM, Ford I, Borer JS, Ewen S, Laufs U, et al. Non-adherence to ivabradine and placebo and outcomes in chronic heart failure: an analysis from SHIFT. ESC Heart Failure 2016;18:672-83.

Boehm M, Robertson M, Borer J, Ford I, Komajda M, Mahfoud F, et al. Effect of visit-to-visit variation of heart rate and systolic blood pressure on outcomes in chronic systolic heart failure: results from the systolic heart failure treatment with the If inhibitor ivabradine trial (SHIFT) trial. Journal of the American Heart Association 2016;5(2):e002160.

Boehm M, Robertson M, Ford I, Borer JS, Komajda M, Kindermann I, et al. Influence of cardiovascular and noncardiovascular co-morbidities on outcomes and treatment effect of heart rate reduction with ivabradine in stable heart failure (from the SHIFT Trial). American Journal of Cardiology 2015;116(12):1890-7.

Boehm M, Swedberg K, Komajda M, Borer JS, Ford I, DubostBrama $\mathrm{A}$, et al. Heart rate as a risk factor in chronic heart failure
(SHIFT): the association between heart rate and outcomes in a randomised placebo-controlled trial. Lancet 2010;376:886-94.

* Boehm M, Swedberg K, Komajda M, Borer JS, Ford I, Reil J, et al. Ivabradine and outcomes in chronic heart failure (SHIFT): a randomised placebo-controlled study. Lancet 2010;376(9744):875-85

Boehm M, Swedberg K, Komajda M, Tavazzi L, Borer JS, Moyne A, et al. Ivabradine effect on outcomes in patients with systolic heart failure according to the duration of their disease: analysis from SHIFT. ESC Heart Failure 2017;19(Suppl S1):225.

Borer J, Boehm M, Ford I, Komajda M, Tavazzi L, LopezSendon J, et al. Effect of therapeutic heart rate slowing on recurring hospitalizations for worsening heart failure in CAD patients. Cardiology 2013;126:11.

Borer J, Swedberg K, Komajda M, Boehm M, Tavazzi L, Ford L. Heart rate slowing with ivabradine in patients with heart failure who also have angina pectoris. Cardiology 2015;132(S1):11.

Borer J, Swedberg K, Komajda M, Ford I, Tavazzi L, Boehm M, et al. Safety of continuing ivabradine treatment during hospitalization for worsening of heart failure in the SHIFT study. Circulation 2015;132(Suppl 3):18395

Borer JS, Boehm M, Ford I, Komajda M, Swedberg K, Tavazzi L. Effect of ivabradine on early readmissions after hospitalization for worsening heart failure. JACC: Heart Failure 2015;3(3):267-72.

Borer JS, Boehm M, Ford I, Komajda M, Tavazzi L, Sendon JL, et al. Effect of ivabradine on recurrent hospitalization for worsening heart failure in patients with chronic systolic heart failure: the SHIFT Study. European Heart Journal 2012;33:2813-20.

Borer JS, Boehm M, Ford I, Komajda M, Tavazzi L, Swedberg K. Efficacy and safety of ivabradine in patients with severe chronic systolic heart failure/left ventricular dysfunction in the SHIFT trial. ESC Heart Failure 2013;12(Suppl 1):S151.

Borer JS, Boehm M, Ford I, Robertson M, Komajda M, Tavazzi L, et al. Efficacy and safety of ivabradine in patients with severe chronic systolic heart failure (from the SHIFT study). American Journal of Cardiology 2014;113(3):497-503.

Borer JS, Komajda M, Ford I, Tavazzi L, Dominjon F, Maya J, et al. Effects of heart rate reduction in black patients from the SHIFT (systolic heart failure treatment with the if inhibitor ivabradine trial) study. Journal of Cardiac Failure 2015;21(8):S45.

Borer JS, Swedberg K, Komajda M, Boehm M, Tavazzi L, Ford L. Efficacy profile of ivabradine in patients with heart failure plus angina pectoris. JACC 2015;65(10 Suppl):A791.

Borer JS, Swedberg K, Komajda M, Ford I, Tavazzi L, Boehm M, et al. Beta blocker dosage and use over time in the systolic heart failure treatment with the if inhibitor ivabradine trial (SHIFT) study. JACC 2015;65(10S):A872.

Borer JS, Swedberg K, Komajda M, Ford I, Tavazzi L, Boehm M, et al. Efficacy profile of ivabradine in patients with heart failure plus angina pectoris. Cardiology 2017;136:138-44. 
Bouabdallaoui N, O'Meara E, Bernier V, Komajda M, Swedberg K, Tavazzi L, et al. Beneficial effects of ivabradine in patients with heart failure, low ejection fraction, and heart rate above 77 b.p.m. ESC Heart Failure 2019;6:1199-207.

Camm J, Talajic M, Komajda M, Bohm M, Borer J, Ford I, et al. Cardiac safety of the sino atrial node $f$ channel blocker ivabradine in chronic heart failure: an ECG-holter sub-study. Journal of Cardiac Failure 2014;20(8S):S38.

Cleland JG, Robertson M, Ford I, Mareev Y, Borer J, Komajda M, et al. Effect of ivabradine on mortality in patients with heart failure and a reduced left ventricular ejection fraction not receiving a beta-blocker: an analysis from SHIFT. European Heart Journal 2017;38(Suppl_1):ehx501.246.

Cleland JG, Robertson M, Ford I, Mareev Y, Borer J, Komajda M, et al. Effect of ivabradine on mortality in patients with heart failure and a reduced left ventricular ejection fraction not receiving a beta-blocker: an analysis from SHIFT. European Heart Journal 2017;38(Suppl 1):42.

Dietl A, Simon I, Danner E, Morbach C, Stoerk S, Komajda M, et al. Ivabradine improves systolic ejection time in heart failure with reduced ejection fraction by heart rate-dependent and -independent mechanisms - results from the SHIFT echocardiography substudy. European Journal of Heart Failure 2019;21(Suppl 1):5.

Komajda M, Tavazzi L, Swedberg K, Boehm M, Borer JS, Moyne A, et al. Chronic exposure to ivabradine reduces readmissions in the vulnerable phase after hospitalization for worsening systolic heart failure: a post-hoc analysis of SHIFT. ESC Heart Failure 2016;18:1182-9.

Komajda M, Tavazzi L, Swedberg K, Boehm M, Borer JS, Robertson M, et al. Clinical profiles and outcomes of patients with chronic heart failure and diabetes: efficacy and safety of ivabradine. A SHIFT study analysis. ESC Heart Failure 2014;16:42.

Komajda MM, Tavazzi L, Swedberg K, Boehm M, Borer JS, Ford I. Reduction in early recurrent hospitalisations after discharge for worsening heart failure with ivabradine: a post-hoc analysis of SHIFT. ESC Heart Failure 2016;18(S1):293.

Krotneva S, Kansal A, Zheng Y, Patel H, Kielhorn A, Böhm M, et al. Estimation of decrements of utility associated with hospitalizations in a population with heart failure from the Systolic Heart failure treatment with the IF inhibitor ivabradine Trial (SHIFT). Circulation 2016;134:16738.

Krotneva S, Kansal AR, Ishak KJ, Kielhorn A, Patel H, Borer JS. Effect of ivabradine on readmission: a post-hoc bayesian analysis of 30-day readmission rates in the systolic heart failure treatment with the if inhibitor ivabradine trial (SHIFT). Journal of Cardiac Failure 2015;21(8):S107.

Krotneva S, Kansal AR, Zheng Y, Patel HK, Kielhorn A, Boehm M, et al. Estimation of decrements of utility associated with hospitalizations in a population with heart failure from the systolic heart failure treatment with the if inhibitor ivabradine trial (SHIFT). Circulation 2018;134:A16738.
Krum H, Sindone A. Significant reduction in all-cause mortality with ivabradine in chronic heart failure patients with baseline heart rate $>=77$ BPM: subgroup analysis of SHIFT. Heart, Lung and Circulation 2013;22:S87-8.

Lainscak M, Tavazzi L, Swedberg K, Komajda M, Boehm M, Borer J, et al. Clinical profile, outcomes, and ivabradine effects in patients with chronic obstructive pulmonary disease and chronic heart failure: The SHIFT trial analysis. European Respiratory Journal 2013;42:P1860.

NCT02441218. Effects of ivabradine on cardiovascular events in patients with moderate to severe chronic heart failure and left ventricular systolic dysfunction. A three-year international multicentre study (SHIFT). clinicaltrials.gov/ct2/show/ NCT02441218 (first received 21 November 2018).

Nguyen L, Squara P, Amour J, Cholley B. Intravenous ivabradine in low cardiac output syndrome after cardiac surgery treated by dobutamine: a phase II trial. Archives of Cardiovascular Diseases 2018;10(S1):41.

Ramires FJ, Martinez F, Gómez EA, Demacq C, Gimpelewicz CR, Rouleau JL. Post hoc analyses of SHIFT and PARADIGM-HF highlight the importance of chronic Chagas' cardiomyopathy. ESC Heart Failure 2018;5:1069-71.

Reil JC, Tardif JC, Ford I, Lloyd SM, O'Meara E, Komajda M, et al. Selective heart rate reduction with ivabradine unloads the left ventricle in heart failure patients. JACC 2013;62(21):1977-85.

Swedberg K, Komajda M, Boehm M, Borer J, Robertson M, Tavazzi $L$, et al. Effects on outcomes of heart rate reduction by ivabradine in patients with congestive heart failure: is there an influence of beta-blocker dose?: findings from the SHIFT (Systolic Heart failure treatment with the I(f) inhibitor ivabradine Trial) study. JACC 2012;59(22):1938-45.

Swedberg K, Komajda M, Bohm M, Borer JS, Ford I, Tavazzi L. Rationale and design of a randomized, double-blind, placebocontrolled outcome trial of ivabradine in chronic heart failure: the Systolic Heart Failure Treatment with the I(f) Inhibitor Ivabradine Trial (SHIFT). ESC Heart Failure 2010;12(1):75-81.

Tardif JC, O'Meara E, Komajda M, Boehm M, Borer JS, Ford I, et al. Effects of selective heart rate reduction with ivabradine on left ventricular remodelling and function: results from the SHIFT echocardiography substudy. European Heart Journal 2011;32(20):2507-15.

Tavazzi L, Swedberg K, Komajda M, Boehm M, Borer JS, Lainscak M, et al. Clinical profiles and outcomes of patients with chronic heart failure and chronic obstructive pulmonary disease: an efficacy and safety analysis of SHIFT study. International Journal of Cardiology 2013;170(2):182-8.

Tavazzi L, Swedberg K, Komajda M, Boehm M, Borer JS, Lainscak $M$, et al. Efficacy and safety of ivabradine in chronic heart failure across the age spectrum: insights from the SHIFT study. ESC Heart Failure 2013;15(11):1296-303.

Voors A, Veldhuisen D, Robertson M, Ford I, Borer J, Boehm M, et al. The effect of heart rate reduction with ivabradine on renal 
function in patients with chronic heart failure: an analysis from SHIFT. ESC Heart Failure 2014;16(4):426-34.

Voors A, Veldhuisen D, Robertson M, Ford I, Borer J, Boehm M, et al. The effect of heart rate reduction with ivabradine on renal function in patients with chronic heart failure: an analysis from SHIFT. European Heart Journal 2013;34(Suppl 1):162-3.

\section{Tatarchenko 2008 \{published data only\}}

Tatarchenko IP, Pozdnyakova NV, Biryuchenko MV, Kapelovich VYu, Sekerko SA, Kupaeva RA. Clinical efficacy of ivabradin and nebivolol addition in combined treatment of ischemic heart disease patients with left ventricular dysfunction. Terapevticheskii Arkhiv 2008;80(9):40-4.

\section{Tsutsui 2016 \{published and unpublished data\}}

Tsutsui H, Momomura S. Heart rate control with $\mathrm{I}_{\mathrm{f}}$ inhibitor, ivabradine, in Japanese patients with chronic heart failure - a randomized, double-blind, placebo-controlled phase II study. Circulation Journal 2016;80:668-76.

\section{Tsutsui 2019 \{published data only\}}

JPRN-JapicCTI-153007. ONO-1162 phase 3 study. rctportal.niph.go.jp/en/detail?trial_id=JapicCTI-153007 (first registered 1 September 2015).

* Tsutsui H, Momomura S, Yamashina A, Shimokawa H, Kihara Y, Saito Y, et al. Efficacy and safety of ivabradine in Japanese patients with chronic heart failure - J-SHIFT study. Circulation Journal 2019;83:2049-60.

\section{Tumasyan 2016 \{published data only\}}

Tumasyan LRL, Adamyan KG, Chilingaryan AL. Efficacy of ivabradine therapy on right heart parameters and prognosis in patients with severe systolic chronic heart failure. European Heart Journal 2012;33:808.

* Tumasyan LRL, Adamyan KG. Efficacy of long-term ivabradine therapy on prognosis, right heart and left atrial parameters in patients with severe systolic chronic heart failure. ESC Heart Failure 2016;18:110.

\section{Tumasyan 2017 \{published data only\}}

Tumasyan LR, Adamyan KG. Comparative efficacy of longterm digoxin and ivabradine therapy on prognosis, left and right heart functional parameters in patients with chronic heart failure and preserved ejection fraction. ESC Heart Failure 2017;19:413.

\section{Tumasyan 2018 \{published data only\}}

Tumasyan LRL, Adamyan KG. Comparative efficacy of longterm digoxin and ivabradine therapy on prognosis, left and right heart functional parameters in patients with chronic heart failure and mid-ranged ejection fraction. European Heart Journal 2018;20(S1, 5-638):256.

\section{References to studies excluded from this review}

\author{
Aalbers 2012 \{published data only\} \\ Aalbers J. Ivabradine reduces total hospital burden in heart \\ failure. Cardiovascular Journal of Africa 2012;23(9):528.
}

\section{Abdel-Salam 2015 \{published data only\}}

Abdel-Salam Z, Rayan M, Saleh A, Abdel-Barr MG, Hussain M, Nammas W. I $I_{f}$ current inhibitor ivabradine in patients with idiopathic dilated cardiomyopathy: impact on the exercise tolerance and quality of life. Cardiology Journal 2015;22:227-32.

\section{Adamyan 2010 \{published data only\}}

Adamyan KG, Chilingaryan AL. Adding ivabradine on top of target dose bisoprolol improves diastolic function and physical performance in patients with diastolic heart failure due to impaired relaxation. European Heart Journal 2010;31:849-50.

\section{Adamyan 2011 \{published data only\}}

Adamyan KG, Chilingaryan AL. Ivabradin compared with bisoprolol reduces segmental diastolic dysfunction and improves diastolic functional reserve in patients with diastolic heart failure. European Heart Journal 2011;32(Suppl):786.

\section{Adamyan 2013 \{published data only\}}

Adamyan KG, Chilingaryan AL, Tumasyan LR, Tunyan LG. Beta blockers or combination of beta blocker with ivabradine better alters the course of heart failure with reduced ejection fraction when the target heart rate is achieved. European Heart Journal 2013;34(Suppl 1):P3300.

\section{Adamyan 2015b \{published data only\}}

Adamyan KG, Tunyan LG, Chilingaryan AL. Comparative efficacy of amiodarone with ivabradin combination or amiodarone with bisoprolol combination in the prevention of atrial fibrillation recurrence in patients with left ventricular diastolic dysfunction. Rational Pharmacotherapy in Cardiology 2015;11(5):483-8.

\section{Al 2013 \{published data only\}}

Al ST, Sallam M, Al HK, Elhawary A. Effect of carvedilol versus carvedilol/ivabradine combination on heart rate, quality of life, morbidity and mortality in patients with stable ischemic heart failure. Clinical Therapeutics 2013;35:e70.

\section{Amosova 2011a \{published data only\}}

Amosova E, Andrejev E, Zadereij I, Rudenko U. Anti-ischemic effect and heart rate response during exercise when using ivabradine in combination with bisoprolol versus uptitration of bisoprolol in patients with chronic coronary artery disease. European Heart Journal 2010;31:488.

* Amosova E, Andrejev E, Zaderey I, Rudenko U, Ceconi C, Ferrari R. Efficacy of ivabradine in combination with betablocker versus uptitration of beta-blocker in patients with stable angina. Cardiovascular Drugs and Therapy 2011;25:531.

Amosova EN, Andrejev E, Zadereij I. Anti-ischemic efficacy of ivabradine in combination with bisoprolol versus uptitration of bisoprolol. JACC 2010;55(10 Suppl):A123.E1153.

\section{Amosova 2011b \{published data only\}}

Amosova E, Prudky I, Xu Y, Bezrodnyi A, Andrejev E. Efficacy of ivabradine in combination with beta-blocker, compared with uptitration of beta-blocker, on systolic function and left ventricular remodeling in patients after Q-wave myocardial infarction. European Heart Journal 2011;32:340. 
Amosova 2012a \{published data only\}

* Amosova K, Rudenko IU, Prudky I, Xu Y, Bezrodnyi A. Early effects of ivabradine in combination with beta-blockers compared to beta-blockers uptitration on systolic and diastolic function, NT-proANP and exercise capacity in pts after Q-MI with $\mathrm{EF}<45 \%$. European Heart Journal 2012;33:923.

Amosova KM, Xu Y, Rudenko IU, Prudky I, Bezrodnyi A, Gorda I. Early effects of heart rate control with ivabradine in combination with metoprolol compared with metoprolol uptitration on global and longitudinal LV functions, NT-proANP in Q-MI patients with EF<45\%. ESC Heart Failure 2013;12:S141.

\section{Amosova 2012b \{published data only\}}

Amosova K, Xu Y, Prudkiy I, Rudenko I, Bezrodnyi A, Sychenko Y. Effect of ivabradine in combination with beta-blockers versus beta-blockers uptitration on left ventricular functions in patients with acute anterior myocardial infarction and early systolic dysfunction. JACC 2012;59(13 Suppl):E554.

\section{Amosova 2014 \{published data only\}}

* Amosova K, Mishalov V, Igor KI, Rudenko Y, Bezrodniy A, Gorda I, et al. Advantages of ivabradine-b-blocker combination effects on LV longitudinal function and pulse wave propagation indices compared to that of b-blocker uptitration in CAD with moderate EF lowering. ESC Heart Failure 2014;16:161.

Amosova KM, Katsytadze II, Rudenko YU, Bezrodniy A. Early effects of Ivabradin-b-blocker combination compared to bblocker uptitration on LV and pulsatile arterial functions in postinfarction patients with mild CHF and EF lowering. ESC Heart Failure 2015;17:341-2.

\section{Cavusoglu 2012 \{published data only\}}

Cavusoglu Y, Mert KU, Nadir A, Mutlu F, Gencer E, Ulus T, et al. Dobutamine-induced increase in heart rate is blunted by ivabradine treatment in patients with acutely decompensated heart failure. European Heart Journal 2012;33:8.

\section{Cavusoglu 2015 \{published data only\}}

Cavusoglu Y, Mert U, Nadir A, Mutlu F, Morrad B, Ulus T. Ivabradine treatment prevents dobutamine-induced increase in heart rate in patients with acute decompensated heart failure. Journal of Cardiovascular Medicine 2015;16(9):603-9.

\section{Chumburidze 2013 \{published data only\}}

Chumburidze S. Efficacy and safety of ivabradin in patients with idiopathic dilated cardiomyopathy. Cardiology 2013;125:424.

\section{CN-01908706 2018 \{published data only\}}

CTRI/2018/08/015182. Comparison of two drugs, ivabradine and amiodarone, in the management of Junctional ectopic tachycardia, an abnormality in cardiac rhythm in patients under 18 years who undergo cardiac surgery. CENTRAL 2019;08(3):15182.

\section{Cocco 2013 \{published data only\}}

Cocco G, Jerie P. Comparison between ivabradine and lowdose digoxin in the therapy of diastolic heart failure with preserved left ventricular systolic function. Clinical Practice 2013;3:e29(2):77-83.

\section{Cullington 2011 \{published data only\}}

Cullington D, Goode KM, Cleland JG, Clark AL. Limited role for ivabradine in the treatment of chronic heart failure. Heart 2011;97(23):1961-6.

\section{De 2014 \{published data only\}}

De T, Kahali D, Mishra A, Sharma JC, Bera S, Ghosh Dastidar P, et al. Benefit of ivabradine combined with beta-blocker in comparison with increased dose of beta-blocker in stable angina. Indian Heart Journal 2014;66:S15-6.

\section{De Ferrari 2008 \{published data only\}}

De Ferrari GM, Mazzuero A, Agnesina L, Bertoletti A, Lettino M, Campana $\mathrm{C}$, et al. Favourable effects of heart rate reduction with intravenous administration of ivabradine in patients with advanced heart failure. ESC Heart Failure 2008;10(6):550-5.

\section{EUCTR2011-002520-40-IT \{published data only\}}

EUCTR2011-002520-40-IT. Comparison of the effect of carvedilol, ivabradine and their combination on exercise capacity in patients with heart failure. www.clinicaltrialsregister.eu/ctr-search/trial/2011-002520-40/IT (first entered 5 March 2012).

\section{Fomin 2016 \{published data only\}}

Fomin IV, Valikulova FY, Vaysberg AR, Gurvich EV. Assessment of the dynamics of silent ischemia on the effects of heart rate reducing drugs in patients with ischemic heart disease and diabetes in an actual ambulatory practice. ESC Heart Failure 2016;18:345-6.

\section{Gallet 2014 \{published data only\}}

Gallet R, Ternacle J, Damy T, Guendouz S, Bremont C, Seemann A, et al. Hemodynamic effects of Ivabradine in addition to dobutamine in patients with severe systolic dysfunction. International Journal of Cardiology 2014;176(2):450-5

\section{Gurcagan 2015 \{published data only\}}

Gurcagan AA, Altay S. Effect of ivabradine on functional exercise capacity in patients with systolic heart failure. ESC Heart Failure 2015;17:293-4.

\section{Hidalgo 2015a \{published data only\}}

Hidalgo F, Anguita Sanchez M, Comin Colet J, Muniz Garcia J, Crespo Leiro MG, Formiga F, et al. Medium-term follow up of hospitalized patients with systolic heart failure undergoing early treatment with beta-blockers more ivabradine: a randomized study. ESC Heart Failure 2015;17:88-9.

Hidalgo 2015b \{published data only\} Hidalgo F, Anguita Sanchez M, Comin Colet J, Muniz Garcia J, Crespo Leiro MG, Formiga F, et al. Effect of early treatment with ivabradine plus beta-blockers versus only beta-blockers in patients hospitalized with systolic heart failure: a randomized study. ESC Heart Failure 2015;15:326.

Hidalgo 2016a \{published data only\}

Hidalgo F, Anguita M, Castillo J, Rodriguez S, Pardo L, Duran E, et al. Effect of early treatment with ivabradine combined with beta-blockers versus beta-blockers alone in patients 
hospitalised with heart failure and reduced left ventricular ejection fraction (ETHIC-AHF): a randomised study. International Journal of Cardiology 2016;217:7-11.

\section{Hidalgo 2016b \{published data only\}}

Hidalgo F, Anguita Sanchez M, Castillo Dominguez JC, Rodriguez Diego S, Pardo Gonzalez L, Ruiz Ortiz M, et al. Longterm follow up of hospitalized patients with systolic heart failure undergoing early treatment with beta-blockers more ivabradine: a randomized study. ESC Heart Failure 2016;18:384.

\section{Hidalgo 2018 \{published data only\}}

Hidalgo F. Effect of early treatment with ivabradine plus betablockers on long-term outcomes in patients hospitalized with systolic heart failure. Revista Espanola de Cardiologia 2018;71(12):1074-88.

\section{Iliuta 2014 \{published data only\}}

Iliuta L, Filipescu D, Moldovan H, Radulescu B, Vasile R. Ivabradine versus betblockers in patients with conduction abnormalities or left ventricular dysfunction undergoing coronary artery bypass grafting. European Heart Journal 2009;30:916

* Iliuta L, Rac-Albu M. Ivabradine versus beta-blockers in patients with conduction abnormalities or left ventricular dysfunction undergoing cardiac surgery. Cardiology and Therapy 2014;3(1-2):13-26.

\section{Kanorsky 2016 \{published data only\}}

Kanorsky SG, Borisenko YV. Comparative evaluation of bblockers and If-channel inhibitor in patients with chronic heart failure and preserved left ventricular ejection fraction. Kardiologiia 2016;56(2):24-9.

\section{Kosheleva 2010 \{published data only\}}

Kosheleva NA, Rebrov AP. Dynamics of structural functional parameters of cardiovascular system in patients with stable angina and congestive heart failure treated with Ivabradine for six months. Kardiologiia 2010;50(9):34-40.

Lofrano-Alves 2015 \{published data only\}

Lofrano-Alves MS, Issa VS, Bocchi EA. Control of sinus node tachycardia as additional therapy in patients with decompensated heart failure (CONSTATHE). Journal of Heart and Lung Transplantation 2015;34(4):S69.

\section{Lutay 2012 \{published data only\}}

Lutay YA, Parkhomenko AN, Irkin OI, Stepura AA. Addition of ivabradine during beta-blockers titration improves systolic and diastolic LV function in patients with recent Q-wave myocardial infarction. European Heart Journal 2012;33:907.

\section{Mansour 2011 \{published data only\}}

Mansour S, Youssef A, Rayan M, Ayman SM. Efficacy of ivabradine in idiopathic dilated cardiomyopathy patients with chronic heart failure. Egyptian Heart Journal 2011;63:79-85.

\section{Mert 2017 \{published data only\}}

Mert KU, Mert GO, Morrad B, Tahmazov S, Mutlu F, Cavusoglu Y. Effects of ivabradine and beta-blocker therapy on dobutamine- induced ventricular arrhythmias. Kardiologia Polska 2017;75(8):786-93.

Nguyen 2017 \{published data only\}

Nguyen LS, Squara P, Amour J, Cholley B. Intravenous ivabradine in low cardiac output syndrome treated by dobutamine following cardiac surgery: a phase II trial. ESC Heart Failure 2017;19:526.

\section{Ozturk 2016 \{published data only\}}

Ozturk S, Erdem FH, Erdem A, Ayhan S, Donmez I, Yazici M. The effects of ivabradine on left atrial electromechanical function in patients with systolic heart failure. Journal of Interventional Cardiac Electrophysiology 2016;46(3):253-8.

Pal 2015 \{published data only\}

Pal N, Sivaswamy N, Mahmod M, Yavari A, Rudd A, Singh S, et al. Effect of selective heart rate slowing in heart failure with preserved ejection fraction. Circulation 2015;132(18):1719-25.

Raja 2011 \{published data only\}

Raja DC, Kapoor A, Khanna R, Kumar S, Garg N, Tewari S, et al. Heart rate manipulation in dilated cardiomyopathy: assessing the role of ivabradine. European Heart Journal 2011;32(Suppl):340.

Raja 2018 \{published data only\}

Raja DC, Kapoor A, Sinha A, Kashyap S, Khanna R, Kumar S, et al. Heart rate manipulation in dilated cardiomyopathy: assessing the role of Ivabradine. Indian Heart Journal 2018;70(2):246-51.

\section{Rajagopal 2010 \{published data only\}}

Rajagopal J, Srinivas A, Keshavamurthy BC, Guruprasad HP, Jayakumar $P$, Arjun A, et al. Use of ivabradine in the management of acute anterior wall myocardial infarction complicated by left ventricular failure. JACC 2010;55(10A):A101.E947.

\section{Reil 2012 \{published data only\}}

Reil JC, Tardif JC, Ford I, Lloyd SM, O'Meara E, Komajda M, et al. Selective heart rate reduction with ivabradine unloads the left ventricle in heart failure patients. Journal of the American College of Cardiology 2012;62(21):1977-85.

\section{Riccioni 2012 \{published data only\}}

Riccioni G, Prencipe G, Ferrara V, Cappetti S, Cannone M. Ivabradine improves quality of life in subjects with chronic heart failure respect the treatment with beta-blockers. Cardiovascular Therapeutics 2012;30:55.

\section{Sallam 2016 \{published data only\}}

Sallam M, Al-Saadi T, Alshekaili L, Al-Zakwani I. Impact of ivabradine on health-related quality of life of patients with ischaemic chronic heart failure. Current Vascular Pharmacology 2016;14(5):481-6

\section{Santos 2014 \{published data only\}}

Santos M, Leite-Moreira AF. Effect of ivabradine on heart failure with preserved ejection fraction. Journal of the American College of Cardiology 2014;63(6):608-9. 


\section{Sisakian 2014 \{published data only\}}

Sisakian HH, Sargsyan T, Khachatryan A. Effect of ivabradine on severely impaired left ventricular diastolic dysfunction in patients with chronic heart failure. ESC Heart Failure 2014;16:265

\section{Tagliamonte 2016 \{published data only\}}

Tagliamonte E, Cirillo T, Rigo F, Ciampi Q, Caruso A, Astarita C, et al. Effects of ivabradine on coronary flow reserve and left ventricular diastolic function in patients without coronary artery stenosis. ESC Heart Failure 2016;18:109.

\section{Tregubov 2015 \{published data only\}}

Tregubov VG, Kanorskiy SG, Pokrovskiy VM. Regulatory adaptive status in assessment of efficacy of pharmacotherapy and prognostication of complications in functional class III chronic heart failure. Kardiologiia 2016;56(1):12-7.

* Tregubov VG, Kanorsky SG, Pokrovsky VM. Evaluation of the regulatory-adaptive status for prognostication in systolic chronic heart failure. Klinicheskaia Meditsina (Moskva) 2015;93(11):22-8.

\section{Tumasyan 2009 \{published data only\}}

Tumasyan LR, Adamyan KG. Comparative efficacy of carvedilol and ivabradine in severe chronic heart failure of ischemic origin with baseline heart rate below and above 70 beat per minute. European Heart Journal 2009;30:427.

Vatinian 2015 \{published data only\}

Vatinian S, Gurgenyan S, Nikoghosyan K. Efficacy of addition of ivabradine to bisoprolol in patients with essential hypertension, coronary artery disease and reduced left ventricular systolic function. European Heart Journal 2015;36:672-3.

\section{Volterrani 2011 \{published data only\}}

Volterrani M, Cice G, Caminiti G, Vitale C, D'Isa S, Perrone FP, et al. Effect of Carvedilol, Ivabradine or their combination on exercise capacity in patients with Heart Failure (the CARVIVA HF trial). International Journal of Cardiology 2011;151(2):218-24.

\section{Xu 2011 \{published data only\}}

Xu Y. Effects of ivabradine in combination with metoprolol on left ventricle remodeling after Q-wave myocardial infarction with early moderate left ventricle systolic dysfunction. International Journal of Cardiology 2011;152(Suppl 1):55-6.

\section{Yao 2014 \{published data only\}}

Yao X, Andrii B. Effects of heart rate control with ivabradine plus beta-blocker on exercise tolerance in patients after Qwave myocardial infarction with early left ventricular systolic dysfunction. JACC 2014;64(16):C204.

\section{References to ongoing studies}

\section{ACTRN12612000710820 \{published data only\}}

ACTRN12612000710820. Novel interventions in heart failure with preserved ejection fraction using ivabradine. www.anzctr.org.au/Trial/Registration/TrialReview.aspx? ACTRN=12612000710820 (data registered 3 July 2012).

\section{ChiCTR-IIR-17013377 \{published data only\}}

ChiCTR-IIR-17013377. Efffect of ivabradine in heart failure with preserved ejection fraction: a multicenter and randomized controlled clinical trial. www.chictr.org.cn/showprojen.aspx? proj $=22845$ (date of registration 14 November 2017).

EUCTR2012-002742-20-CZ \{published data only\}

EUCTR2012-002742-20-CZ. Effect of ivabradine versus placebo on cardiac function and on capacity to perform exercise in patients suffering from diastolic heart failure. www.clinicaltrialsregister.eu/ctr-search/trial/2012-002742-20/ GB (first entered 18 March 2013).

\section{EUCTR2014-003286-21-IE \{published data only\}}

EUCTR2014-003286-21-IE. A multicentre, interventional, parallel group, randomised, open-label, exploratory study to assess the earlier introduction of Ivabradine in the Management of Systolic Dysfunction Heart Failure. The QUALIVA study. www.clinicaltrialsregister.eu/ctr-search/trial/2014-003286-21/IE (first entered 28 November 2014).

\section{NCT02188082 \{published data only\}}

NCT02188082. Clinical trial of systolic heart failure treatment of ivabradine hemisulfate sustained-release tablets (FIRST). clinicaltrials.gov/ct2/show/NCT02188082 (first posted 11 July 2014).

\section{NCT03701880 \{published data only\}}

NCT03701880. Early use of ivabradine in heart failure. clinicaltrials.gov/ct2/show/NCT03701880 (first posted 10 October 2018).

\section{Additional references}

\section{Adena 2018}

Adena MA, Hamann G, Sindone AP. Cost-effectiveness of ivabradine in the treatment of chronic heart failure. Heart, Lung and Circulation 2018;28(3):414-22.

\section{Ambrosy 2014}

Ambrosy AP, Fonarow GC, Butler J, Chioncel O, Greene SJ, Vaduganathan $\mathrm{M}$, et al. The global health and economic burden of hospitalizations for heart failure. Journal of the American College of Cardiology 2014;63:1123-33.

\section{American Thoracic Society 2002}

American Thoracic Society, Board of Directors. ATS statement: guidelines for the six-minute walk test. American Journal of Respiratory and Critical Care Medicine 2002;166(1):111-7.

\section{Bauriedel 2005}

Bauriedel G, Skowasch D, Luderitz B. Die chronische Herzinsuffizienz. Deutsches Ärzteblatt 2005;102:1-12.

\section{Benjamin 2017}

Benjamin EJ, Blaha MJ, Chiuve SE, Cushman M, Das SR, Deo R, et al. Heart disease and stroke statistics - 2017 update: a report from the American Heart Association. Circulation 2017; 135:485-603. 


\section{Bleumink 2004}

Bleumink GS, Knetsch AM, Sturkenboom MCJM, Straus SMJM, Hofman A, Deckers JW, et al. Quantifying the heart failure epidemic: prevalence, incidence rate, lifetime risk and prognosis of heart failure. The Rotterdam Study. European Heart Journal 2004;25:1614-9.

\section{Borer 2016}

Borer JS, Deedwania PC, Kim JB, Boehm M. Benefits of heart rate slowing with ivabradine in patients with systolic heart failure and coronary artery disease. American Journal of Cardiology 2016;118(12):1948-53.

\section{CDC 2017}

Centers for Disease Control and Prevention. Heart failure in the United States. www.cdc.gov/dhdsp/data_statistics/fact_sheets/ docs/fs_heart_failure.pdf (accessed 20 June 2017).

\section{Centre for Reviews and Dissemination 2017}

Centre for Reviews and Dissemination. NHS EED (NHS Economic Evaluation Database). www.crd.york.ac.uk/crdweb/ (accessed prior to 22 March 2018).

\section{Chang 2014}

Chang CJ, Chu PH, Fann CS. Cost effectiveness of ivabradine in chronic heart failure patients with heart rate above Bpm in Taiwan. Value Health 2014;17:A488.

\section{Cook 2014}

Cook C, Cole G, Asaris P, Jabbour R, Francis D. The annual global economic burden of heart failure. Heart 2014;100:A28-9.

\section{Drummond 1996}

Drummond MF, Jefferson TO. British Medical Journal Checklist for authors and peer reviewers of economic submissions. BMJ 1996;313(7052):275-83.

\section{EMA 2017}

European Medicines Agency. Annex I Summary of product characteristics (of ivabradine). www.ema.europa.eu/docs/ en_GB/document_library/EPAR_-_Product_Information/ human/000597/WC500043590.pdf (accessed prior to 22 March 2018).

\section{Ezekowitz 2017}

Ezekowitz JA, O'Meara EO, McDonald MA, Abrams H, Chan M, Ducharme A. 2017 comprehensive update of the Canadian Cardiovascular Society guidelines for the management of heart failure. Canadian Journal of Cardiology 2017;33:1342-433.

\section{FDA 2020}

US Food and Drug Administration. CORLANOR(R) (ivabradine) Label. www.accessdata.fda.gov/drugsatfda_docs/ label/2019/209964lbl.pdf (accessed prior to 24 June 2020).

\section{Fernandez de Bobadilla 2014}

Fernandez de Bobadilla J, Gonzalez FO, Lopez de Sa E, LopezSendon JL. Cost-effectiveness analysis of ivabradine in heart failure with reduced left ventricular ejection fraction in Spain. Value in Health 2014;17:A486.

\section{Fox 2013}

Fox K, Komajda M, Ford I, Robertson M, Böhm M, Borer JS, et al. Effect of ivabradine in patients with left-ventricular systolic dysfunction: a pooled analysis of individual patient data from the BEAUTIFUL and SHIFT trials. European Heart Journal 2013;34:2263-70.

\section{German Society for Cardiology 2013}

German Society for Cardiology. ESC Pocket Guidelines: Heart Failure [ESC Pocket Guidelines: Herzinsuffizienz]. leitlinien.dgk.org/files/2013_PocketLeitlinien_Herzinsuffizienz_Update_2012_Internet.pdf (accessed prior to 22 March 2018).

\section{GRADEpro GDT [Computer program]}

McMaster University (developed by Evidence Prime) GRADEpro GDT. Version (accessed 9 April 2018). Hamilton (ON): McMaster University (developed by Evidence Prime), 2015. Available at gradepro.org.

\section{Griffiths 2014}

Griffiths A, Paracha N, Davies A, Branscombe N, Cowie MR, Sculpher M. The cost effectiveness of ivabradine in the treatment of chronic heart failure from the UK National Health Service perspective (Provisional abstract). Heart 2014;100(13):1031-6.

\section{Hartmann 2018}

Hartmann C, Bosch NL, Miguita LA, Tierie E, Zytinski L, Baena CP. The effect of ivabradine therapy on heart failure patients with reduced ejection fraction: a systematic review and meta-analysis. International Journal of Clinical Pharmacology 2018;40(6):1443-53.

\section{Heidenreich 2011}

Heidenreich PA, Trogdon JG, Khavjou OA, Butler J, Dracup K, Ezekowitz MD, et al. Forecasting the future of cardiovascular disease in the United States. Circulation 2011;123:933-44.

\section{Higgins 2011}

Higgins JP, Green S, editor(s). Cochrane Handbook for Systematic Reviews of Interventions Version 5.1.0 (updated March 2011). The Cochrane Collaboration, 2011. Available from handbook.cochrane.org.

\section{International Journal of Cardiology 2017}

International Journal of Cardiology. Retraction notice to "Ivabradine as adjuvant treatment for chronic heart failure" [International Journal of Cardiology 2017; 227:43-50]. International Journal of Cardiology 2017;247:55.

\section{Jakobsen 2014}

Jakobsen JC, Wetterslev J, Winkel P, Lange T, Gluud C. Thresholds for statistical and clinical significance in systematic reviews with meta-analytic methods. BMC Medical Research Methodology 2014;14:120.

\section{Kansal 2016}

Kansal AR, Cowie MR, Kielhorn A, Krotneva S, Tafazzoli A, Zheng $\mathrm{Y}$, et al. Cost-effectiveness of ivabradine for heart failure 
in the United States. Journal of the American Heart Association 2016;5:06.

\section{Kourlaba 2014}

Kourlaba G, Parissis J, Karavidas A, Beletsi A, Milonas C, Branscombe N, et al. Economic evaluation of ivabradine in the treatment of chronic heart failure in Greece. BMC Health Services Research 2014;14:631.

\section{Krittayaphong 2019}

Krittayaphong R, Yadee J, Permsuwan U. Cost-effectiveness analysis of the adjunctive therapy of ivabradine for the treatment of heart failure with reduced ejection fraction. ClinicoEconomics and Outcomes Research 2019;11:767-77.

\section{Laribi 2012}

Laribi S, Aouba A, Nikolaou M, Lassus J, Cohen Solal A, Plaisance $P$, et al. Trends in death attributed to heart failure over the past two decades in Europe. European Journal of Heart Failure 2012;14:234-9.

\section{Lechat 2001}

Lechat P, Hulot JS, Escolano S, Mallet A, Leizorovicz A, WerhlenGrandjean M, et al. Heart rate and cardiac rhythm relationships with bisoprolol benefit in chronic heart failure in CIBIS II Trial. Circulation 2001;103:1428-33.

\section{Lefebvre 2011}

Lefebvre C, Manheimer E, Glanville J. Chapter 6: Searching for studies. In: Higgins JP, Green S, editor(s). Cochrane Handbook for Systematic Reviews of Interventions Version 5.1.0 (updated March 2011). The Cochrane Collaboration, 2011. Available from handbook.cochrane.org.

\section{Matsuzaki 2010}

Matsuzaki M, Ishii M, Izumi T, Ito H, Ito H, Ueda Y, et al. Guidelines for treatment of chronic heart failure (JCS 2010) (updated September 13, 2013). www.j-circ.or.jp/guideline/pdf/ JCS2010_matsuzaki_h.pdf (accessed prior to 8 October 2020).

\section{McAlister 2009}

McAlister FA, Wiebe N, Ezekowitz JA, Leung AA, Armstrong PW. Meta-analysis: beta-blocker dose, heart rate reduction, and death in patients with heart failure. Annals of Internal Medicine 2009;150:784-94.

\section{Mizzaci 2017}

Mizzaci CC, Porfírio GJM, Vilela AT, Guillhen JCS, Riera R. Ivabradine as adjuvant treatment for chronic heart failure. International Journal of Cardiology 2017;227:43-50.

\section{Mozaffarian 2016}

Mozaffarian D, Benjamin EJ, Go AS, Arnett DK, Blaha MJ, Cushman M, et al. Heart disease and stroke statistic. 2016 update. Circulation 2016;133:e38-360.

\section{Narayanan 2017}

Narayanan MA, Reddy YNV, Baskaran J, Deshmukh A, Benditt DG, Raveendran G. Ivabradine in the treatment of systolic heart failure - a systematic review and meta-analysis. World Journal of Cardiology 2017;9(2):182-90.

\section{O'Connor 2010}

O'Connor CM, Miller AB, Blair JEA, Konstam MA, Wedge P, Bahit MC, et al. Causes of death and rehospitalization in patients hospitalized with worsening heart failure and reduced left ventricular ejection fraction: results from efficacy of vasopressin antagonism in heart failure outcome study with tolvaptan (EVEREST) program. American Heart Journal 2010;159:841-9.

\section{Pei 2019}

Pei H, Miao W, Xie W, Wang W, Zhao D, Su G, et al. Ivabradine improves cardiac function and increases exercise capacity in patients with chronic heart failure. International Heart Journal 2019;60(4):899-909.

\section{Pitt 2005}

Pitt B, White H, Nicolau J, Martinez F, Gheorghiade M, Aschermann $\mathrm{M}$, et al. Eplerenone reduces mortality 30 days after randomization following acute myocardial infarction in patients with left ventricular systolic dysfunction and heart failure. Journal of the American College of Cardiology 2005;46(3):425-31.

\section{Polistena 2014}

Polistena B, Maggioni A, Oliva F, Spandonaro F. Costeffectiveness and budget impact of ivabradine in heart failure therapy (Provisional abstract). Giornale Italiano di Cardiologia 2014;15:626-33.

\section{Ponikowski 2016}

Ponikowski P, Voors AA, Anker SD, Bueno H, Cleland JGF, Coats AJS, et al. Guidelines for the diagnosis and treatment of acute and chronic heart failure: the Task Force for the Diagnosis and Treatment of Acute and Chronic Heart Failure. European Journal of Heart Failure 2016;37(27):2129-200.

\section{Review Manager 2014 [Computer program]}

Nordic Cochrane Centre, The Cochrane Collaboration Review Manager 5 (RevMan 5). Version 5.3. Copenhagen: Nordic Cochrane Centre, The Cochrane Collaboration, 2014.

\section{Roger 2013}

Roger VL. Epidemiology of heart failure. Circulation Research 2013;113:646-59.

\section{Servier Deutschland GmbH 2016}

Servier Deutschland GmbH. Fachinformation Procoralan ${ }^{\circledast}$. www.fachinfo.de/pdf/009422 (accessed prior to 22 March 2018).

\section{Statistisches Bundesamt 2017}

Statistisches Bundesamt (Destatis). Todesursachen - Die 10 häufigsten Todesursachen insgesamt. www.destatis.de/DE/ ZahlenFakten/GesellschaftStaat/Gesundheit/Todesursachen/ Tabellen/Sterbefaellelnsgesamt.html (accessed prior to 22 March 2018).

\section{Taheri 2018}

Taheri S, Heidari E, Aivazi MA, Shams-Beyranvand M, Varmaghani M. Cost-effectiveness analysis of Ivabradine in treatment of patients with heart failure in Iran. 
International Journal of Technology Assessment in Health Care 2018;34(6):576-83.

\section{Thomsen 2016}

Thomsen MM, Lewinter C, Køber L. Varying effects of recommended treatments for heart failure with reduced ejection fraction: meta-analysis of randomized controlled trials in the ESC and ACCF/AHA guidelines. ESC Heart Failure 2016;3:235-44.

\section{van Deursen 2014}

van Deursen VM, Urso R, Laroche C, Damman K, Dahlström U, Tavazzi L, et al. Co-morbidities in patients with heart failure: an analysis of the European Heart Failure Pilot Survey. European Journal of Heart Failure 2014;16:103-11.

\section{Ware 1992}

Ware JEJ, Sherbourne CD. The MOS 36-item short-form health survey (SF-36). I. Conceptual framework and item selection. Medical Care 1992;30(6):473-83.

\section{CHARACTERISTICS OF STUDIES}

Characteristics of included studies [ordered by study ID]

\section{Yancy 2013}

Yancy CW, Jessuo M, Bozkurt B, Butler J, Casey DE Jr, Drazner MH, et al. 2013 ACCF/AHA guideline for the management of heart failure. A report of the American College of Cardiology Foundation/American Heart Association Task Force on Practice Guidelines. Circulation 2013;128:240-327.

\section{Zannad 2011}

Zannad F, McMurray JJ, Krum H, van Veldhuisen DJ, Swedberg K, Shi H, et al. Eplerenone in patients with systolic heart failure and mild symptoms. New England Journal of Medicine 2011;364(1):11-21.

* Indicates the major publication for the study

Abdel 2011

\title{
Study characteristics
}

Study design: $\mathrm{RCT}$
Unit of randomisation: No information
Total duration of study: 12 weeks
Run-in period: No information
Intervention time: No information
Follow-up: No information
Setting: Beni-Suef University, Beni-Suef, Egypt

Participants

\author{
Type of heart failure: $\mathrm{CHF}$ \\ $\mathbf{N}=100$ participants (ivabradine: 50 ; placebo: 50 ) \\ Mean age: No information \\ Gender: No information \\ Severity of condition: \\ - LV dysfunction \\ - $\mathrm{EF}<35 \%$ \\ Inclusion criteria: \\ - Sinus rhythm \\ - $\mathrm{HR}>80 \mathrm{bpm}$ \\ - Symptomatic heart failure (NYHA class II and III) \\ - Left ventricular systolic dysfunction (EF $<35 \%)$
}


Abdel 2011 (Continued)

- Patients in sinus rhythm (HR> $80 \mathrm{bpm}$ ) with symptomatic heart failure (NYHA class II and III) despite optimal medical therapy who were proved to have left ventricular systolic dysfunction $(\mathrm{EF}<35 \%)$ secondary to ischaemic or idiopathic cardiomyopathy

Exclusion criteria: No information

Withdrawals: No information

Intervention: Ivabradine max. 5 to 7.5 mg twice a day
Comparison: Placebo
Concomitant medications: No information
Excluded medications: No information
Outcomes and time points measured in the study:
[Day 0, 12 weeks]
- Change in the exercise duration on treadmill
- Change in echocardiographic parameters
Conclusion: "Ivabradine therapy for 12 weeks when added to optimum medical therapy in patients
with left ventricular systolic dysfunction secondary to ischaemic or idiopathic cardiomyopathy in-
creased significantly the exercise duration and functional capacity. It also decreased significantly the
resting HR and peak HR during exercise testing with trends towards increase in (2D) EF but it did not
reach statistical significance."

Notes Funding for trial: No information

Notable conflicts of interest of authors: No information

Contact to authors/unpublished data: We contacted Yasser A Abdel-Hadi via email on 22 November 2018 to inquire about funding, way of randomisation, age, sex, duration IP, and missing data. We did not receive an answer.

\section{Risk of bias}

\begin{tabular}{lll}
\hline Bias & Authors' judgement & Support for judgement \\
\hline $\begin{array}{l}\text { Random sequence genera- } \\
\text { tion (selection bias) }\end{array}$ & Unclear risk & Insufficient information to base judgement \\
\hline $\begin{array}{l}\text { Allocation concealment } \\
\text { (selection bias) }\end{array}$ & Unclear risk & Insufficient information to base judgement \\
\hline $\begin{array}{l}\text { Blinding of participants } \\
\text { and personnel (perfor- } \\
\text { mance bias) }\end{array}$ & Unclear risk & Insufficient information to base judgement \\
$\begin{array}{l}\text { All outcomes } \\
\text { Blinding of outcome as- } \\
\text { sessment (detection bias) } \\
\text { All outcomes }\end{array}$ & Unclear risk & Insufficient information to base judgement \\
\hline $\begin{array}{l}\text { Incomplete outcome data } \\
\text { (attrition bias) } \\
\text { All outcomes }\end{array}$ & Unclear risk & Insufficient information to base judgement \\
\hline
\end{tabular}


Abdel 2011 (Continued)

Selective reporting (re- Unclear risk Insufficient information to base judgement
porting bias)

Other bias Unclear risk Insufficient information to base judgement

Adamyan 2008

\section{Study characteristics}

\begin{tabular}{ll}
\hline Study design: RCT \\
Unit of randomisation: No information \\
Total duration of study: No information \\
Run-in period: No information \\
Intervention time: 90 days \\
Follow-up: At 30 days and 90 days \\
Setting: No information
\end{tabular}

Participants

Type of heart failure: End stage of $\mathrm{HF}$

$\mathbf{N}=145$ participants (ivabradine: 70; SC: 75 )

Mean age: $58 \pm 7$ years

Gender: 109 (75\%) male, 36 (25\%) female

Severity of condition: $\mathrm{HFrEF}<35 \%$

Inclusion criteria:

- Postinfarction end-stage HF

- NYHA class IV (EF < 35\%)

- Inappropriate HR (91 \pm 4 bpm)

- Intolerance beta-blockers

- Treatment with SC

Exclusion criteria: No information

Withdrawals: No information

Interventions

Intervention: Ivabradine $7.5 \mathrm{mg}$ twice a day

Comparison: SC

\section{Concomitant medications:}

- Digoxin

- Spironolacton

- ACE receptor-blocker or AT1 receptor-blocker

- Furosemide

Excluded medications: No information 
Adamyan 2008 (Continued)

[Day $0,30,90]$

- Time of standard therapy segment depressions $\geq 1 \mathrm{~mm}$ and $\geq 1 \mathrm{~mm}$ duration

- HRV as standard deviation of normal RR intervals by 24-hour echocardiography monitoring

- End diastolic volume

- Tissue Doppler patterns

- Early diastolic tissue velocity of LV lateral mitral annulus

- Myocardial performance index

- Exercise time before stress-ECG test

- Exercise time after stress-ECG test

- Stroke volume index before stress-ECG test

- Stroke volume index after stress-ECG test

\section{Conclusion:}

- Noticeable side effects requiring the withdrawal of drugs were not observed.

- Thus, in participants with postinfarction HF NYHA class IV and BB intolerance, addition of ivabradine to SC further improves cardiac parameters in terms of LV remodeling, contractility and ischaemia, and reduces hospitalisation rate probably through $\mathrm{HR}$ control.

Notes

Funding for trial: No information

Notable conflicts of interest of authors: No information

Contact to authors/unpublished data: We contacted KG Adamyan and S Grigoryan via email on 22 November 2018 to ask for funding, country, number of centres, and missing data. The email to KG Adamyan failed, but S Grigoryan answered that she had forwarded the email to the correct email address. Nevertheless, we did not receive an answer.

\section{Risk of bias}

\begin{tabular}{|c|c|c|}
\hline Bias & Authors' judgement & Support for judgement \\
\hline $\begin{array}{l}\text { Random sequence genera- } \\
\text { tion (selection bias) }\end{array}$ & Unclear risk & Insufficient information to base judgement \\
\hline $\begin{array}{l}\text { Allocation concealment } \\
\text { (selection bias) }\end{array}$ & Unclear risk & Insufficient information to base judgement \\
\hline $\begin{array}{l}\text { Blinding of participants } \\
\text { and personnel (perfor- } \\
\text { mance bias) } \\
\text { All outcomes }\end{array}$ & High risk & No blinding possible due to comparison with standard care. \\
\hline $\begin{array}{l}\text { Blinding of outcome as- } \\
\text { sessment (detection bias) } \\
\text { All outcomes }\end{array}$ & Unclear risk & Insufficient information to base judgement \\
\hline $\begin{array}{l}\text { Incomplete outcome data } \\
\text { (attrition bias) } \\
\text { All outcomes }\end{array}$ & Unclear risk & Insufficient information to base judgement \\
\hline $\begin{array}{l}\text { Selective reporting (re- } \\
\text { porting bias) }\end{array}$ & Unclear risk & Insufficient information to base judgement \\
\hline Other bias & Unclear risk & Insufficient information to base judgement \\
\hline
\end{tabular}


Adamyan 2015a

\section{Study characteristics}

Methods

\section{Study design: RCT}

Unit of randomisation: No information

Total duration of study: 36 months

Run-in period: No information

Intervention time: No information

Follow-up: No information

Setting: Institute of Cardiology, Yerevan, Armenia

\section{Participants}

\section{Type of heart failure: $\mathrm{CHF}$}

$\mathbf{N}=104$ participants (ivabradine and BB: 51; SC: 53)

Mean age: 63.2 years (no SD reported)

Gender: No information

Severity of condition: No information

Inclusion criteria:

- CHF

- Preserved LV ejection fraction

- NYHA class III

Exclusion criteria: No information

Withdrawals: No information

\section{Comparison: SC}

\section{Concomitant medications:}

- beta-secretase inhibitors

- BB

- Diuretics

Excluded medications: No information

\section{Outcomes}

\section{Outcomes and time points measured in the study:}

[Day 0, Month 12, 24, and 36]

- Deceleration time of transmitral $E$ waves

- Deceleration time of transtricuspidal E waves

- E/A ratio of transmitral flow

- RV fractional area change

- Tricuspidal annulus plane systolic excursion

- Pulmonary artery ejection time

- RA and LA fractional contribution

- Functional index

- Relation of pulmonary vein 
- Systolic and diastolic fraction

- Systolic contribution

- Difference between duration of reversal atrial flow

- Late transmitral filling

- NT-pro-BNP level

- C-reactive protein level

\section{Conclusion:}

- "1. Decrease of NT-pro-BNP $\geq 50 \%$, reversal atrial flow to late transmitral filling $\geq 80 \%$, C-reactive protein level $\geq 40 \%, H R \geq 25 \%$ and increase of Deceleration time of transmitral $E$ waves (ECG) $\geq 80 \%$, RA and LA functional index, pulmonary vein systolic contribution $\geq 50 \%$, RA and LA fractional contribution, RV fractional area change, Deceleration time of transtricuspidal E waves and pulmonary artery ejection time at $\geq 25 \%$ identified pts with cardiac risk reduction."

- "2. Ivabradine use associated with lower mortality and morbidity due to significant improvement of left ventricular, right ventricular, left atrial and right atrial functional parameters, neurohormonal and inflammation status and HR reduction."

Notes

Funding for trial: No information

Notable conflicts of interest of authors: No information

Contact to authors/unpublished data: We contacted KG Adamyan and S Grigoryan via email on 22 November 2018 to ask for funding, country, number of centres, and missing data. The email to KG Adamyan failed, but S Grigoryan answered that she had forwarded the email to the correct email address. Nevertheless, we did not receive an answer.

\section{Risk of bias}

\begin{tabular}{|c|c|c|}
\hline Bias & Authors' judgement & Support for judgement \\
\hline $\begin{array}{l}\text { Random sequence genera- } \\
\text { tion (selection bias) }\end{array}$ & Unclear risk & Insufficient information to base judgement \\
\hline $\begin{array}{l}\text { Allocation concealment } \\
\text { (selection bias) }\end{array}$ & Unclear risk & Insufficient information to base judgement \\
\hline $\begin{array}{l}\text { Blinding of participants } \\
\text { and personnel (perfor- } \\
\text { mance bias) } \\
\text { All outcomes }\end{array}$ & High risk & No blinding possible due to comparison with standard care. \\
\hline $\begin{array}{l}\text { Blinding of outcome as- } \\
\text { sessment (detection bias) } \\
\text { All outcomes }\end{array}$ & Unclear risk & Insufficient information to base judgement \\
\hline $\begin{array}{l}\text { Incomplete outcome data } \\
\text { (attrition bias) } \\
\text { All outcomes }\end{array}$ & Unclear risk & Insufficient information to base judgement \\
\hline $\begin{array}{l}\text { Selective reporting (re- } \\
\text { porting bias) }\end{array}$ & Unclear risk & Insufficient information to base judgement \\
\hline Other bias & Unclear risk & Insufficient information to base judgement \\
\hline
\end{tabular}


Bansal 2019

\section{Study characteristics}

$\begin{array}{ll}\text { Methods } & \text { Study design: RCT } \\ \text { Unit of randomisation: No information } & \text { Total duration of study: No information } \\ \text { Run-in period: No information } \\ \text { Intervention time: No information } \\ \text { Follow-up: No information } \\ \text { Setting: Safdarjung Hospital, New Delhi, } \\ \text { Type of heart failure: Ischaemic heart f } \\ \text { N }=309 \text { (ivabradine: } 157, \text { SC: 152) } \\ \text { Mean age: No information } \\ \text { Gender: No information } \\ \text { Severity of condition: No information } \\ \text { Inclusion criteria: No information } \\ \text { Exclusion criteria: No information } \\ \text { Withdrawals: No information }\end{array}$

\begin{tabular}{ll}
\hline Interventions & Intervention: Ivabradine \\
Comparison: SC \\
Concomitant medications: Optimal medical therapy \\
Excluded medications: No information
\end{tabular}

Outcomes

Outcomes and time points measured in the study:

- Left ventricular dimension

- Left ventricular ejection fraction

- Exercise duration (in seconds)

- Serum BNP level

- Sodium level

\section{Conclusion:}

"Patients in low serum sodium levels at baseline had lower ejection fraction, exercise duration and higher BNO level and LV end-systolic and end-diastolic dimensions in both groups as compared to patients with higher serum Sodium values. Serum sodium may serve as a simple clue to lower EF, higher BNP and poorer effort tolerance in stable patients of ischemic systolic heart failure"

Notes

Funding for trial: Medication is funded by the government

Notable conflicts of interest of authors: No information

Contact to authors/unpublished data: No

\section{Risk of bias}


Bansal 2019 (Continued)

\begin{tabular}{lll} 
Bias & Authors' judgement & Support for judgement \\
\hline $\begin{array}{l}\text { Random sequence genera- } \\
\text { tion (selection bias) }\end{array}$ & Unclear risk & Insufficient information to base judgement \\
\hline $\begin{array}{l}\text { Allocation concealment } \\
\text { (selection bias) }\end{array}$ & Unclear risk & Insufficient information to base judgement \\
\hline $\begin{array}{l}\text { Blinding of participants } \\
\text { and personnel (perfor- } \\
\text { mance bias) } \\
\begin{array}{l}\text { All outcomes } \\
\end{array}\end{array}$ & Unclear risk & Insufficient information to base judgement \\
\end{tabular}

\begin{tabular}{|c|c|c|}
\hline $\begin{array}{l}\text { Blinding of outcome as- } \\
\text { sessment (detection bias) } \\
\text { All outcomes }\end{array}$ & Unclear risk & Insufficient information to base judgement \\
\hline $\begin{array}{l}\text { Incomplete outcome data } \\
\text { (attrition bias) } \\
\text { All outcomes }\end{array}$ & Low risk & $\begin{array}{l}\text { Less than } 20 \% \text { missing data. Outcomes reported for } 309 \text { of } 309 \text { participants } \\
(100 \%) \text {. }\end{array}$ \\
\hline $\begin{array}{l}\text { Selective reporting (re- } \\
\text { porting bias) }\end{array}$ & Unclear risk & Insufficient information to base judgement \\
\hline Other bias & Unclear risk & Insufficient information to base judgement \\
\hline
\end{tabular}

Chaudhari 2014

\title{
Study characteristics
}

Methods

\author{
Study design: RCT \\ Unit of randomisation: No information \\ Total duration of study: No information \\ Run-in period: No information \\ Intervention time: 6 months \\ Follow-up: At 6 months
}

Setting: Monocenter, Safdarjang Hospital and Vardhman Mahavir Medical College, New Delhi, India

\section{Participants}

\section{Type of heart failure: Ischaemic HF}

$\mathbf{N}=158$ (ivabradine: $78 ;$ SC: 80 )

\section{Mean age:}

- Ivabradine: $57.52 \pm 9.3$ years

- Standard care: $59.47 \pm 8.3$ years (S Bansal on 2 December 2018 via email)

\section{Gender:}

- Ivabradine: $70(89.74 \%)$ male

- Standard care: 65 (81.25\%) male (S Bansal on 2 December 2018 via email)

Severity of condition: LVEF $<40 \%$ 
Chaudhari 2014 (Continued)

Inclusion criteria: Stable, ischaemic HF

Exclusion criteria: No information

Withdrawals: No information

$\begin{array}{ll}\text { Interventions } & \text { Intervention: Ivabradine } 5 \text { mg twice a day } \\ \text { Comparison: SC } \\ \text { Concomitant medications: No information } \\ \text { Excluded medications: No information }\end{array}$

Outcomes Outcomes and time points measured in the study:

[Month 0,6]

- LV dimension

- LVEF

- Exercise duration (in seconds)

- Quality of life score assessment by KCCQ

- Serum BNP level

\section{Conclusion:}

- There was no significant difference in mortality and morbidity with ivabradine therapy in patients with heart failure in whom betablockers were contraindicated. Hospitilisation was more or less same in both the groups.

Notes

Funding for trial: "Our hospital is a federal government university teaching hospital. The diagnosis and treatment are free. However, free samples of Ivabradine were provided by an Indian company - M/ S Cipla Private Limited, an Indian pharmaceutical company." (S Bansal on 2 December 2018 via email)

Notable conflicts of interest of authors: No information

Unpublished data: Information about the trial's funding, way of randomisation, age, sex, NYHA, and EF was provided via email by S Bansal on 2 December 2018.

Contact to authors/unpublished data: We contacted S Bansal via email on 22 November 2018 to ask for funding, way of randomisation, age, sex, NYHA, EF, and missing data. S Bansal answered on 2 December 2018 providing information about funding, way of randomisation, age, sex, NYHA, EF, and other additional outcomes such as BNP levels.

\section{Risk of bias}

\begin{tabular}{lll}
\hline Bias & Authors' judgement & Support for judgement \\
\hline $\begin{array}{l}\text { Random sequence genera- } \\
\text { tion (selection bias) }\end{array}$ & High risk & $\begin{array}{l}\text { "Simple manual (non computer based) randomization was used. Every third } \\
\text { individual in the outpatient clinic who satisfied the inclusion criteria was con- } \\
\text { sidered for Ivabradine add-on therapy over and above GDMT." (S Bansal on } 2 \\
\text { December 2018 via email) }\end{array}$ \\
& & \\
&
\end{tabular}

Allocation concealment Unclear risk $\quad$ Insufficient information to base judgement
(selection bias)

Blinding of participants High risk No blinding possible due to comparison with SC
and personnel (perfor-


Chaudhari 2014 (Continued)
Blinding of outcome as-
Unclear risk
Insufficient information to base judgement sessment (detection bias)

All outcomes

Incomplete outcome data Unclear risk Insufficient information to base judgement
(attrition bias)
All outcomes

\begin{tabular}{|c|c|c|}
\hline $\begin{array}{l}\text { Selective reporting (re- } \\
\text { porting bias) }\end{array}$ & Unclear risk & Insufficient information to base judgement \\
\hline Other bias & Unclear risk & $\begin{array}{l}\text { "Our hospital is a federal government university teaching hospital. The diag- } \\
\text { nosis and treatment are free. However, free samples of Ivabradine were pro- } \\
\text { vided by an Indian company - M/S Cipla Private Limited, an Indian pharma- } \\
\text { ceutical company." (S Bansal on } 2 \text { December } 2018 \text { via email) }\end{array}$ \\
\hline
\end{tabular}

De Masi De Luca 2013

\title{
Study characteristics
}

\begin{tabular}{ll}
\hline Methods & Study design: $\mathrm{RCT}$ \\
Unit of randomisation: No information \\
Total duration of study: 3 months \\
Run-in period: No information \\
Intervention time: No information \\
Follow-up: No information \\
Setting: No information \\
\hline
\end{tabular}

Participants

\author{
Type of heart failure: $\mathrm{CHF}$ \\ $\mathbf{N}=111$ participants (ivabradine: 53; placebo: 58 ) \\ Mean age: $61 \pm 13$ years (no SD reported) \\ Gender: 78 (70\%) male, 33 (30\%) female
}

Severity of condition: $\mathrm{LVEF} \geq 50 \%$

\section{Inclusion criteria:}

- HFnEF

- NYHA II/IV

- $\mathrm{HR}>70 \mathrm{bpm}$

- $\operatorname{LVEF} \geq 50 \%$

Exclusion criteria: No information

Withdrawals: No information

$\begin{array}{ll}\text { Interventions } & \text { Intervention: Ivabradine } 5 \text { to } 7.5 \mathrm{mg} \text { twice a day } \\ \text { Comparison: Placebo } \\ \text { Concomitant medications: SC }\end{array}$


Excluded medications: No information

Outcomes and time points measured in the study:
[Day 0,3 months]
- Clinical examination (NYHA class)
- Cardiopulmonary test
$*$ pulmonary venous oxygen tension
$*$ exercise duration
Conclusion: "Thus the data of our study suggest that the addition of Ivabradine to optimal medical
treatment for the HFNF improves physical performance and neurohormonal parameters"
Funding for trial: No information
Notable conflicts of interest of authors: No information
Contact to authors/unpublished data: We contacted G de Masi de Luca via email on 22 November
2018 to ask for funding, country, number of centres, duration IP administration, and missing data. We
did not receive an answer.

\section{Risk of bias}

\begin{tabular}{|c|c|c|}
\hline Bias & Authors' judgement & Support for judgement \\
\hline $\begin{array}{l}\text { Random sequence genera- } \\
\text { tion (selection bias) }\end{array}$ & Unclear risk & Insufficient information to base judgement \\
\hline $\begin{array}{l}\text { Allocation concealment } \\
\text { (selection bias) }\end{array}$ & Unclear risk & Insufficient information to base judgement \\
\hline $\begin{array}{l}\text { Blinding of participants } \\
\text { and personnel (perfor- } \\
\text { mance bias) } \\
\text { All outcomes }\end{array}$ & Unclear risk & Insufficient information to base judgement \\
\hline $\begin{array}{l}\text { Blinding of outcome as- } \\
\text { sessment (detection bias) } \\
\text { All outcomes }\end{array}$ & Unclear risk & Insufficient information to base judgement \\
\hline $\begin{array}{l}\text { Incomplete outcome data } \\
\text { (attrition bias) } \\
\text { All outcomes }\end{array}$ & Unclear risk & Insufficient information to base judgement \\
\hline $\begin{array}{l}\text { Selective reporting (re- } \\
\text { porting bias) }\end{array}$ & Unclear risk & Insufficient information to base judgement \\
\hline Other bias & Unclear risk & Insufficient information to base judgement \\
\hline
\end{tabular}

Fox 2008

\section{Study characteristics}

\section{Methods}

Study design: RCT 
Fox 2008 (Continued)

Unit of randomisation: No information

\section{Total duration of study:}

- Screening: December 2004 to December 2006

- Randomisation: January 2005 to January 2007

Run-in period: 14 days without study treatment

Intervention time: Until the very last follow-up ( month 19) (K Fox via email on 23 November 2018)

Follow-up: At 2 weeks; 1, 3, 6, 12, 18, and 24 months

Setting: Multicentre, 781 centres in 33 countries

\section{Participants}

Type of heart failure: Stable coronary artery disease

$\mathbf{N}=10,917$ (ivabradine and beta-blockers: 5479; placebo: 5438)

Mean age: $65.2 \pm 8.5$ years

Gender: 9047 (83\%) male, 1870 (17\%) female

Severity of condition: $\mathrm{HFrEF}<40 \%$

\section{Inclusion criteria:}

- Male or female

- Age at the date of selection: $\geq 55$ years in non-diabetic patients or $\geq 18$ years in diabetic patients (type 1 or 2)

- Evidence of coronary artery disease documented by:

* previous MI at least 6 months before randomisation, confirmed by electrocardiogram demonstrating abnormal $Q$ waves in 2 contiguous leads and/or biochemical markers of cardiac necrosis;

* previous (at least 6 months before randomisation) percutaneous or surgical coronary revascularisation;

* angiographic evidence of at least $50 \%$ narrowing of $\geq 1$ major coronary vessel.

- In sinus rhythm with a resting HR of $\geq 60 \mathrm{bpm}$ on a recent resting standard 12-lead ECG

- With LVEF $\leq 39 \%$ on recently performed measurement from a 2-dimensional echocardiography

- With left ventricular dilatation on an echocardiographically measured short-axis internal dimension at end diastole $>56 \mathrm{~mm}$ (examination performed in the previous 4 weeks)

- In stable condition (for at least 3 months) with regard to angina and/or heart failure symptoms

- On appropriate and stable doses, for at least 1 month, of conventional cardiovascular medications

- Written informed consent obtained

\section{Exclusion criteria:}

- Patients unlikely to co-operate in the study or with inability or unwillingness to give informed consent

- Pregnant or breastfeeding women or women of childbearing potential

- Patients with recent (<6 months) MI or coronary revascularisation or with a history of stroke or cerebral transient ischaemic attack within the preceding 3 months or scheduled for revascularisation (percutaneous coronary intervention and coronary artery bypass graft) 
Fox 2008 (Continued)

- Patients with at least one of the following criteria:

* implanted pacemaker or implantable cardioverter defibrillator;

* valvular disease likely to require surgery within the next 3 years;

* sick sinus syndrome, sinoatrial block, congenital long QT interval, complete atrioventricular block;

* severe or uncontrolled hypertension (systolic blood pressure $>180 \mathrm{mmHg}$ or diastolic blood pressure > $110 \mathrm{mmHg}$ );

* current severe symptoms of heart failure (NYHA class IV);

* expectation of death from other illness during the course of the trial;

* with known severe liver disease or renal disease;

* requiring or likely to require the following medications: macrolide antibiotics, cyclosporin, gestodene, antiretroviral drugs or azole antifungals such as ketoconazole or with known hereditary problems of galactose intolerance, Lapp lactase deficiency, or glucose-galactose malabsorption.

\section{Withdrawals:}

- 230 participants:

* 10 participants refused medication;

* 216 participants withdrew consent;

* 3 participants were not correctly randomised;

* 1 participant lost to follow-up.

Interventions

\section{Intervention:}

Week 1 to 2: Ivabradine $5 \mathrm{mg}$ twice a day

\section{After week 2:}

- Resting HR $\geq 60 \mathrm{bpm}$ : ivabradine $7.5 \mathrm{mg}$ twice a day

- Resting HR $<50$ bpm/bradycardia: ivabradine $5 \mathrm{mg}$ twice a day

Comparison: Placebo

\section{Concomitant medications:}

- $\mathrm{BB}(87 \%)$

- Renin-angiotensin system agents (89\%)

- Antithrombotic agents (94\%)

- Lipid-lowering agents (76\%)

Excluded medications: CYP P450 3A4 inhibitors

\section{Outcomes}

\section{Outcomes and time points measured in the study:}

[2 weeks; 1, 3, and 6 months; and every 6 months thereafter]

- Primary endpoint:

* Composite of cardiovascular death

* Admission to hospital for acute MI

* Admission to hospital for new-onset or worsening HF

- Secondary endpoints:

* All-cause mortality

* Cardiac death (death from MI or HF, or death related to a cardiac procedure)

* Cardiovascular death (defined as cardiac death, death from a vascular procedure, presumed arrhythmic death, stroke death, other vascular death, or sudden death of unknown cause) or admission to hospital for new-onset or worsening heart failure

* The composite of admission to hospital for fatal and non-fatal acute MI or unstable angina

* Coronary revascularisation

* Admission to hospital for HF

* Admission to hospital for MI 
Fox 2008 (Continued)

Conclusion: Reduction in heart rate with ivabradine does not improve cardiac outcomes in all patients with stable coronary artery disease and left-ventricular systolic dysfunction, but could be used to reduce the incidence of coronary artery disease outcomes in a subgroup of patients who have heart rates of $70 \mathrm{bpm}$ or greater.

Funding for trial: Servier, France
Notes
- All authors have received fees, research grants, or both from Servier.
- PGS has also received a research grant from Sanofi-Aventis, and has received fees for speaking or
consulting from Astelias, AstraZeneca, Bayer, Boehringer-Ingelheim, BMS, Endotis, GSK, Medtronic,
MSD Nycomed, Sanofi-Aventis, and The Medicines Company.

Contact to authors/unpublished data: We contacted K Fox via email on 22 November 2018 to ask for intervention time and missing data. K Fox answered on 23 November 2018, providing the information that the participants were on ivabradine or placebo until their very last follow-up. Concerning missing data, he attached the SHIFT paper about rehospitalisation (Borer 2012 reference of Swedberg 2010), which we had already considered in our work.

\section{Risk of bias}

\begin{tabular}{|c|c|c|}
\hline Bias & Authors' judgement & Support for judgement \\
\hline $\begin{array}{l}\text { Random sequence genera- } \\
\text { tion (selection bias) }\end{array}$ & Low risk & $\begin{array}{l}\text { "The random-allocation schedule was computer-generated by non-adaptive } \\
\text { balanced randomisation, stratified both by centre and by whether treatment } \\
\text { at enrolment included a BB or not." }\end{array}$ \\
\hline $\begin{array}{l}\text { Allocation concealment } \\
\text { (selection bias) }\end{array}$ & Low risk & $\begin{array}{l}\text { "An independent organisation, Clinphone (Nottingham, UK), supervised ran- } \\
\text { domisation. We used a central interactive voice-response system and an in- } \\
\text { teractive web-response system to ensure that investigators were unaware of } \\
\text { treatment allocation." }\end{array}$ \\
\hline $\begin{array}{l}\text { Blinding of participants } \\
\text { and personnel (perfor- } \\
\text { mance bias) } \\
\text { All outcomes }\end{array}$ & Low risk & "We did a randomised, double-blind, placebo-controlled, parallel-group trial" \\
\hline $\begin{array}{l}\text { Blinding of outcome as- } \\
\text { sessment (detection bias) } \\
\text { All outcomes }\end{array}$ & Unclear risk & $\begin{array}{l}\text { No blinding. However, the measured outcomes are objective outcomes (mor- } \\
\text { tality,length of stay, etc.) and are thus not likely to be influenced by lack of } \\
\text { blinding. }\end{array}$ \\
\hline $\begin{array}{l}\text { Incomplete outcome data } \\
\text { (attrition bias) } \\
\text { All outcomes }\end{array}$ & Low risk & $\begin{array}{l}\text { Less than } 20 \% \text { missing data. Outcomes reported for } 10,907 \text { of } 10,917 \text { partici- } \\
\text { pants }(99.9 \%) \text {. }\end{array}$ \\
\hline $\begin{array}{l}\text { Selective reporting (re- } \\
\text { porting bias) }\end{array}$ & Low risk & $\begin{array}{l}\text { All outcomes stated in the methods section were adequately reported or ex- } \\
\text { plained in the results. }\end{array}$ \\
\hline Other bias & Unclear risk & $\begin{array}{l}\text { "Representatives of the sponsor were non-voting members of the study exec- } \\
\text { utive committee and were involved with the executive committee in the study } \\
\text { design, interpretation of the data, and the writing of the report. The corre- } \\
\text { sponding author had full access to all data and had final responsibility for the } \\
\text { decision to submit the paper for publication." }\end{array}$ \\
\hline
\end{tabular}


Komajda 2017

\section{Study characteristics}

Methods

Study design: RCT

Unit of randomisation: No information

Total duration of study: 25 June 2013 to 7 July 2015

Run-in period: 2 weeks

Intervention time: 8 months

Follow-up: 8 months

Setting: 86 centres in 19 countries

Participants

Type of heart failure: $\mathrm{CHF}$

$\mathbf{N}=179$ participants (ivabradine: 95 ; placebo: 84 )

\section{Mean age:}

- Ivabradine: $72 \pm 6$ years

- Placebo: $73 \pm 6$ years

\section{Gender:}

- Ivabradine: 36 (37.9\%) male, 59 (62.1\%) female

- Placebo: 27 (32.1\%) male, 57 (67.9\%) female

Severity of condition: $L V E F \geq 45 \%$

Inclusion criteria:

- NYHA class II/III

- Sinus rhythm

- $H R \geq 70$ bpm

- NT-pro-BNP $\geq 220 \mathrm{pg} / \mathrm{mL}$

- $B N P \geq 80 \mathrm{pg} / \mathrm{mL}$

- $\operatorname{LVEF} \geq 45 \%$

- Age $\geq 50$ years

\section{Exclusion criteria:}

- Severe valvular disease

- Primary hypertrophic or restrictive cardiomyopathy

- Systemic illness

- Infiltrative heart disease

- Permanent atrial fibrillation

- Recent (<3 months) atrial fibrillation-related hospitalisation

- Pacemaker carriage

- Severe or uncontrolled hypertension

Withdrawals: No information

- Ivabradine max. $5 \mathrm{mg}$ twice a day

- After 2 weeks, if resting HR > 60 bpm: ivabradine max. $7.5 \mathrm{mg}$ twice a day

- If HR was 50 to $60 \mathrm{bpm}$, the dose was maintained at $5 \mathrm{mg}$ twice a day 
- If HR was < $50 \mathrm{bpm}$ : reduction of ivabradine to $2.5 \mathrm{mg}$ twice a day

- At any time during the study the drug dose could be adjusted up or down by $2.5 \mathrm{mg}$ bpm if there were signs or symptoms related to bradycardia

Comparison: Placebo

Concomitant medications: SC

Excluded medications:

- Non-dihydropyridine calcium channel blockers

- Class I antiarrhythmics

- Strong inhibitors of cytochrome P450 3A4

Outcomes and time points measured in the study:
ODay 0 and months 2, 4, 8]
Primary endpoints:
- Echo-Doppler ratio
- Distance on the 6-minute walking test
- Plasma NT-pro-BNP concentration
Secondary endpoints:
- HR
- Total mitral flow duration
- Indexed left ventricular end-diastolic volume
- Stroke volume
- LA volume Index
- ECG
- Indexed left ventricular mass
- Ratio of arterial elastance/ventricular end-systolic elastance
- NYHA class
- Occurrence of emergent adverse events

Conclusion: "In patients with HFpEF, HR reduction with ivabradine did not improve outcomes. These findings do not support the use of ivabradine in HFpEF"

Notes

Funding for trial: "The EDIFY trial was sponsored by Les Laboratories Servier (Surenes, France). The sponsor was responsible for study management, data collection and data analysis"

Notable conflicts of interest of authors: No information

Contact to authors/unpublished data: We contacted M Komajda via email on 22 November 2018 to ask for way of randomisation and missing data. We did not receive an answer.

\section{Risk of bias}

\begin{tabular}{lll}
\hline Bias & Authors' judgement & Support for judgement \\
\hline $\begin{array}{l}\text { Random sequence genera- } \\
\text { tion (selection bias) }\end{array}$ & Unclear risk & $\begin{array}{l}\text { "The randomization was balanced (1:1) and stratified on centres." No informa- } \\
\text { tion provided about method of generating the random sequence. }\end{array}$ \\
\hline $\begin{array}{l}\text { Allocation concealment } \\
\text { (selection bias) }\end{array}$ & Unclear risk & Insufficient information to base judgement \\
\hline
\end{tabular}


Komajda 2017 (Continued)

Blinding of participants and personnel (performance bias)

All outcomes
Low risk "Randomized, double-blind, placebo-controlled trial."

"Study investigators and participants were masked to treatment for the duration of the trial."

$\begin{array}{ll}\text { Blinding of outcome as- } & \text { Unclear risk }\end{array}$ Insufficient information to base judgement

All outcomes

Incomplete outcome data Unclear risk Insufficient information to base judgement
(attrition bias)

All outcomes

\begin{tabular}{lll}
\hline $\begin{array}{l}\text { Selective reporting (re- } \\
\text { porting bias) }\end{array}$ & Unclear risk & Insufficient information to base judgement \\
\hline Other bias & Unclear risk & Insufficient information to base judgement \\
\hline
\end{tabular}

Kosmala 2013

\section{Study characteristics}

Study design: RCT
Unit of randomisation: No information
Total duration of study: Screening from December 2011 to December 2012
Run-in period: No information
Intervention time: 7 days
Follow-up: No information
Setting:
- Wroclaw Medical University, Wroclaw, Poland
- University of Queensland, Department of Medicine, Brisbane, Australia
- University of Tasmania, Menzies Research Institute Tasmania, Hobart, Australia

\section{Participants}

\section{Type of heart failure: $\mathrm{CHF}$}

$\mathbf{N}=61$ (ivabradine and BB: 30; placebo: 31 )

Mean age: $67 \pm 8$ years

Gender: $11(18 \%)$ male, 50 (82\%) female

Severity of condition: $\mathrm{HFPEF} \geq 50 \%$

\section{Inclusion criteria:}

- Met the exercise capacity and post-exercise LV filling pressure ratio criteria

- Categorised in NYHA functional II or III

\section{Exclusion criteria:}

- Absence of stable sinus rhythm 
- Ischaemic heart disease (excluded on the basis of the absence of significant atherosclerotic lesions on coronary angiography and no evidence of inducible ischaemia during exercise testing)

- Moderate and severe valvular heart disease

- Heart rate $<60$ bpm

- Sick sinus syndrome

- Second-degree and third-degree atrioventricular block

- Severe obesity (body mass index $>36 \mathrm{~kg} / \mathrm{m}^{2}$ )

- Established or suspected pulmonary diseases (vital capacity $<80 \%$ or forced expiratory volume in 1 second $<80 \%$ of age-specific and sex-specific reference values)

- Haemoglobin $11 \mathrm{~g} / \mathrm{dL}$

- Treatment with non-dihydropyridine calcium-channel blockers, class I antiarrhythmic agents, strong inhibitors of cytochrome P450 3A4, and QT interval-prolonging medications

Withdrawals: None

Interventions

Intervention: Ivabradine $5 \mathrm{mg}$ twice a day

Comparison: Placebo

Concomitant medications: BB

Excluded medications:

- Non-dihydropyridine calcium-channel blockers

- Class I antiarrhythmic agents

- Strong inhibitors of cytochrome P450 3A4

- QT interval-prolonging medications

\section{Outcomes}

\section{Outcomes and time points measured in the study:}

[0d, 7d]

- Exercise capacity

- Ratio of peak early diastolic mitral flow velocity to peak early diastolic mitral annular velocity

- $\mathrm{HR}$

- $\mathrm{pVO}_{2}$

- Postexercise LV filling pressure

- Alterations in myocardial deformation

- LV systolic and diastolic function

- Plasma BNP

\section{Conclusion:}

- In participants with HFpEF, short-term treatment with ivabradine increased exercise capacity, with a contribution from improved LV filling pressure response to exercise as reflected by the ratio of peak early diastolic mitral flow velocity to peak early diastolic mitral annular velocity.

- Because this patient population is symptomatic on exertion, therapeutic treatments targeting abnormal exercise haemodynamic status may prove useful.

- Ivabradine therapy is an effective therapy to increase exercise tolerance in patients with HFpEF.

- This beneficial effect is potentially mediated by the improved LV filling pressure response to exercise.

Notes

Funding for trial: Paid with internal funds from Wroclaw Medical University and Brisbane University. (W Kosmala via email on 22 November 2018)

Notable conflicts of interest of authors: No information 
Contact to authors/unpublished data: We contacted W Kosmala via email on 22 November 2018 to ask for funding and missing data. W Kosmala answered on 22 November 2018, providing information about funding and that no other outcome data were available.

\title{
Risk of bias
}

\begin{tabular}{|c|c|c|}
\hline Bias & Authors' judgement & Support for judgement \\
\hline $\begin{array}{l}\text { Random sequence genera- } \\
\text { tion (selection bias) }\end{array}$ & Low risk & $\begin{array}{l}\text { "The procedure of randomization to receive either ivabradine } 5 \mathrm{mg} \text { or placebo } \\
\text { twice daily was performed by computerized sequence generation." }\end{array}$ \\
\hline $\begin{array}{l}\text { Allocation concealment } \\
\text { (selection bias) }\end{array}$ & Unclear risk & Insufficient information to base judgement \\
\hline Blinding of participants & Low risk & $\begin{array}{l}\text { "The present study was designed as a prospective, blinded, parallel-group, } \\
\text { placebo-controlled trial." }\end{array}$ \\
\hline All outcomes & & $\begin{array}{l}\text { "The hospital pharmacies were responsible for drug randomization and dis- } \\
\text { pensing, and both the investigators and patients were blinded to the treat- } \\
\text { ment option." }\end{array}$ \\
\hline $\begin{array}{l}\text { Blinding of outcome as- } \\
\text { sessment (detection bias) } \\
\text { All outcomes }\end{array}$ & Unclear risk & Insufficient information to base judgement \\
\hline $\begin{array}{l}\text { Incomplete outcome data } \\
\text { (attrition bias) } \\
\text { All outcomes }\end{array}$ & Low risk & $\begin{array}{l}\text { Less than } 20 \% \text { missing data. Outcomes reported for } 61 \text { of } 61 \text { participants } \\
(100 \%) \text {. }\end{array}$ \\
\hline $\begin{array}{l}\text { Selective reporting (re- } \\
\text { porting bias) }\end{array}$ & Low risk & $\begin{array}{l}\text { All outcomes stated in the methods section were adequately reported or ex- } \\
\text { plained in the results. }\end{array}$ \\
\hline Other bias & Low risk & $\begin{array}{l}\text { Paid with internal funds from Wroclaw Medical University and Brisbane Univer- } \\
\text { sity }\end{array}$ \\
\hline
\end{tabular}

Potapenko 2011

\section{Study characteristics}

Methods

\author{
Study design: RCT \\ Unit of randomisation: No information \\ Total duration of study: No information \\ Run-in period: No information
}

Intervention time: 3.5 years

Follow-up: $36.1 \pm 6.2$ months

Setting: University of Peoples' Friendship Moscow; City Hospital N64

Participants

Type of heart failure: MI with systolic CHF

$\mathbf{N}=49$ participants (ivabradine and beta-blockers: 23; SC: 26)

Mean age: $63.1 \pm 8.1$ years 
Gender: 40 (81.6\%) male, 9 (18.4\%) female

Severity of condition: No information

Inclusion criteria:

- Sinus rhythm

- $>3$-month history of MI

- $\mathrm{EF}<40 \%$

- $H R \geq 60 \mathrm{bpm}$

- NYHA II-III

\section{Exclusion criteria:}

- Revascularisation of myocardium conducted during the past 6 months

- Existence of an indication for a revascularisation emergency surgery

- Stroke or temporary disturbances in cerebral perfusion during the past 3 months

- Implanted artificial pacemaker or cardioverter defibrillator

- Heart valve defect with a high chance of surgical treatment during the course of the following 3 years

- Sinus node weakness

- Sinoatrial block

- Long QT syndrome

- Atrioventricular block

Withdrawals: 6 withdrawals (12\%)

Interventions

Intervention: Ivabradine (initial dose $5 \mathrm{mg}$ twice a day; after 2 weeks with a heart rate of $60 / \mathrm{min}$ or higher: $7.5 \mathrm{mg}$ twice a day; if heart rate dropped below 50/min or other clinical symptoms of bradycardia: again $5 \mathrm{mg}$ twice a day; if symptoms did not improve: ivabradine treatment stopped)

Comparison: SC

Concomitant medications:

- $\mathrm{BB}(85.7 \%)$

- ACE inhibitor (96\%)

Excluded medications: No information

Outcomes

Outcomes and time points measured in the study:

[Day 0, Year 3.5]

- $\mathrm{HR}$

- BP

- Parameters of ECG

- Levels of electrolytes

- Creatinin in blood plasma

- Frequency of hospitalisations

- Recurrent non-fatal MI and lethality (combined endpoint)

Conclusion: "In the same trend in BP and Echocardiography, group 1 (Ivabradine) patients showed significant and more pronounced HR lowering than group 2 patients. Addition of ivabradine to standard treatment of systolic chronic cardiac failure after MI promoted less frequency of hospitalizations, recurrent non-fatal MI, fatal cardiovascular events. This effect was especially strong in high baseline HR." 
Potapenko 2011 (Continued)

Contact to authors/unpublished data: We contacted AV Potapenko via email on 22 November 2018 to ask for an English publication. We did not receive an answer.

\section{Risk of bias}

\begin{tabular}{|c|c|c|}
\hline Bias & Authors' judgement & Support for judgement \\
\hline $\begin{array}{l}\text { Random sequence genera- } \\
\text { tion (selection bias) }\end{array}$ & Unclear risk & Insufficient information to base judgement \\
\hline $\begin{array}{l}\text { Allocation concealment } \\
\text { (selection bias) }\end{array}$ & Low risk & $\begin{array}{l}\text { "The procedure of randomization to receive either ivabradine or SC was per- } \\
\text { formed by sealed envelopes." }\end{array}$ \\
\hline $\begin{array}{l}\text { Blinding of participants } \\
\text { and personnel (perfor- } \\
\text { mance bias) } \\
\text { All outcomes }\end{array}$ & High risk & No blinding possible due to comparison with SC. \\
\hline $\begin{array}{l}\text { Blinding of outcome as- } \\
\text { sessment (detection bias) } \\
\text { All outcomes }\end{array}$ & Unclear risk & Insufficient information to base judgement \\
\hline $\begin{array}{l}\text { Incomplete outcome data } \\
\text { (attrition bias) } \\
\text { All outcomes }\end{array}$ & Low risk & $\begin{array}{l}\text { Less than } 20 \% \text { missing data. Outcomes reported for } 42 \text { of } 49 \text { participants } \\
(88 \%) \text {. }\end{array}$ \\
\hline $\begin{array}{l}\text { Selective reporting (re- } \\
\text { porting bias) }\end{array}$ & Low risk & $\begin{array}{l}\text { All outcomes stated in the methods section were adequately reported or ex- } \\
\text { plained in the results. }\end{array}$ \\
\hline Other bias & Unclear risk & Insufficient information to base judgement \\
\hline
\end{tabular}

Sarullo 2010

\section{Study characteristics}

\begin{tabular}{ll}
\hline Methods & Study design: RCT \\
Unit of randomisation: No information \\
Total duration of study: No information \\
Run-in period: No information \\
Intervention time: 3 months \\
Follow-up: 3 months \\
Setting: Buccheri La Ferla-Fatebenefratelli Hospital, Palermo, Italy (F Sarullo via email on 22 Novem- \\
ber 2018$)$ \\
Type of heart failure: Ischaemic HF \\
N $=60$ participants (ivabradine and BB: $30 ;$ placebo: 30 ) \\
Mean age: \\
Participants \\
- Ivabradine: $52.1 \pm 6.1$ years
\end{tabular}


Sarullo 2010 (Continued)

\section{Gender:}

- Ivabradine: 23 (76\%) male, 7 (24\%) female

- Placebo: 22 (74\%) male, 8 (26\%) female

Severity of condition: $\mathrm{LVEF} \leq 40 \%$

Inclusion criteria:

- NYHA class II/III

- Sinus rhythm

- Resting HR > 70 bpm

- Clinically stable

- Standard medical therapy in the 3 months before the study

- Mitral insufficiency was present in 20 participants and was mild in all participants

\section{Exclusion criteria:}

- Unstable angina

- Recent acute myocardial infarction

- Decompensated congestive HF

- Haemodynamically significant valvular heart disease

- Atrial fibrillation

- Poorly controlled cardiac arrhythmias

- Significant chronic pulmonary illness

- Renal insufficiency (serum creatinine $\geq 2.5 \mathrm{mg} / \mathrm{dL}$ )

- Exercise testing limited by angina or leg claudication

- Abnormal blood pressure during exercise $>250 \mathrm{mmHg}$

- Diastolic blood pressure $>120 \mathrm{mmHg}$

- Systolic blood pressure response decrease $>20 \mathrm{mmHg}$ after a normal increase or decrease below the resting level

- Neurological or orthopaedic limitations

Withdrawals: No information

- Ivabradine $5 \mathrm{mg}$ twice a day

- After 2 weeks and $\mathrm{HR} \geq 70$ bpm ivabradine $7.5 \mathrm{mg}$ twice a day

Comparison: Placebo

\section{Concomitant medications:}

- ACE inhibitors (lisinopril 10 to $40 \mathrm{mg} /$ day)

- BB (carvedilol, bisoprolol)

- Amiodarone

- Nitrates

- Statins

- Antiplatelet agents

- Diuretics

- Aspririn

Excluded medications: No information

[Day 0, Month 3] 
Sarullo 2010 (Continued)

- Maximal exercise test with respiratory gas analysis

- Endurance test with constant workload

- Symptom-limited incremental cycle ergometer exercise testing with electrocardiographic monitoring

- Echocardiography

- NT-pro-BNP

- Quality of life

Conclusion: "The "Off-Label" use of ivabradine significantly improves the exercise capacity, gas exchange, functional HF class, quality of life, and neurohormonal modulation in pts with ischemic CHF"

Notes

Funding for trial: "The authors received no financial support for the research and/or authorship of this article."

Notable conflicts of interest of authors: "The authors declare no conflicts of interest with respect to the authorship and/or publication of this article."

Contact to authors/unpublished data: We contacted F Sarullo via email on 22 November 2018 to ask for way of randomisation, number of centres, country, and missing data. F Sarullo answered on 22 November 2018, providing the information about randomisation, number of centres, country, and that no other unpublished data were available.

\section{Risk of bias}

\begin{tabular}{|c|c|c|}
\hline Bias & Authors' judgement & Support for judgement \\
\hline $\begin{array}{l}\text { Random sequence genera- } \\
\text { tion (selection bias) }\end{array}$ & Low risk & $\begin{array}{l}\text { "The procedure of randomization to receive either ivabradine } 5 \mathrm{mg} \text { or placebo } \\
\text { twice daily was performed by computerized sequence generation. " (F Sarullo } \\
\text { via email on } 22 \text { November 2018) }\end{array}$ \\
\hline $\begin{array}{l}\text { Allocation concealment } \\
\text { (selection bias) }\end{array}$ & Low risk & $\begin{array}{l}\text { "The tablets of ivabradine and placebo were prepared and placed before the } \\
\text { randomization in numbered anonymous bottles." (F Sarullo via email on } 22 \\
\text { November 2018) }\end{array}$ \\
\hline $\begin{array}{l}\text { Blinding of participants } \\
\text { and personnel (perfor- } \\
\text { mance bias) } \\
\text { All outcomes }\end{array}$ & High risk & "The single blind design was carried out..." \\
\hline $\begin{array}{l}\text { Blinding of outcome as- } \\
\text { sessment (detection bias) } \\
\text { All outcomes }\end{array}$ & Low risk & $\begin{array}{l}\text { No blinding. However, the measured outcomes are objective outcomes (mor- } \\
\text { tality, length of stay, etc.) and thus not likely to be influenced by lack of blind- } \\
\text { ing. }\end{array}$ \\
\hline $\begin{array}{l}\text { Incomplete outcome data } \\
\text { (attrition bias) } \\
\text { All outcomes }\end{array}$ & Unclear risk & Insufficient information to base judgement \\
\hline $\begin{array}{l}\text { Selective reporting (re- } \\
\text { porting bias) }\end{array}$ & Low risk & $\begin{array}{l}\text { All outcomes stated in the methods section were adequately reported or ex- } \\
\text { plained in the results. }\end{array}$ \\
\hline Other bias & Low risk & $\begin{array}{l}\text { "The authors received no financial support for the research and/or authorship } \\
\text { of this article." }\end{array}$ \\
\hline
\end{tabular}

\section{Study characteristics}


Sisakian 2016 (Continued)

Methods

\section{Study design: RCT}

Unit of randomisation: Computer-based randomisation

Total duration of study: No information

Run-in period: No information

Intervention time: 3 months

Follow-up: 3 months

Setting: Outpatient unit of the Department of General and Invasive Cardiology of University Hospital 1 of the Yerevan State Medical University

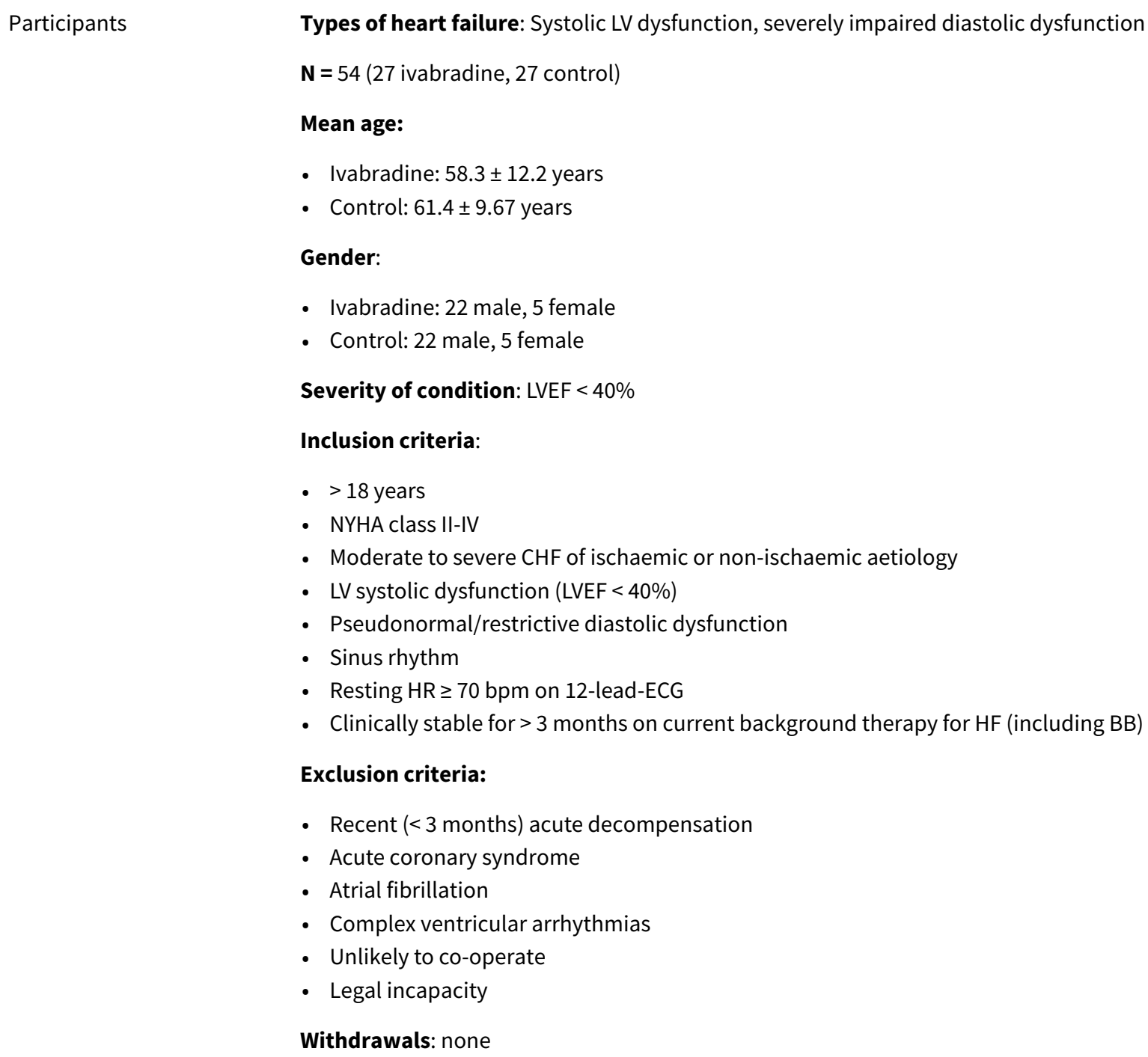

\section{Exclusion criteria:}

- Recent (<3 months) acute decompensation

- Acute coronary syndrome

- Atrial fibrillation

- Complex ventricular arrhythmias

- Unlikely to co-operate

- Legal incapacity

Withdrawals: none

- Ivabradine $5 \mathrm{mg}$ twice a day added on baseline therapy

- Adjusted up to $7.5 \mathrm{mg}$ if tolerated to achieve a resting $\mathrm{HR}<70 \mathrm{bpm}$

- Adjusted down to $2.5 \mathrm{mg}$ if $\mathrm{HR}<55 \mathrm{bpm}$

Comparison: Control 
Sisakian 2016 (Continued)

\section{Concomitant medication:}

- $B B$

- $A C E$ inhibitors

- ARB

- Diuretics

- Aldosterone antagonists

- Digitalis

Excluded medication: No information

\section{Outcomes}

\section{Outcomes and time points measured in the study:}

[Day 0, 3 months]

- E/A ratio

- E wave

- DT (deceleration time)

- LAVI (left atrial volume index)

- E/Em ratio

\section{Conclusion:}

"Treatment with ivabradine significantly improves LV diastolic function through reducing E/A ratio, E/ Em ratio and increasing DT in patients with systolic HF and severe diastolic dysfunction. These changes may contribute to the improvement of intracardiac haemodynamics with decrease of LAVI and improvement of LV filling. The beneficial effect of ivabradine on diastolic function may potentially contribute to the better clinical state and prognosis in patients with CHF."

Funding for trial: No information
Conflicts of interest: None to declare
Contact to authors/unpublished data: We contacted H Sisakian via email on 6 June 2020 to ask for
the randomisation tool used to allocate participants. H Sisakian answered on 10 June 2020 , providing
the information on the randomisation tool used.

\section{Risk of bias}

\begin{tabular}{|c|c|c|}
\hline Bias & Authors' judgement & Support for judgement \\
\hline $\begin{array}{l}\text { Random sequence genera- } \\
\text { tion (selection bias) }\end{array}$ & Low risk & "Yes, it was computer generated" (H Sisakian on 10 June 2020 via email) \\
\hline $\begin{array}{l}\text { Allocation concealment } \\
\text { (selection bias) }\end{array}$ & Low risk & $\begin{array}{l}\text { "Patients were empirically allocated" } \\
\text { "Yes, it was computer generated" (H Sisakian on } 10 \text { June } 2020 \text { via email) }\end{array}$ \\
\hline $\begin{array}{l}\text { Blinding of participants } \\
\text { and personnel (perfor- } \\
\text { mance bias) } \\
\text { All outcomes }\end{array}$ & Unclear risk & Insufficient information to base judgement \\
\hline
\end{tabular}

\begin{tabular}{lll}
\hline $\begin{array}{l}\text { Blinding of outcome as- } \\
\text { sessment (detection bias) }\end{array}$ & Unclear risk & Insufficient information to base judgement \\
$\begin{array}{ll}\text { All outcomes } \\
\text { Incomplete outcome data }\end{array}$ & Low risk & $\begin{array}{l}\text { Less than } 20 \% \text { missing data. Outcomes reported for } 54 \text { of } 54 \text { participants } \\
(100 \%) .\end{array}$
\end{tabular}


Sisakian 2016 (Continued)

All outcomes

Selective reporting (re- Unclear risk Insufficient information to base judgement
porting bias)

Other bias Unclear risk Insufficient information to base judgement

Swedberg 2010

\section{Study characteristics}

Study design: RCT
Unit of randomisation: No information
Total duration of study: 42 months (3 October 2006 to 31 March 2010)
Run-in period: 14 days
Intervention time: 1 year
Follow-up: 18 to 28 months
Setting: 677 centres in 37 countries

Participants

Type of heart failure: CHF, LV-dysfunction

$\mathbf{N}=6505$ (ivabradine and BB: 3241; placebo: 3264)

Mean age: $60.4 \pm 11.4$ years

Gender: 4970 (76.4\%) male, 1535 (23.6\%) female

Severity of condition: LVEF $\leq 35 \%$

Inclusion criteria:

- Symptomatic HF

- LVEF of $\leq 35 \%$

- Sinus rhythm with heart rate $\geq 70 \mathrm{bpm}$

- Had been admitted to hospital for HF within the previous year

- Were on stable background treatment including a BB if tolerated

\section{Exclusion criteria:}

- Recent (<2 months) MI

- Ventricular or atrioventricular pacing operative for $40 \%$ or more of the day

- Atrial fibrillation or flutter

- Symptomatic hypotension

- Patients have not been on optimum and stable background treatment for at least 4 weeks

- Non-dihydropyridine calcium-channel blockers

- Class I antiarrhythmics

- Strong inhibitors of cytochrome P450 3A4

Withdrawals: 131 participants $\left(N_{\text {new }}=6505\right)$ 
- The mean dosage was 6.4 (SD 1.6) mg twice a day at 28 days (end of titration) and 6.5 (SD 1.6) mg twice a day at 1 year

Comparison: Placebo

\section{Concomitant medications:}

- Renin-angiotensin-aldosterone system antagonists

- SC

\section{Excluded medications:}

- Non-dihydropyridine calcium-channel blockers

- Class I antiarrhythmics

- Strong inhibitors of cytochrome P450 3A4

Outcomes

\section{Outcomes and time points measured in the study:}

[Day 0, 1 year]

- $\mathrm{HR}$

- Primary endpoint:

* the composite of cardiovascular death or hospital admission for worsening HF

- Secondary endpoints:

* the composite of cardiovascular death or hospital admission for worsening HF in participants receiving at least $50 \%$ of the target daily dose of a BB (as defined by the European Society of Cardiology guidelines) at randomisation. (For metoprolol tartrate, for which a dose is not identified in the guidelines, the study authors defined the target dose as $150 \mathrm{mg}$ daily.)

* all-cause death

* cardiovascular death

* hospital admission for worsening HF

* all-cause admission to hospital

* cardiovascular admission

* death from HF

* the composite of cardiovascular death, hospital admission for worsening HF, or hospital admission for non-fatal MI

* $\mathrm{KCCQ}$

Conclusion: "Our results support the importance of heart-rate reduction with ivabradine for improvement of clinical outcomes in HF and confirm the important role of HR in the pathophysiology of this disorder"

- "Funding Servier, France"

- "The sponsor was responsible for data management and final data analyses. All analyses were verified by the independent statistical centre at Robertson Centre for Biostatistics, University of Glasgow, UK. The executive committee was responsible for the design of the study, the interpretation of the results, the development and writing of the report, and the decision to submit for publication and, after study conclusion and unmasking, had full access to all data. Members of the medical and scientific departments of the sponsor supported the work of the executive committee, but did not make any scientific or research decisions independent of this committee"

Notable conflicts of interest of authors: "KS, MK, MB, JSB, IF, and LT have received fees, research grants, or both from Servier. ADB and GL are employees of Servier. KS has received also research grants from Amgen and AstraZeneca, and honoraria from Amgen, Novartis, and AstraZeneca. MK has received consultancy fees from Nile Therapeutics and Bristol-Myers Squibb, and payment for service on speakers' bureau from Sanofi-Aventis, Menarini, Bristol-Myers Squibb, Merck, and AstraZeneca. IF has received fees from Medtronic, Biotronik, Solvay, Vifor Pharma, IKKF, and GlaxoSmithKline. MB has received fees AstraZeneca, Boehringer Ingelheim, Sanofi-Aventis, and Pfizer. JSB has received consult- 
Swedberg 2010 (Continued)

ing fees from Celladon, Gilead, Sanofi-Aventis, ARMGO, Novartis, Novacardia (Merck), BioMarin, Roche, Pfizer, Rigel, BioTronik, Salix, XOMA, Lux, Cardiopep, Bristol-Myers Squibb, and Cardioxyl. LT has received consultancy fees from Medtronic and Menarini, and payment service for speakers' bureau from Abbot, AstraZeneca, and Pfizer"

Contact to authors/unpublished data: We contacted K Swedberg via email on 22 November 2018 to ask for NYHA class and missing data. We did not receive an answer.

\section{Risk of bias}

\begin{tabular}{|c|c|c|}
\hline Bias & Authors' judgement & Support for judgement \\
\hline $\begin{array}{l}\text { Random sequence genera- } \\
\text { tion (selection bias) }\end{array}$ & Low risk & $\begin{array}{l}\text { "Patients were randomly allocated to treatment groups by computer-generat- } \\
\text { ed assignment." }\end{array}$ \\
\hline $\begin{array}{l}\text { Allocation concealment } \\
\text { (selection bias) }\end{array}$ & Low risk & $\begin{array}{l}\text { "The allocation sequence was generated at the sponsor level through validat- } \\
\text { ed in-house application software; access was restricted to people responsible } \\
\text { for study therapeutic units production until database lock." }\end{array}$ \\
\hline $\begin{array}{l}\text { Blinding of participants } \\
\text { and personnel (perfor- } \\
\text { mance bias) } \\
\text { All outcomes }\end{array}$ & Low risk & "Double-blind trial" \\
\hline $\begin{array}{l}\text { Blinding of outcome as- } \\
\text { sessment (detection bias) } \\
\text { All outcomes }\end{array}$ & Unclear risk & $\begin{array}{l}\text { No blinding. However, the measured outcomes are objective outcomes (mor- } \\
\text { tality, length of stay, etc.) and thus not likely to be influenced by lack of blind- } \\
\text { ing. }\end{array}$ \\
\hline $\begin{array}{l}\text { Incomplete outcome data } \\
\text { (attrition bias) } \\
\text { All outcomes }\end{array}$ & Low risk & $\begin{array}{l}\text { Less than } 20 \% \text { missing data. Outcomes reported for } 6505 \text { of } 6558 \text { participants } \\
(99.2 \%) .\end{array}$ \\
\hline $\begin{array}{l}\text { Selective reporting (re- } \\
\text { porting bias) }\end{array}$ & Low risk & $\begin{array}{l}\text { All outcomes stated in the methods section were adequately reported or ex- } \\
\text { plained in the results. }\end{array}$ \\
\hline Other bias & Unclear risk & $\begin{array}{l}\text { "Members of the medical and scientific departments of the sponsor support- } \\
\text { ed the work of the executive committee, but did not make any scientific or re- } \\
\text { search decisions independent of this committee." }\end{array}$ \\
\hline
\end{tabular}

Tatarchenko 2008

\section{Study characteristics}

\begin{tabular}{ll}
\hline Methods & Study design: RCT \\
& Unit of randomisation: No information \\
& Total duration of study: No information \\
& Run-in period: No information \\
& Intervention time: No information \\
& Follow-up: No information \\
& Setting: No information \\
\hline Participants & Type of heart failure: CHF, LV-dysfunction \\
\hline
\end{tabular}


Tatarchenko 2008 (Continued)

$\mathbf{N}=92$ (ivabradine: 29 , nebivolol: 33, SC: 30 )

Mean age: $57.3 \pm 4.5$ years

Gender: No information

Severity of condition: No information

Inclusion criteria:

- $\mathrm{CHF}$

- NYHA II-III

Exclusion criteria: No information

Withdrawals: No information

\section{Comparison:}

- Standard care

- Nebivolol $5 \mathrm{mg} / \mathrm{d}$

Concomitant medications:

- ACE inhibitors

- Diuretics

- Aspirins

- Statins

- Nitrates on demand

Excluded medications: No information

Outcomes and time points measured in the study:
- QoL
- Circadian indices of myocardial ischaemia
- Left ventricular contractility
Conclusion: "Addition of ivabradin and nebivolol to combined treatment of ischemic heart disease
with LV dysfunction raises efficacy of treatment."

Notes

Funding of trial: No information

Notable conflicts of interest of authors: No information

Contact to authors/unpublished data: No information

\section{Risk of bias}

\begin{tabular}{lll}
\hline Bias & Authors' judgement & Support for judgement \\
\hline $\begin{array}{l}\text { Random sequence genera- } \\
\text { tion (selection bias) }\end{array}$ & Unclear risk & Insufficient information to base judgement \\
\hline $\begin{array}{l}\text { Allocation concealment } \\
\text { (selection bias) }\end{array}$ & Unclear risk & Insufficient information to base judgement \\
\hline $\begin{array}{l}\text { Blinding of participants } \\
\text { and personnel (perfor- } \\
\text { mance bias) }\end{array}$ & High risk & Blinding impossible due to comparison with SC. \\
\hline
\end{tabular}

Ivabradine as adjuvant treatment for chronic heart failure (Review) 
Tatarchenko 2008 (Continued)

All outcomes

Blinding of outcome as-
sessment (detection bias) $\quad$ Unclear risk Insufficient information to base judgement

sessment (detection bias)

All outcomes

Incomplete outcome data Unclear risk Insufficient information to base judgement

(attrition bias)

All outcomes

\begin{tabular}{lll}
\hline $\begin{array}{l}\text { Selective reporting (re- } \\
\text { porting bias) }\end{array}$ & Unclear risk & Insufficient information to base judgement \\
\hline Other bias & Unclear risk & Insufficient information to base judgement \\
\hline
\end{tabular}

Tsutsui 2016

\section{Study characteristics}

Methods

Study design: RCT

Unit of randomisation: No information

Total duration of study: 15 months (December 2013 to February 2015)

Run-in period: 2 weeks

Intervention time: 6 weeks

Follow-up: 2 weeks

Setting: 73 institutions in Japan

Participants

Type of heart failure: CHF, LV-dysfunction

$\mathbf{N}=126$ (ivabradine and BB: 84; placebo: 42)

Mean age: $59 \pm 13.1$ years

Gender: 108 (85.7\%) male, 18 (14.3\%) female

Severity of condition: $\mathrm{HFrEF} \leq 35 \%$

\section{Inclusion criteria:}

- Age $\geq 20$ years

- Resting HR $\geq 75$ bpm in sinus rhythm

- Stable symptomatic CHF of NYHA functional class $\geq$ II

- $\operatorname{LVEF} \leq 35 \%$

- Under optimal, stable treatment according to the Japanese Guideline for Treatment of CHF (Matsuzaki 2010)

\section{Exclusion criteria:}

- Congenital heart disease

- Ml within 2 months

- Persistent atrial fibrillation or atrial flutter

- Sick sinus syndrome

- Sinoatrial node block or second- or third-degree atrioventricular block 
Tsutsui 2016 (Continued)

- Atrioventricular pacing operative for $\geq 40 \%$ of the day or with backup pacing rate $\geq 60 \mathrm{bpm}$

- Severe or uncontrolled hypertension or symptomatic hypotension

- Moderate or severe hepatic disease

- Severe renal disease

- Anaemia

\section{Withdrawals:}

- 4 withdrawals

- Additionally 3 participants ( 1 in the $2.5 \mathrm{mg}$ group and 2 in the $5 \mathrm{mg}$ group) were excluded for violation of the major inclusion criteria

Interventions

\section{Intervention:}

- Starting dose of ivabradine $2.5 \mathrm{mg}$ twice a day (2.5 mg group); $5 \mathrm{mg}$ twice a day group. The dose was increased up to $7.5 \mathrm{mg}$ twice a day.

- The final mean doses at 6 weeks were similar between the $2.5 \mathrm{mg}$ and $5 \mathrm{mg}$ groups $(6.5 \pm 1.8 \mathrm{mg}$ twice a day vs $7.1 \pm 1.1 \mathrm{mg}$ twice a day, $\mathrm{P}=0.416$ )

Comparison: Placebo

\section{Concomitant medications:}

- $S C$

- ACE inhibitor

- Angiotensin-receptor blocker

- $\mathrm{BB}$

- Mineralocorticoid receptor antagonist

- Diuretics

- Digitalis

\section{Excluded medications:}

- Non-dihydropyridine calcium-channel blockers

- Class I antiarrhythmics

- Moderate or strong inhibitors of cytochrome P450 3A4

Outcomes

Outcomes and time points measured in the study:

$[0,6$ weeks $]$

Primary endpoint:

- Reduction in resting HR from baseline at the 6-week treatment

Secondary endpoint:

- Change in NYHA functional class

- LVEF

- Concentrations of plasma B-type natriuretic peptide (BNP)

- NT-pro-BNP

Conclusion: "Ivabradine starting at 2.5 or $5 \mathrm{mg}$ BID effectively reduced resting HR in Japanese HF patients. Ivabradine at the starting dose of $2.5 \mathrm{mg}$ BID could be safer than $5 \mathrm{mg}$ BID."

Notes

Funding for trial: "This trial was designed and performed by the sponsor (Ono Pharmaceutical)."

Notable conflicts of interest of authors: "The data were collected and analyzed and the first draft manuscript was written by the sponsor. It was fully reviewed and revised by the authors." 
Tsutsui 2016 (Continued)

Contact to authors/unpublished data: We contacted H Tsuitsui via email on 22 November 2018 to ask for way of randomisation and missing data. H Tsuitsui answered on 26 November 2018, providing information about method of randomisation and that there were no additional data.

\section{Risk of bias}

\begin{tabular}{lll}
\hline Bias & Authors' judgement & Support for judgement \\
\hline $\begin{array}{l}\text { Random sequence genera- } \\
\text { tion (selection bias) }\end{array}$ & Low risk & $\begin{array}{l}\text { "We used a computer-based dynamic allocation method by baseline resting } \\
\text { heart rate and the dose of beta-blocker to balance the baseline." (H Tsuitsui } \\
\text { via email on 22 November 2018) }\end{array}$ \\
\hline
\end{tabular}

\begin{tabular}{lll}
\hline $\begin{array}{l}\text { Allocation concealment } \\
\text { (selection bias) }\end{array}$ & Unclear risk & Insufficient information to base judgement \\
\hline $\begin{array}{l}\text { Blinding of participants } \\
\text { and personnel (perfor- } \\
\text { mance bias) }\end{array}$ & Low risk & "The pts and investigators were masked to the treatment allocation." \\
All outcomes & \\
\hline
\end{tabular}

\begin{tabular}{|c|c|c|}
\hline $\begin{array}{l}\text { Blinding of outcome as- } \\
\text { sessment (detection bias) } \\
\text { All outcomes }\end{array}$ & Unclear risk & Insufficient information to base judgement \\
\hline $\begin{array}{l}\text { Incomplete outcome data } \\
\text { (attrition bias) } \\
\text { All outcomes }\end{array}$ & Low risk & $\begin{array}{l}\text { Less than } 20 \% \text { missing data. Outcomes reported for } 122 \text { of } 126 \text { participants } \\
(96.8 \%) .\end{array}$ \\
\hline $\begin{array}{l}\text { Selective reporting (re- } \\
\text { porting bias) }\end{array}$ & Low risk & $\begin{array}{l}\text { All outcomes stated in the methods section were adequately reported or ex- } \\
\text { plained in the results. }\end{array}$ \\
\hline Other bias & Unclear risk & $\begin{array}{l}\text { "This trial was designed and performed by the sponsor (Ono Pharmaceutical). } \\
\text { The data were collected and analyzed and the first draft manuscript was writ- } \\
\text { ten by the sponsor. It was fully reviewed and revised by the authors." }\end{array}$ \\
\hline
\end{tabular}

Tsutsui 2019

\section{Study characteristics}

\begin{tabular}{|c|c|}
\hline Methods & $\begin{array}{l}\text { Study design: RCT } \\
\text { Unit of randomisation: No information } \\
\text { Total duration of study: } 35 \text { months (October } 2016 \text { to August 2019) } \\
\text { Run-in period: } 2 \text { weeks } \\
\text { Intervention time: } 52 \text { weeks } \\
\text { Follow-up: } 52 \text {-week follow-up of the last enrolled patient. } \\
\text { Setting: } 146 \text { institutions in Japan }\end{array}$ \\
\hline Participants & $\begin{array}{l}\text { Type of heart failure: CHF, LV-dysfunction } \\
\mathbf{N}=254 \text { (ivabradine } 127 ; \mathrm{PC}: 127 \text { ) } \\
\text { Mean age: } 60.6 \pm 13.5 \text { years }\end{array}$ \\
\hline
\end{tabular}


Gender: 209 (82.4\%) male, 45 (17.6) female

Severity of condition: $\mathrm{HFrEF} \leq 35 \%$

Inclusion criteria:

- Age $\geq 20$ years

- Optimised and unchanged medications and dosages for $\mathrm{CHF} \geq 4$ weeks

- NYHA functional class II, III, or IV $\geq 4$ weeks, and stable clinical condition $\geq 4$ weeks

- LVEF 35\% within the previous 12 weeks

- Resting heart rate $\geq 75$ beats/min in sinus rhythm

- A history of hospital admission for worsening heart failure within the previous 52 weeks

\section{Exclusion criteria:}

- Myocardial infarction or coronary revascularisation within the previous 8 weeks

- Severe primary valvular disease or scheduled surgery for valvular heart disease

- Stroke or transient cerebral ischaemia within the previous 4 weeks

- Active myocarditis

- Congenital heart diseases

- Heart transplantation candidates

- Cardiac resynchronisation therapy within the previous 24 weeks

- Pacemaker with atrial or ventricular pacing (except for biventricular pacing) $>40 \%$ of the day, or with stimulation threshold at the atrial or ventricular level $\geq 60 \mathrm{bpm}$

- Persistent atrial fibrillation or flutter

- Sick sinus syndrome, sinoatrial block, second- and third-degree atrioventricular block

- Symptomatic or sustained ( $\geq 30 \mathrm{~s}$ ) ventricular tachycardia unless a cardioverter/defibrillator is implanted

- Cardioverter/defibrillator shock within the previous 24 weeks

- Family history or congenital long QT syndrome or treated with selected QT-prolonging drugs

- Severe or uncontrolled hypertension (SBP > $180 \mathrm{mmHg}$ or DBP > $110 \mathrm{mmHg}$ )

- Hypotension (sitting SPB $<85 \mathrm{mmHg}$ or symptomatic hypotension)

- Moderate or severe liver disease, severe renal disease, or anaemia

Withdrawals:

- 11 withdrawals

- 2 lost to follow-up

- Starting dose of ivabradine $2.5 \mathrm{mg}$ twice a day. The dose was adjusted at each visit up to $7.5 \mathrm{mg}$ twice a day.

Comparison: Placebo

\section{Concomitant medications:}

- BB (carvedilol, bisoprolol)

\section{Excluded medications:}

- BB (other than carvedilol, bisoprolol)

- Non-dihydropyridine calcium-channel blockers

- Class I antiarrhythmics

- moderate and strong cytochrome P450 3A4 inhibitors

- Cytochrome P340 3A4 inducers

- unapproved drugs 
Tsutsui 2019 (Continued)

Outcomes

Outcomes and time points measured in the study:

- Primary endpoints:

* composite of cardiovascular death

* hospital admission for worsening HF

- Secondary endpoints

* all-cause cardiovascular, or HF death

* hospital admission for all causes

* cardiovascular causes or worsening HF, and a composite of cardiovascular death, hospital admission for worsening HF, or hospital admission for non-fatal myocardial infarction

* Changes in resting HR

* Changes in NYHA functional class

* LVEDV index

* LVESV index

* LVEF

* BNP and NT-pro-BNP

\section{Conclusion:}

"In conclusion, ivabradine had efficacy and safety in Japanese patients with HFrEF, consistent with the SHIFT study."

Notable conflicts of interests: "H.T. received remuneration from Otsuka, Takeda, Mitsubishi Tanabe, Daiichi Sankyo, Boehringer Ingelheim Japan, Bayer, and Pfizer; research funding from Boehringer Ingelheim Japan and Mitsubishi Tanabe; and scholarship funds from MSD, Daiichi Sankyo, Sankyo, Mitsubishi Tanabe, Otsuka, Bayer, and Boehringer Ingelheim; scholarship funds from Daiichi Sankyo, Mitsubishi Tanabe, Otsuka, Bayer, Boehringer Ingelheim, Takeda, Mochida, and Ono Pharma Co.; and is affiliated with an endowed department sponsored by Medtronic Japan. M.Y. received remuneration and scholarship funds from Ono Pharmaceutical Co. Ltd. K.Y. received remuneration from Otsuka Pharmaceutical Co. Ltd., Takeda Pharmaceutical Co. Ltd., Ono Pharmaceutical Co. Ltd., Daiichi Sankyo Co. Ltd., and Mitsubishi Tanabe Pharma Co. Ltd; and scholarship funds from St. Jude Medical Japan Co. Ltd., Otsuka Pharmaceutical Co. Ltd., Daiichi Sankyo Co. Ltd., Johnson \& Johnson, Biotronik Japan Inc., Japan Lifeline Co. Ltd., Teijin Pharma Ltd., Mitsubishi Tanabe Pharma Co. Ltd., Fukuda Denshi, Takeda Pharmaceutical Co. Ltd., Nihon Kohden Co. Ltd. Novartis, Pfizer Inc, and Boston Scientific Co. Ltd. Y. Sakata received remuneration from Otsuka Pharmaceutical and Daiichi Sankyo, and scholarship funds from Ono Pharmaceutical. T.T. and Y. Kawasaki are employees of Ono Pharmaceutical. The remaining authors have nothing to disclose."

Contact to authors/unpublished data: No information

\section{Risk of bias}

Bias Authors' judgement Support for judgement

Random sequence genera- Low risk tion (selection bias)
"A minimization method for dynamic allocation was used with adjustment for study site, baseline resting HR ( $\geq 85$ and $<85$ beats $/ \mathrm{min}$ ), and $\beta$-blocker dose before study treatment $(0,>0-<50$, and $\geq 50 \%$ of the target dose of carvedilol $20 \mathrm{mg} /$ day and bisoprolol $5 \mathrm{mg} /$ day) to balance baseline covariates."

\begin{tabular}{lll}
\hline $\begin{array}{l}\text { Allocation concealment } \\
\text { (selection bias) }\end{array}$ & Unclear risk & Insufficient information to base judgement \\
\hline $\begin{array}{l}\text { Blinding of participants } \\
\text { and personnel (perfor- }\end{array}$ & Low risk & $\begin{array}{l}\text { Participants and investigators were masked to treatment allocation, and study } \\
\text { medications (ivabradine or placebo) were the same size and colour. }\end{array}$
\end{tabular}

mance bias)

All outcomes 
Tsutsui 2019 (Continued)

\begin{tabular}{|c|c|c|}
\hline $\begin{array}{l}\text { Blinding of outcome as- } \\
\text { sessment (detection bias) } \\
\text { All outcomes }\end{array}$ & Low risk & $\begin{array}{l}\text { "An endpoint adjudication committee, independent from the sponsor and } \\
\text { ivestigators, evaluated all clinical events according to prespecified definitions } \\
\text { in a blinded manner" }\end{array}$ \\
\hline
\end{tabular}

\begin{tabular}{|c|c|c|}
\hline $\begin{array}{l}\text { Incomplete outcome data } \\
\text { (attrition bias) } \\
\text { All outcomes }\end{array}$ & Low risk & $\begin{array}{l}\text { Less than } 20 \% \text { missing data. Outcomes reported for } 253 \text { of } 254 \text { participants } \\
(99.6 \%) \text {. }\end{array}$ \\
\hline $\begin{array}{l}\text { Selective reporting (re- } \\
\text { porting bias) }\end{array}$ & Low risk & $\begin{array}{l}\text { All outcomes stated in the methods section were adequately reported or ex- } \\
\text { plained in the results. }\end{array}$ \\
\hline Other bias & Unclear risk & $\begin{array}{l}\text { "This trial was designed and performed by the sponsor, Ono Pharmaceutical } \\
\text { Co., Ltd. The data were collected and analyzed, and the first draft manuscript } \\
\text { was written by the sponsor." }\end{array}$ \\
\hline
\end{tabular}

Tumasyan 2016

\section{Study characteristics}

\begin{tabular}{ll}
\hline Study design: RCT \\
Unit of randomisation: No information \\
Total duration of study: No information \\
Run-in period: No information \\
Intervention time: 3 years \\
Follow-up: No information \\
Setting: Institute of Cardiology, Yerevan, Armenia
\end{tabular}

\section{Participants}

Type of heart failure: CHF, LV-dysfunction

$\mathbf{N}=106$ (ivabradine and BB: 53; SC: 53)

Mean age: $57.4 \pm 0.4$ years

Gender: No information

Severity of condition: $\mathrm{HFrEF}<40 \%$

Inclusion criteria: NYHA class III-IV

Exclusion criteria: No information

Withdrawals: No information

Intervention: Ivabradine max. 7.5 mg twice a day
Comparison: SC
Concomitant medications:
- ACE inhibitors
- BB
- Digoxin
Diuretics


Excluded medications: No information

Outcomes and time points measured in the study:
[0 d, 3,6,12, 24, 36 months]
- Mortality
- Hospitalisation rate
- RV EF
- Fractional area change
- Tricuspid annulus plane systolic excursion
- Fractional contribution
- Relation of pulmonary vein
- Systolic and diastolic fraction
- Systolic contribution
- Difference between duration of reversal atrial flow and late transmittal filling
- Pulmonary artery ejection time
- BNP
- NT-pro-BNP
- C-reactive protein levels

\section{Conclusion:}

- Decrease of BNP, NT-pro-BNP $\geq 50 \%, C$-reactive protein levels and changes in duration of reversal atrial flow and late transmittal filling $\geq 40 \%, \mathrm{HR} \geq 30 \%$ and increase of RA and LA functional index $\geq 80 \%$, fractional contribution, RV EF and fractional area change $\geq 40 \%$, pulmonary vein systolic contribution $\geq 50 \%$ identified pts with cardiac events reduction

- Ivabradine use associated with lower mortality and morbidity due to significant improvement of right heart and LA functional parameters, neurohormonal and inflammation status, and HR reduction

Notes

Funding for trial: No information

Notable conflicts of interest of authors: No information

Contact to authors/unpublished data: We contacted KG Adamyan and S Grigoryan via email on 22 November 2018 to ask for funding, country, number of centres, and missing data. The email to KG Adamyan failed, but S Grigoryan answered that she had forwarded the email to the correct email address. Nevertheless, we did not receive an answer.

\section{Risk of bias}

\begin{tabular}{lll}
\hline Bias & Authors' judgement & Support for judgement \\
\hline $\begin{array}{l}\text { Random sequence genera- } \\
\text { tion (selection bias) }\end{array}$ & Unclear risk & Insufficient information to base judgement \\
\hline $\begin{array}{l}\text { Allocation concealment } \\
\text { (selection bias) }\end{array}$ & Unclear risk & Insufficient information to base judgement \\
\hline
\end{tabular}

Blinding of participants

High risk Blinding impossible due to comparison with SC. and personnel (performance bias)

All outcomes

\begin{tabular}{|c|c|c|}
\hline $\begin{array}{l}\text { Blinding of outcome as- } \\
\text { sessment (detection bias) } \\
\text { All outcomes }\end{array}$ & Unclear risk & Insufficient information to base judgement \\
\hline
\end{tabular}


Tumasyan 2016 (Continued)

Incomplete outcome data Unclear risk Insufficient information to base judgement
(attrition bias)

All outcomes

Selective reporting (re- Unclear risk Insufficient information to base judgement
porting bias)

\begin{tabular}{|c|c|c|}
\hline Other bias & Unclear risk & Insufficient information to base judgement \\
\hline
\end{tabular}

Tumasyan 2017

\section{Study characteristics}

\begin{tabular}{|c|c|}
\hline \multirow[t]{7}{*}{ Methods } & Study design: $\mathrm{RCT}$ \\
\hline & Unit of randomisation: No information \\
\hline & Total duration of study: No information \\
\hline & Run-in period: No information \\
\hline & Intervention time: No information \\
\hline & Follow-up: No information \\
\hline & Setting: No information \\
\hline \multirow[t]{11}{*}{ Participants } & Type of heart failure: $\mathrm{CHF}$ \\
\hline & $\mathbf{N}=165$ participants (digoxin: 55; ivabradine and BB: 53; SC: 57) \\
\hline & Mean age: 63.2 years \\
\hline & Gender: No information \\
\hline & Severity of condition: No information \\
\hline & Inclusion criteria: \\
\hline & - NYHA III \\
\hline & - Preserved LVEF \\
\hline & - $\mathrm{HR} \geq 70 \mathrm{bpm}$ \\
\hline & Exclusion criteria: No information \\
\hline & Withdrawals: No information \\
\hline
\end{tabular}

Interventions

Intervention: Ivabradine max. $7.5 \mathrm{mg}$ twice a day

\section{Comparison:}

- Digoxin $0.25 \mathrm{mg}$ twice a day

- No treatment

\section{Concomitant medications:}

- ACE inhibitors

- BB

- Diuretics 
Excluded medications: No information

\section{Outcomes \\ Outcomes and time points measured in the study:}

[Day 0, Month 12, 24, and 36]

- LV, RV, LA, RA atrial parameters

- NT-pro-BNP

- High sensitivity C-reactive protein levels

- RV fractional area change

- Tricuspid annulus plane systolic excursion

- Pulmonary artery ejection time

- RA and LA functional index

- Relation of pulmonary vein systolic and diastolic fraction

- PV systolic contribution

- Difference between duration of reversal atrial flow and late transmitral filling

\section{Conclusion:}

- Changes of duration of reversal atrial flow and late transmittal filling $\geq 80 \%$, RA and LA functional index, PV systolic contribution $\geq 50 \%$, NT-pro-BNP, high sensitivity C-reactive protein levels $\geq 40 \%$; pulmonary artery ejection time and $\mathrm{HR} \geq 25 \%$ identified pts with hospitalisation risk reduction

- Ivabradine and digoxin use associated with similar significant reduction of morbidity and trend of reduction of mortality due to significant improvement of RV, LA and RA functional parameters, neurohormonal and inflammation status, and HR reduction

Funding for trial: No information
Notable conflicts of interest of authors: No information
Contact to authors/unpublished data: We contacted KG Adamyan and S Grigoryan via email on 22
November 2018 to ask for funding, country, number of centres, and missing data. The email to KG
Adamyan failed, but S Grigoryan answered that she had forwarded the email to the correct email ad-
dress. Nevertheless, we did not receive an answer.

\section{Risk of bias}

\begin{tabular}{lll}
\hline Bias & Authors' judgement & Support for judgement \\
\hline $\begin{array}{l}\text { Random sequence genera- } \\
\text { tion (selection bias) }\end{array}$ & Unclear risk & Insufficient information to base judgement \\
\hline $\begin{array}{l}\text { Allocation concealment } \\
\text { (selection bias) }\end{array}$ & Unclear risk & Insufficient information to base judgement \\
\hline $\begin{array}{l}\text { Blinding of participants } \\
\begin{array}{l}\text { and personnel (perfor- } \\
\text { mance bias) }\end{array}\end{array}$ & High risk & Blinding impossible due to comparison with SC. \\
All outcomes & \\
\hline
\end{tabular}

Blinding of outcome as-
$\begin{aligned} & \text { sessment (detection bias) } \\ & \text { All outcomes }\end{aligned}$ Unclear risk Insufficient information to base judgement

Incomplete outcome data Unclear risk Insufficient information to base judgement


Tumasyan 2017 (Continued)

Selective reporting (re- Unclear risk Insufficient information to base judgement
porting bias)

Other bias

Unclear risk

Insufficient information to base judgement

Tumasyan 2018

\section{Study characteristics}

\begin{tabular}{|c|c|}
\hline \multirow[t]{7}{*}{ Methods } & Study design: RCT \\
\hline & Unit of randomisation: No information \\
\hline & Total duration of study: No information \\
\hline & Run-in period: No information \\
\hline & Intervention time: No information \\
\hline & Follow-up: No information \\
\hline & Setting: No information \\
\hline \multirow[t]{11}{*}{ Participants } & Type of heart failure: $\mathrm{CHF}$ \\
\hline & $\mathbf{N}=135$ (digoxin: 44; ivabradine: 46; SC: 45) \\
\hline & Mean age: 60.1 years \\
\hline & Gender: No information \\
\hline & Severity of condition: No information \\
\hline & Inclusion criteria: \\
\hline & - NYHA III-IV \\
\hline & - Symptomatic HFmrEF \\
\hline & - $\mathrm{HR}>70 \mathrm{bpm}$ \\
\hline & Exclusion criteria: No information \\
\hline & Withdrawals: No information \\
\hline \multirow[t]{9}{*}{ Interventions } & Intervention: Ivabradine $15 \mathrm{mg}$ twice a day \\
\hline & Comparison: \\
\hline & - Digoxin $0.25 \mathrm{mg}$ twice a day \\
\hline & - Standard care \\
\hline & Concomitant medications: \\
\hline & - ACE inhibitors \\
\hline & - $\mathrm{BB}$ \\
\hline & - Diuretics \\
\hline & Excluded medications: No information \\
\hline
\end{tabular}


Tumasyan 2018 (Continued)

[Day 0, Month 12, 24, and 36]

- LV, RV, LA, RA atrial parameters

- NT-pro-BNP

- High sensitivity C-reactive protein levels

- Tricuspid annulus annular systolic velocity

- Tricuspid annulus plane systolic excursion

- LV mean e'septal and lateral wall

- Pulmonary artery ejection time

- RA and LA functional index

- Pulmonary vein systolic contribution

- Difference between duration of reversal atrial flow and late transmitral filling

\section{Conclusion:}

"1) Changes of Ar-A = 50\%, RAFI and LAFI, s', e $e^{c}=50 \%$, NT-pro-BNP, hsCRP $=40 \%$; PAET and HR $=25 \%$ identified pts with cardiovascular risk reduction.2) I and D use associated with almost similar significant reduction of morbidity and mortality. 3) Prognostic Improvement, associated with I use, was due to significant decrease of HR and NT-pro-BNP level, and RV functional parameters improvement while $D$ treatment resulted to HR reduction, improvement of LA and RA functional, LV diastolic parameters, neurohormonal and inflammation status"

Notes

Funding for trial: No information

Notable conflicts of interest of authors: No information

Contact to authors/unpublished data: None

\section{Risk of bias}

\begin{tabular}{|c|c|c|}
\hline Bias & Authors' judgement & Support for judgement \\
\hline $\begin{array}{l}\text { Random sequence genera- } \\
\text { tion (selection bias) }\end{array}$ & Unclear risk & Insufficient information to base judgement \\
\hline $\begin{array}{l}\text { Allocation concealment } \\
\text { (selection bias) }\end{array}$ & Unclear risk & Insufficient information to base judgement \\
\hline $\begin{array}{l}\text { Blinding of participants } \\
\text { and personnel (perfor- } \\
\text { mance bias) } \\
\text { All outcomes }\end{array}$ & High risk & Blinding impossible due to comparison with SC. \\
\hline $\begin{array}{l}\text { Blinding of outcome as- } \\
\text { sessment (detection bias) } \\
\text { All outcomes }\end{array}$ & Unclear risk & Insufficient information to base judgement \\
\hline $\begin{array}{l}\text { Incomplete outcome data } \\
\text { (attrition bias) } \\
\text { All outcomes }\end{array}$ & Unclear risk & Insufficient information to base judgement \\
\hline $\begin{array}{l}\text { Selective reporting (re- } \\
\text { porting bias) }\end{array}$ & Unclear risk & Insufficient information to base judgement \\
\hline Other bias & Unclear risk & Insufficient information to base judgement \\
\hline
\end{tabular}

Abbreviations: $\mathrm{ACE}=$ Angiotensin-converting enzyme, $\mathrm{AT} 1=$ angiotensin II type $1, \mathrm{ARB}=$ angiotensin receptor blockers, $\mathrm{BB}=$ beta-blockers, $\mathrm{BID}=$ twice daily, $\mathrm{BNP}=$ brain natriuretic peptide, $\mathrm{BP}=$ blood pressure, $\mathrm{bpm}=$ beats per minute, $\mathrm{CHF}=$ chronic heart failure, $\mathrm{DBP}=$ diastolic 
blood pressure, $\mathrm{e}^{\prime}=$ Early diastolic mitral annulus velocity, $E / A$ = ratio of peak velocity blood flow from gravity in early diastole to peak velocity flow in late diastole caused by atrial contraction, $\mathrm{E} / \mathrm{Em}=$ the ratio of $\mathrm{E}$ and the velocity of the mitral annulus early diastolic wave, $\mathrm{ECG}=$ electrocardiogram, $\mathrm{EF}=$ ejection fraction, $\mathrm{HF}=$ heart failure, $\mathrm{HFmrEF}=$ heart failure with mid-range ejection fraction, $\mathrm{HFnEF}=$ heart failure with normal ejection fraction, $\mathrm{HFpEF}=$ heart failure with preserved ejection fraction, $\mathrm{HFrEF}=$ heart failure with reduced ejection fraction, $\mathrm{HR}=$ heart rate, $\mathrm{HRV}=$ Heart rate variability, $\mathrm{IP}=$ interventional product, $\mathrm{KCCQ}=$ Kansas City Cardiomyopathy Questionnaire, LA $=$ left atrial, LV = left ventricular, LVEDV = LV end-diastolic volume, LVEF = Left ventricular ejection fraction, LVESV $=\mathrm{LV}$ end-systolic volume, max. $=$ maximum, MET $=$ Muscle Energy Technique (physical therapy), $\mathrm{MI}=$ myocardial infarction, $\mathrm{MPI}=$ Myocardial Performance Index, $\mathrm{N}=$ number of participants, NT-pro-BNP $=\mathrm{N}$-terminal pro brain natriuretic peptide, NYHA $=$ New York Heart Association, $\mathrm{PEF}=$ preserved ejection fraction, pts = patients, $\mathrm{PV}=$ pulmonary vein, $\mathrm{pVO2}=$ peak oxygen uptake, $\mathrm{Qol}=$ quality of life, $\mathrm{QT}$ interval = time of ventricular activity including both depolarisation and repolarisation, RA = right atrial, RCT = randomised controlled trial, RR- interval $=$ beat-to-beat interval, $\mathrm{RV}=$ right ventricular, $\mathrm{SBP}=$ systolic blood pressure, $\mathrm{SC}=$ standard care, $\mathrm{SD}=$ standard deviation

\section{Characteristics of excluded studies [ordered by study ID]}

\begin{tabular}{|c|c|}
\hline Study & Reason for exclusion \\
\hline Aalbers 2012 & Study design (no RCT) \\
\hline Abdel-Salam 2015 & Type of participants (focus on cardiomyopathy, not heart failure alone) \\
\hline Adamyan 2010 & Study design (no RCT) \\
\hline Adamyan 2011 & Type of intervention (comparator BB, not placebo or SC) \\
\hline Adamyan 2013 & Type of intervention (comparator BB, not placebo or SC) \\
\hline Adamyan 2015b & Type of participants (focus on atrial fibrillation, not heart failure) \\
\hline Al 2013 & Study design (no RCT) \\
\hline Amosova 2011a & Study design (no RCT) \\
\hline Amosova 2011b & Study design (no RCT) \\
\hline Amosova 2012a & Study design (no RCT) \\
\hline Amosova $2012 b$ & Study design (no RCT) \\
\hline Amosova 2014 & Study design (no RCT) \\
\hline Cavusoglu 2012 & Type of intervention (ivabradine plus dobutamine) \\
\hline Cavusoglu 2015 & Type of intervention (ivabradine plus dobutamine) \\
\hline Chumburidze 2013 & Study design (no RCT) \\
\hline CN-01908706 2018 & Types of participants \\
\hline Cocco 2013 & Type of intervention (comparator BB, not placebo or SC) \\
\hline Cullington 2011 & Study design (no RCT) \\
\hline De 2014 & Study design (no RCT) \\
\hline De Ferrari 2008 & Study design (no RCT) \\
\hline EUCTR2011-002520-40-IT & Prematurely ended \\
\hline
\end{tabular}




\begin{tabular}{|c|c|}
\hline Study & Reason for exclusion \\
\hline Fomin 2016 & Type of intervention (comparator BB, not placebo or SC) \\
\hline Gallet 2014 & Study design (no RCT) \\
\hline Gurcagan 2015 & Study design (no RCT) \\
\hline Hidalgo 2015a & Study design (no RCT) \\
\hline Hidalgo 2015b & Study design (no RCT) \\
\hline Hidalgo 2016a & Study design (no RCT) \\
\hline Hidalgo 2016b & Study design (no RCT) \\
\hline Hidalgo 2018 & Study design (no RCT) \\
\hline Iliuta 2014 & Study design (no RCT) \\
\hline Kanorsky 2016 & Type of intervention (comparator BB, not placebo or SC) \\
\hline Kosheleva 2010 & Type of participants (focus on congestive heart failure) \\
\hline Lofrano-Alves 2015 & Study design (no RCT) \\
\hline Lutay 2012 & Type of participants (focus on myocardial infarction) \\
\hline Mansour 2011 & Type of participants (focus on cardiomyopathy, not heart failure alone) \\
\hline Mert 2017 & Study design (no RCT) \\
\hline Nguyen 2017 & Study design (no RCT) \\
\hline Ozturk 2016 & Study design (no RCT) \\
\hline Pal 2015 & Study design (cross-over study with hypertensive volunteers) \\
\hline Raja 2011 & Type of participants (focus on myocardial infarction) \\
\hline Raja 2018 & Type of participants (focus on cardiomyopathy, not heart failure alone) \\
\hline Rajagopal 2010 & Study design (no RCT) \\
\hline Reil 2012 & Study design (no RCT) \\
\hline Riccioni 2012 & Type of intervention (comparator BB, not placebo or SC) \\
\hline Sallam 2016 & Study design (no RCT) \\
\hline Santos 2014 & Study design (no RCT) \\
\hline Sisakian 2014 & Study design (no RCT) ("empirically allocated") \\
\hline Tagliamonte 2016 & Study design (no RCT) \\
\hline Tregubov 2015 & Type of intervention (comparator BB, not placebo or SC) \\
\hline
\end{tabular}




\begin{tabular}{ll}
\hline Study & Reason for exclusion \\
\hline Tumasyan 2009 & Type of participants (focus on cardiomyopathy, not heart failure alone) \\
\hline Vatinian 2015 & Study design (no RCT) \\
\hline Volterrani 2011 & Type of intervention (comparator BB, not placebo or SC) \\
\hline Xu 2011 & Type of intervention (comparator BB, not placebo or SC) \\
\hline Yao 2014 & Study design (no RCT) \\
\hline
\end{tabular}

$\mathrm{BB}=$ beta-blocker, $\mathrm{RCT}=$ randomised controlled trial, $\mathrm{SC}=$ standard care

Characteristics of ongoing studies [ordered by study ID]

\section{ACTRN12612000710820}

\begin{tabular}{ll}
\hline Study name & Novel interventions in heart failure with preserved ejection fraction using ivabradine \\
\hline Methods & Study design: Single-centre, randomised, double-blinded, placebo cross-over pilot study \\
Unit of randomisation: Blocking is used to ensure that comparison groups will be generated ac- \\
cording to a predetermined ratio, usually 1:1 or groups of approximately the same size. \\
Total duration of study: 18 weeks \\
Intervention time: 18 weeks \\
Follow-up: No information \\
Setting: Department of Cardiovascular Medicine, Flinders Medical Centre, Bedford Park, South \\
Australia
\end{tabular}

Participants

Type of heart failure: HF-PEF

$\mathbf{N}=20$ participants

Age: > 18 years

Gender: Both males and females

\section{Inclusion criteria:}

1. Age $\geq 18$ years

2. HF-PEF (LVEF $\geq 50 \%$ within 6 months of randomisation)

3. NYHA II-III

4. Diastolic dysfunction on echo

5. $E / A=1, E / E^{\prime} \geq 15$, deceleration time $\leq 140 \mathrm{~ms}$

6. Heart rate over $70 / \mathrm{min}$

7. Stable disease, confirmed by no hospital admissions or HF medication changes within 3 months prior to randomisation

8. Informed consent

9. No other causes for exertional dyspnoea

\section{Exclusion criteria:}

1. Atrial fibrillation

2. Contraindications to MRI

3. Significant valvular or coronary disease as primary cause of $\mathrm{HF}$

4. Hypertrophic cardiomyopathy, cardiac amyloidosis, sarcoidosis 


\author{
5. GFR $\geq 45 \mathrm{~mL} / \mathrm{min}$
}

Intervention: Ivabradine max. 5 to $7.5 \mathrm{mg}$
Comparison: Placebo (microcellulose oral capsule twice daily)
Concomitant medications: No information
Excluded medications: No information

Outcomes

Outcomes and time points measured in the study:

[Baseline, 8, 18 weeks]

Primary outcome:

- Improvement in 6-minute walk test

- Peak $\mathrm{VO}_{2}$ as assessed by cardio-pulmonary exercise testing. The $\mathrm{VO}_{2}$ is calculated using the difference between the heart rate at rest and at peak exercise. The heart rate blood pressure and concentration of inspired oxygen will be monitored regularly by monitors.

Secondary outcome:

- RV volume as assessed on cardiac magnetic resonance imaging

- Diastolic parameters of E/E', E/A ratio on echocardiogram

\begin{tabular}{ll}
\hline Starting date & No information \\
\hline Contact information & Dr Govindarajan Srinivasan \\
& Department of Cardiovascular Medicine \\
& Flinders Medical Centre, 1, Flinders Drive \\
& Bedford Park, SA, 5042 \\
& Australia \\
& Phone: $+61-08-82017916$ \\
& Fax: $+61-08-82017701$ \\
& Email: Govindarajan.Srinivasan@health.sa.gov.au \\
\hline
\end{tabular}

Notes

Funding source category: Self-funded/unfunded

Primary sponsor type: Other collaborative groups

Name: South Australian Health and Medical Research Institute

Ethics status: Approved by Southern Adelaide Clinical Human Research Ethics Committee

\title{
ChiCTR-IIR-17013377
}

Study name

Efffect of ivabradine in heart failure with preserved ejection fraction: a multicenter and randomized controlled clinical trial

\section{Methods}

Study design: Multicentre randomised controlled clinical trial (parallel)

Unit of randomisation: Random sequence generated by SPSS software (19.0)

Total duration of study: 31 December 2017 to 30 April 2018

Intervention time: No information

Follow-up: No information 
Participants

Type of heart failure: HF-PEF

$\mathbf{N}=60$ participants (30 intervention; 30 placebo)

Age: 18 to 70 years

Gender: Both males and females

\section{Inclusion criteria:}

- Aged 18 70 years

- With a history of symptomatic chronic heart failure of at least 3 months (NYHA class II or III), to receive the optimal treatment and to be in a stable clinical condition

- $\mathrm{EF} \% \geq 50 \%$

- At least 1 predefined echocardiographic criterion related to diastolic dysfunction as evaluated by the investigating site:

* echo-Doppler E/e' ratio of $>13$;

* e' lateral $<10 \mathrm{~cm} / \mathrm{s}$ and e' septal $<8 \mathrm{~cm} / \mathrm{s}$;

* indexed volume of the left atrium (LAVI) of $>34 \mathrm{~mL} / \mathrm{m}^{2} \mathrm{E} / \mathrm{e}^{\prime}=$ ratio of peak early diastolic mitral flow velocity divided by the mean of the annular lateral (e' lateral) and septal (e' septal) velocities.

- Patient enrolment were exercise capacity $<80 \%$ of age-predicted and sex-predicted normal ranges in Cardiopulmonary Exercise Testing.

\section{Exclusion criteria:}

1. Severe valvular disease, primary hypertrophic or restrictive cardiomyopathy, and systemic illness associated with infiltrative heart disease

2. Permanent atrial fibrillation or recent ( $<3$ months) atrial fibrillation-related hospitalisation, pacemaker carriage

3. Severe or uncontrolled hypertension (systolic blood pressure $>160 \mathrm{mmHg}$ or diastolic blood pressure $>100 \mathrm{mmHg}$ )

4. Treatments not allowed at inclusion and during the study included non-dihydropyridine calcium channel blockers, class I antiarrhythmics, and strong inhibitors of cytochrome P450 3A4

5. Heart rate $<60$ beats/min; sick sinus syndrome; second- and third-degree atrioventricular block

6. Established or suspected pulmonary diseases, sever joint-associated disease, COPD, pulmonary hypertension

7. ACS in recent 2 months or coronary revascularisation in recent 6 months
Intervention: Ivabradine

Comparison: Placebo

Concomitant medications: No information

Excluded medications: Non-dihydropyridine calcium channel blockers, class I antiarrhythmics, and strong inhibitors of cytochrome P450 3A4

\section{Outcomes and time points measured in the study:}

$[1,4$ weeks]

Primary outcome: $\mathrm{VO}_{2}$ peak 
ChiCTR-IIR-17013377 (Continued)

Measure method: Cardiopulmonary Exercise Testing

Starting date 31 December 2017

Contact information Cao Yalin

Department of Cardiology, The First Affiliated Hospital, Sun Yat-sen University

58 Second Zhongshan Road

Yuexiu District

Guangzhou, Guangdong

China

Phone: +86 13650917403

Email: 1132909739@qq.com

Primary sponsor: The First Affiliated Hospital of Sun Yat-sen University Secondary sponsor:

- Nanfang Hospital, Southern Medical University

- Military General Hospital of Guangzhou

- The First People's Hospital of Guangzhou

Ethics status: Approved by ICE for clinical research and animal trials of the First Affiliated Hospital of Sun Yat-sen University

\section{EUCTR2012-002742-20-CZ}

$\begin{array}{ll}\text { Study name } & \text { Effect of ivabradine versus placebo on cardiac function and on capacity to perform exercise in pa- } \\ \text { tients suffering from diastolic heart failure }\end{array}$

Methods

Study design: Interventional clinical trial of medicinal product

Controlled: yes; Randomised: yes; Open: no; Single-blind: no; Double-blind: yes; Parallel group: yes; Cross-over: no; Other: no; If controlled, specify comparator, Other Medicinial Product: no; Placebo: yes; Number of treatment arms in the trial: 2

Unit of randomisation: No information

Total duration of study: 8 months

Intervention time: 8 months

Follow-up: No information

Setting: International multicentre trial (Argentina, Australia, Austria, Belgium, Brazil, the Czech Republic, France, Germany, Hungary, Ireland, Italy, Korea, Republic of Netherlands, Poland, Portugal, Russian Federation, Slovenia, Spain, Taiwan, the United Kingdom)

Participants

\section{Type of heart failure: HF-PEF}

$\mathbf{N}=400$ participants

Age: $>50$ years

Gender: Both males and females 


\section{Inclusion criteria:}

1. Male or female patients

2. Aged 50 years or older

3. Symptomatic chronic heart failure of NYHA class II or III for at least 3 months prior to selection

4. In stable clinical condition with regard to CHF symptoms for at least 4 weeks prior to selection

5. Documented sinus rhythm and HR superior or equal to $70 \mathrm{bpm}$ on a resting standard 12-lead ECG at selection and inclusion

6. Left ventricular ejection fraction superior or equal to $45 \%$ and $E / e^{\prime}>13$ ( $E=$ early diastolic mitral flow velocity; e' = mean of mitral annular lateral and septal proto diastolic velocities) or e' lateral

$<10 \mathrm{~cm} / \mathrm{s}$ and e' septal $<8 \mathrm{~cm} / \mathrm{s}$ or LAVI $>34 \mathrm{~mL} / \mathrm{m}^{2}$ at selection

7. Documented NT-pro-BNP $>=220 \mathrm{pg} / \mathrm{mL}$ or BNP $>=80 \mathrm{pg} / \mathrm{mL}$ at selection

\section{Exclusion criteria:}

1. Recent (less than 3 months) myocardial infarction or coronary revascularisation

2. Scheduled coronary revascularisation

3. Severe aortic or mitral stenosis, or severe aortic regurgitation, or severe primary mitral regurgitation

4. Scheduled surgery for valvular heart disease

5. Congenital heart disease

6. Previous cardiac transplantation or on list for cardiac transplantation

7. Documented permanent atrial fibrillation or other cardiac arrhythmia that interferes with the sinus node function, or recent hospitalisation for atrial fibrillation or other cardiac arrhythmia that interferes with the sinus node function within the last 3 months

8. Patients able to walk more than 450 metres within 6 minutes during the selection and the inclusion visits

9. Previous treatment with ivabradine within the last 6 months before selection, or current treatment with ivabradine

10. Previous mitral valvular surgery or intervention

Interventions

Intervention: Ivabradine $2.5 \mathrm{mg}$ to $5 \mathrm{mg}$ to $7.5 \mathrm{mg}$

Comparison: Placebo

Concomitant medications: No information

Excluded medications: No information

\section{Outcomes}

\section{Outcomes measured in the study:}

Primary outcome: [up to M008]

- Co-primary endpoints based on echocardiography (E/e')

- Neuroendocrine activation (NT-pro-BNP)

- 6-minute walk test

Secondary outcome: [All over the study]

- Efficacy and safety endpoints

\begin{tabular}{ll}
\hline Starting date & 7 Mai 2013 (not recruiting) \\
\hline Contact information & Clinical Studies Department \\
& Institut de Recherches Internationales Servier \\
50, rue Carnot 92284 Suresnes Cedex France
\end{tabular}

Phone: +33155724366

Email: clinicaltrials@servier.com 
EUCTR2012-002742-20-CZ (Continued)

Notes

Primary sponsor: Institut de Recherches Internationales Servier

Ethics status: No information the earlier introduction of Ivabradine in the Management of Systolic Dysfunction Heart Failure. The QUALIVA study

\section{Methods}

\section{Study design: Interventional clinical trial of medicinal product}

Controlled: yes; Randomised: yes; Open: yes; Single-blind: no; Double-blind: no; Parallel group: yes; Cross-over: no; Other: no; If controlled, specify comparator, Other Medicinial Product: yes; Placebo: no; Number of treatment arms in the trial: 2

Unit of randomisation: No information

Total duration of study: No information

Intervention time: 18 weeks

Follow-up: No information

Setting: School of Medicine \& Medical Science, St Vincent's Hospital Dublin 4 Elm Park Ireland

\section{Participants}

Type of heart failure: HF-REF

$\mathbf{N}=50$ participants

Age: 18 years

Gender: Both males and females

\section{Inclusion criteria:}

1. Recently prescribed the beta-blocker bisoprolol or carvedilol (a maximum of 4 weeks since initiating treatment and at least 1 week for bisoprolol and at least 2 weeks for carvedilol since the last BB dose adjustment with doses not greater than bisoprolol $5 \mathrm{mg}$ daily/carvedilol $12.5 \mathrm{mg}$ twice daily, to allow further uptitration)

2. Willing to give written informed consent to participate in the study and to comply with the study procedures and restrictions during the study period

3. Male or female $=18$ years

4. Diagnosed with symptomatic HF-REF and LVEF $=40 \%$ (measured no longer than 3 months before the selection visit)

5. Systolic CHF class II and III (NYHA class)

6. No evidence of clinical decompensation

7. Electrocardiographic documentation of sinus rhythm with resting heart rate $=70 \mathrm{bpm}$

8. $\mathrm{SBP} \leq 120 \mathrm{mmHg}$ and $\geq 100 \mathrm{mmHg}$

9. Able to walk more than 450 metres within 6 minutes during inclusion visit (INCL)

10. Recently prescribed the beta-blockers bisoprolol or carvedilol and undergoing BB titration (at least 1 week for bisoprolol and at least 2 weeks for carvedilol since the last BB dose adjustment), with dose not greater than bisoprolol $5 \mathrm{mg}$ daily/carvedilol $12.5 \mathrm{mg}$ twice daily, to allow further uptitration

11. Having completed other drug titration so as to confine the drug manipulation during the study period to a minimum (e.g. on full-dose ACEi/ARB)

12. ICD implantation is acceptable for inclusion. The presence of a CRT device will be assessed on a case-by-case basis.

\section{Exclusion criteria:}


1. Participation in another study at the same time or within 3 months prior to the selection visit (ASSE) for this study

2. Unable to provide written informed consent

3. Women who are pregnant or breastfeeding or women of childbearing potential not using estro-progestative oral or intrauterine contraception or implants, or women using estro-progestative oral or intrauterine contraception or implants but who consider stopping it during the planned duration of the study. Menopause will be defined as absence of menses for $=1$ year.

4. Current treatment with beta-blocker other than bisoprolol or carvedilol

5. Current treatment with ivabradine or previous treatment in the last 6 months

6. Resting heart rate $<70 \mathrm{bpm}$

7. Able to walk more than 450 metres within 6 minutes during inclusion visit (INCL)

8. History of drug or alcohol use that, in the opinion of the investigator, would interfere with adherence to study requirements

9. Known severe renal insufficiency with calculated creatinine clearance $=15 \mathrm{~mL} / \mathrm{min} / 1.732$

10. Severe hepatic insufficiency

11. Any other significant disease or disorder which, in the opinion of the investigator, may either put the person at risk by participation in the study, or may influence the result of the study 12. Prior or concurrent malignancy within 5 years prior to starting the study treatment 13. Known contraindication/allergy/sensitivity/intolerance to study medications or their ingredients (ivabradine, bisoprolol and/or carvedilol)

14. Documented permanent atrial fibrillation or other cardiac arrhythmia that interferes with the sinus node function, or recent hospitalisation for atrial fibrillation or other cardiac arrhythmia that interferes with the sinus node function within the last 3 months

15. Severe hypotension $(<90 / 50 \mathrm{mmHg})$

16. Cardiogenic shock

17. Sick sinus syndrome, sino-atrial block, second- and third-degree AV-block

18. Unstable or acute heart failure

19. Unstable angina

20. Recent myocardial infarction or coronary revascularisation (less than 2 months)

21. Pacemaker-dependent

22. Other clinically significant ECG findings as judged by the investigator

23. Patients with familial history or congenital or substance-induced long QT syndrome or treated with selected QT-prolonging products (see section 12.9)

24. Scheduled for procedures requiring general anaesthesia during the study

25. Clinically significant abnormalities as judged by the investigator in haematology and biochemistry parameters. Special attention should be given to potentially significant abnormal values of the renal or liver function test.

26. Clinically significant findings as judged by the investigator during the procedures performed at the selection or inclusion visits

27. Any treatment with unauthorised medications (see section 12.9) that could not be interrupted for the duration of the study

28. Patients requiring a treatment that is unauthorised during the study or for whom such a treatment is considered

Interventions

Intervention: Ivabradine $5 \mathrm{mg}$ to $7.5 \mathrm{mg}$

Comparison: Bisoprolol (Cardicor) 1.25 to $10 \mathrm{mg}$; carvedilol 3.125 to $50 \mathrm{mg}$

Concomitant medications: Bisoprolol or carvedilol

Excluded medications: Beta-blocker other than bisoprolol or carvedilol

Outcomes

\section{Outcomes measured in the study:}

Primary outcome: [baseline, week 18]

- Difference in metres between the 6MWT

Secondary outcome: [baseline, week 18]

- Other domain scores of the KCCQ assessed

- Functional capacity (NYHA class) and clinical symptoms of heart failure assessed during the study 
- Clinical outcomes assessed during the study

- BNP measured

- Renal function

- Becks Depression Score

- Number/time to occurrence of the first event of 1 of the following: patient death from any cause; hospitalisation for any cause; emergency room visits for any cause; and outpatient visits for management of clinical deterioration of heart failure

- Adverse event recording (safety follow-up)

\begin{tabular}{ll}
\hline Starting date & 17 August 2015, not recruiting \\
\hline Contact information & Prof Ken McDonald \\
& School of Medicine \& Medical Science \\
& St Vincent's Hospital \\
& Dublin 4 Elm Park \\
& Ireland
\end{tabular}

Phone: 35316638110

Email: Kenneth.mcdonald@ucd.ie

Ethics status: Approved

Allocation: Randomised Intervention model: Parallel assignment Masking: Double (participant, investigator)

Primary purpose: Treatment

Unit of Randomisation: No information

Total duration of study: No information

Intervention time: 32 weeks

Follow-up: No information

Setting: The military general hospital of Beijing PLA; The second affiliated hospital of suzhou university; Subei People's Hospital of Jiangsu province; the First Hospital of Jilin University; shengjing hospital of China medical university; Qilu Hospital of Shandong University; the Second Hospital of Shandong University; The first affiliated hospital of zhejiang university school of medicine; Hangzhou First People's Hospital; The second affiliated hospital of zhejiang university school of medicine; The first affiliated hospital of wenzhou medical university; The second affiliated hospital of wenzhou medical university

Participants

Type of heart failure: Chronic systolic heart failure

$\mathbf{N}=336$ participants 


\section{Age: 18 to 75 years}

Gender: Both males and females

\section{Inclusion criteria:}

1. Aged from 18 to 75 years, males or females

2. Willing to provide written informed consent

3. NYHA class II, III, or IV for $\geq 4$ weeks, in stable clinical condition for $\geq 4$ weeks

4. Optimised and unchanged chronic heart failure medications and dosages for $\geq 4$ weeks

5. Sinus rhythm with resting heart rate $\geq 70 \mathrm{bpm}$

6. Left-ventricular systolic dysfunction, with ejection fraction $\geq 40 \%$ documented within previous 1 month

\section{Exclusion criteria:}

1. Unstable cardiovascular condition (e.g. hospital admission for worsening heart failure)

2. Recent ( $<2$ months) myocardial infarction or recent or scheduled coronary revascularisation

3. Stroke or transient cerebral ischaemia within previous 4 weeks

4. Severe primary valvular disease

5. Scheduled surgery of valvular heart disease

6. Active myocarditis

7. Congenital heart diseases

8. Peripartum cardiomyopathy

9. Hyperthyroid heart disease

10. On list for cardiac transplantation

11. Cardiac resynchronisation therapy started within previous 6 months

12. Pacemaker with atrial or ventricular pacing (except biventricular pacing) $>40 \%$ of the time, or with stimulation threshold at the atrial or ventricular level $>60 \mathrm{bpm}$

13. Permanent atrial fibrillation or flutter

14. Sick sinus syndrome, sinoatrial block, second- and third-degree atrio-ventricular block

15. History of symptomatic or sustained $(\geq 30 \mathrm{~s}$ ) ventricular arrhythmia unless a cardioverter/defibrillator implanted

16. Cardioverter/defibrillator shock within previous 6 months

17. Family history or congenital long QT syndrome or treated with selected QT-prolonging products (except amiodarone)

18. Contraindication or intolerance to ivabradine or lactulose

19. Severe or uncontrolled hypertension (SBP $\geq 180 \mathrm{mmHg}$ or $\mathrm{DBP} \geq 110 \mathrm{mmHg}$ )

20. Known anaemia (haemoglobin $<100 \mathrm{~g} / \mathrm{L}$ )

21. Known moderate or severe liver disease (ALT/AST > 3ULN), known severe renal disease ( $\mathrm{Cr}>$ 2ULN)

22. Pregnant or lactating women and women planning to become pregnant

23. Use of an investigational drug within 30 days of enrolment

24. Has a history of psychological illness/condition that interferes with ability to understand or complete requirements of the study

Concomitant medications: Optimised and unchanged chronic heart failure medications and dosages for $\geq 4$ weeks

Excluded medications: Use of an investigational drug within 30 days of enrolment

\section{Outcomes}

\section{Outcomes measured in the study:}

Primary outcome: [baseline, week 18]

- Change from baseline in left ventricular end systolic volume index by ultrasound cardiogram

Secondary outcome: [baseline, week 32]

- Change from baseline in left ventricular end diastolic volume index and left ventricular ejection fraction (LVEF) 
NCT02188082 (Continued)

- Incidence of hospital admission for worsening heart failure, any cardiovascular hospital admission, cardiovascular mortality, all-cause mortality

- Change from baseline in distance of 6-minute walking test

- Change from baseline in heart rate

- Change from baseline in scores of Kansas City Cardiomyopathy Questionnaire

- Change from baseline in NT-pro-BNP

\begin{tabular}{ll}
\hline Starting date & May 2014, recruiting \\
\hline Contact information & Jianan Wang, Doctor \\
& The Second Affiliated Hospital of Zhejiang University School of Medicine \\
Hangzhou, Zhejiang & China \\
& 310009 \\
& Phone: No information \\
& Email: No information \\
\hline Notes & Primary sponsor: Jiangsu HengRui Medicine Co., Ltd. \\
Ethics status: No information
\end{tabular}

\section{NCT03701880}

Study name

The impact of ivabradine administration on clinical outcome and biomarkers of decompensated heart failure

Methods

\section{Study design: Interventional}

Allocation: Randomised

Intervention model: Parallel assignment

Masking: None (open-label)

Primary purpose: Treatment

Unit of randomisation: Not applicable

Total duration of study: No information

Intervention time: 3 months

Follow-up: No information

Setting: El Demerdash Hospital, Cairo, Egypt

\section{Participants}

Type of heart failure: HF-REF, decompensated heart failure

$\mathbf{N}=50$ participants

Age: $>18$ years

Gender: Both males and females

\section{Inclusion criteria:}

1. Patient with acute heart failure either newly diagnosed or decompensated heart failure after stabilisation 
NCT03701880 (Continued)
2. Patients $>18$ years old
3. Left ventricular ejection fraction less than $40 \%$ of presumed irreversible aetiology
4. Clinically stable 24 to 48 hours after admission
5. Sinus rhythm with heart rate above $70 \mathrm{bpm}$
6 . No previous treatment with ivabradine

\section{Exclusion criteria:}

1. Patients less than 18 years

2. Arterial fibrillation before inclusion

3. Ventricular dysfunction due to acute event (myocarditis, AMI)

4. Cardiogenic shock

5. Patients are taking drug interact with ivabradine

6. Carrier or candidate for pacemaker, heart transportation, cardiac surgery, or other cardiovascular procedure

Interventions

Intervention: Ivabradine 5 to $7.5 \mathrm{mg}$

Comparison: Bisoprolol 2.5 to $10 \mathrm{mg}$

Concomitant medications: No information

Excluded medications: No information

\begin{tabular}{|c|c|}
\hline Outcomes & $\begin{array}{l}\text { Outcomes measured in the study: } \\
\text { Primary outcome: [3 months] } \\
\text { - Serum pro-BNP level } \\
\text { Secondary outcomes: [3 months] } \\
\text { - ST2 serum level } \\
\text { - The effect on patient quality of life using Minnesota Living with Heart Failure Questionnaire [3 } \\
\text { months of follow-up] } \\
\text { - HYHA class assessment } \\
\text { - Left ventricular ejection fraction assessment } \\
\text { - Blood pressure }\end{array}$ \\
\hline Starting date & 16 September 2018 , not recruiting \\
\hline Contact information & $\begin{array}{l}\text { Nouran Ahmed Aly } \\
\text { Teaching Assistant of Clinical Pharmacy Department } \\
\text { Sadat City University } \\
\text { Phone: No information } \\
\text { Email: No information }\end{array}$ \\
\hline Notes & $\begin{array}{l}\text { Primary sponsor: Ain Shams University } \\
\text { Collaborator: Sadat City University } \\
\text { Ethics status: No information }\end{array}$ \\
\hline
\end{tabular}

Abbreviations: $\mathrm{ACE}=$ Angiotensin-converting enzyme, $\mathrm{ACS}=$ Acute coronary syndrome, $\mathrm{ARB}=$ angiotensin receptor blockers, $\mathrm{BNP}=$ brain natriuretic peptide,, $\mathrm{bpm}=$ beats per minute, $\mathrm{COPD}=$ Chronic obstructive pulmonary disease, $\mathrm{CHF}=$ chronic heart failure, $\mathrm{CRT}=\mathrm{Cardiac}$ 
resynchronization therapy, $\mathrm{e}^{\prime}=$ Early diastolic mitral annulus velocity, $\mathrm{E} / \mathrm{A}=$ ratio of peak velocity blood flow from gravity in early diastole to peak velocity flow in late diastole caused by atrial contraction, $E / E^{\prime}=$ ratio between early mitral inflow velocity and mitral annular early diastolic velocity, $\mathrm{ECG}=$ electrocardiogram, $\mathrm{EF}=$ ejection fraction, $\mathrm{GFR}=\mathrm{Glomerular}$ filtration rate, $\mathrm{HF}=$ heart failure, $\mathrm{HFpEF}=\mathrm{heart}$ failure with preserved ejection fraction, $\mathrm{HR}=$ heart rate, $\mathrm{ICD}=$ implantable cardioverter-defibrillator, $\mathrm{KCCQ}=\mathrm{Kansas}$ City Cardiomyopathy Questionnaire, LAVI = Left Atrial Volume Index, LVEF = Left ventricular ejection fraction, max. = maximum, MRI = magnetic resonance imaging, 6MWT = six minute walk test, NT-pro-BNP = N-terminal pro brain natriuretic peptide, NYHA = New York Heart Association, $\mathrm{pVO} 2$ = peak oxygen uptake, QT interval = time of ventricular activity including both depolarisation and repolarisation, RV = right ventricular, $\mathrm{SBP}=$ systolic blood pressure

\section{DATA AND ANALYSES}

Comparison 1. Usual care with ivabradine compared to placebo, usual care, or no treatment in participants with HFrEF (long-term treatment ( $\geq 6$ months) with ivabradine)

\begin{tabular}{lllll}
\hline Outcome or subgroup title & No. of studies & $\begin{array}{l}\text { No. of partici- } \\
\text { pants }\end{array}$ & Statistical method & Effect size \\
\hline $\begin{array}{l}1.1 \text { Mortality from cardiovascular causes } \\
\text { follow-up range 19 months to 23 months) }\end{array}$ & 3 & 17676 & $\begin{array}{l}\text { Risk Ratio (M-H, Random, } \\
95 \% \mathrm{Cl})\end{array}$ & $0.99[0.88,1.11]$ \\
\hline 1.2 Rate of serious adverse events & 2 & Risk Ratio (M-H, Random, & $0.96[0.92,1.00]$ \\
\hline
\end{tabular}

Analysis 1.1. Comparison 1: Usual care with ivabradine compared to placebo, usual care, or no treatment in participants with HFrEF (long-term treatment ( $\geq 6$ months) with ivabradine), Outcome 1: Mortality from cardiovascular causes (follow-up range 19 months to 23 months)

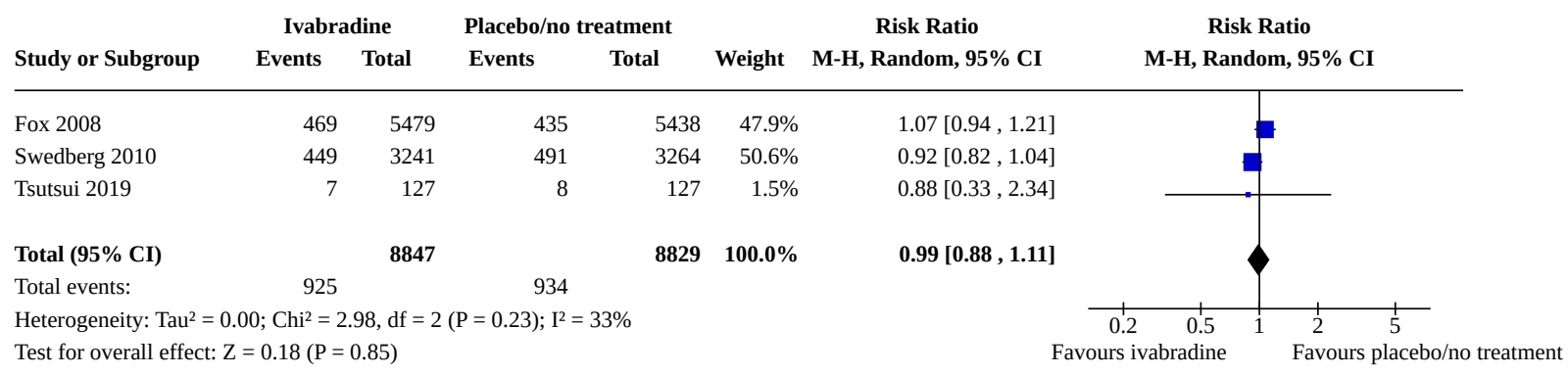

Test for subgroup differences: Not applicable

\section{Analysis 1.2. Comparison 1: Usual care with ivabradine compared to placebo, usual care, or no treatment in participants with HFrEF (long-term treatment ( $\geq 6$ months) with ivabradine), Outcome 2: Rate of serious adverse events}

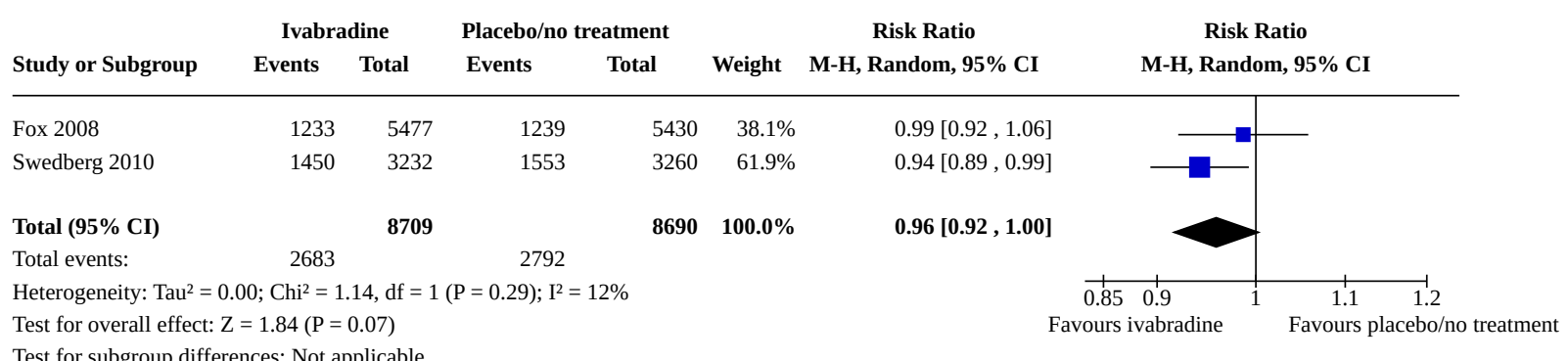




\section{ADDITIONAL TABLES}

Table 1. New York Heart Association (NYHA) classification

\begin{tabular}{lll}
\hline Class & Definition & Other descriptor \\
\hline I & No symptoms & Asymptomatic \\
\hline II & Symptoms with ordinary activity & Mild symptoms \\
\hline III & $\begin{array}{l}\text { Symptoms with less than ordinary } \\
\text { activity }\end{array}$ & Moderate symptoms \\
\hline IV & $\begin{array}{l}\text { Symptoms at rest or with any minimal } \\
\text { activity }\end{array}$ & Severe symptoms \\
\hline
\end{tabular}




\begin{tabular}{|c|c|c|c|c|c|c|c|c|c|}
\hline Reference & $\begin{array}{l}\text { Number } \\
\text { of centres }\end{array}$ & Intervention & $\begin{array}{l}\text { Ivabra- } \\
\text { dine } \\
\text { [n] }\end{array}$ & $\begin{array}{l}\text { Place- } \\
\text { bo/SC } \\
\text { [n] }\end{array}$ & Dosage & $\begin{array}{l}\text { Duration } \\
\text { IP }\end{array}$ & $\begin{array}{l}\text { Timing } \\
\text { outcomes }\end{array}$ & $\begin{array}{l}\text { Ejection } \\
\text { fraction } \\
{[\%]}\end{array}$ & Guideline adherence ${ }^{\star \star \star}$ \\
\hline \multicolumn{10}{|c|}{ Short-term treatment ( $<6$ months) with ivabradine } \\
\hline $\begin{array}{l}\text { Abdel } \\
2011^{\star}\end{array}$ & 1 & $\begin{array}{l}\text { Ivabradine } \\
\text { Placebo }\end{array}$ & 50 & 50 & $\begin{array}{l}5 \mathrm{mg} / 7.5 \mathrm{mg} \\
\text { twice a day }\end{array}$ & ns & W 0,12 & $\mathrm{EF}<35$ & ns \\
\hline $\begin{array}{l}\text { Adamyan } \\
2008^{\star}\end{array}$ & ns & $\begin{array}{l}\text { Ivabradine } \\
\text { SC }\end{array}$ & 70 & 75 & $\begin{array}{l}7.5 \mathrm{mg} \text { twice a } \\
\text { day }\end{array}$ & D 90 & D 0, 30, 90 & $\mathrm{EF}<35$ & $\begin{array}{l}\text { Patients with intolerance to BB were } \\
\text { included; ACE/ARB and MRA were } \\
\text { given. }\end{array}$ \\
\hline $\begin{array}{l}\text { Bansal } \\
2019\end{array}$ & 1 & $\begin{array}{l}\text { Ivabradine } \\
\text { SC }\end{array}$ & 157 & 152 & ns & ns & D 0 & ns & ns \\
\hline $\begin{array}{l}\text { Sarullo } \\
2010\end{array}$ & 1 & $\begin{array}{l}\text { Ivabradine } \\
\text { Placebo }\end{array}$ & 30 & 30 & $\begin{array}{l}5 \mathrm{mg} / 7.5 \mathrm{mg} \\
\text { twice a day }\end{array}$ & M 3 & M 0, 3 & $\mathrm{LVEF} \leq 40$ & BB (60.1\%); ACE inhibitor (85\%) \\
\hline $\begin{array}{l}\text { Tsutsui } \\
2016\end{array}$ & 73 & $\begin{array}{l}\text { Ivabradine } \\
\text { Placebo }\end{array}$ & 84 & 42 & $\begin{array}{l}2.5 \text { to } 7.5 \mathrm{mg} \\
\text { twice a day }\end{array}$ & W 6 & W 0,6 & $\mathrm{LVEF} \leq 35$ & $\begin{array}{l}\text { BB }(92.9 \%) \text {; ACE inhibitor ( } 45.8 \%) \text {; } \\
\text { ARB }(26.8 \%) \text {; ACE inhibitor or ARB } \\
(70.6 \%) \text { MRA }(55.1 \%)\end{array}$ \\
\hline \multicolumn{10}{|c|}{ Long-term treatment ( $\geq 6$ months) with ivabradine } \\
\hline $\begin{array}{l}\text { Chaudhari } \\
2014^{\star}\end{array}$ & 1 & $\begin{array}{l}\text { Ivabradine } \\
\text { SC }\end{array}$ & 78 & 80 & $\begin{array}{l}5 \text { mg twice a } \\
\text { day }\end{array}$ & M 6 & $M 0,6$ & LVEF $<40$ & ns \\
\hline Fox 2008 & 781 & $\begin{array}{l}\text { Ivabradine } \\
\text { Placebo }\end{array}$ & 5479 & 5438 & $\begin{array}{l}5 \mathrm{mg} / 7.5 \mathrm{mg} \\
\text { twice a day }\end{array}$ & $\sim \mathrm{M} 19$ & $\begin{array}{l}\text { D 0, W 2, M } \\
1,3,6,12 \\
18,24\end{array}$ & LVEF $<40$ & $\begin{array}{l}\text { BB }(83.5 \%) \text {; ACE inhibitor or ARB or } \\
\text { both }(89.5 \%) \text {; MRA }(29.5 \%)\end{array}$ \\
\hline $\begin{array}{l}\text { Potapenko } \\
2011\end{array}$ & 1 & $\begin{array}{l}\text { Ivabradine } \\
\text { SC }\end{array}$ & 23 & 26 & $\begin{array}{l}5 \mathrm{mg} / 7.5 \mathrm{mg} \\
\text { twice a day }{ }^{\star \star}\end{array}$ & $Y 3,5$ & Y 3,5 & LVEF $<40$ & BB (85.7\%); ACE inhibitor (96\%) \\
\hline $\begin{array}{l}\text { Sisakian } \\
2016\end{array}$ & 1 & $\begin{array}{l}\text { Ivabradine } \\
\text { SC }\end{array}$ & 27 & 27 & $\begin{array}{l}2.5 \mathrm{mg} / 5 \\
\mathrm{mg} / 7.5 \mathrm{mg} \\
\text { twice a day }\end{array}$ & M 3 & D $0,14,28$ & LVEF $<40$ & $\begin{array}{l}\text { BB (79.7\%); ACE inhibitor and/or ARB } \\
(85.2 \%) \text {; MRA ( } 25.5 \%)\end{array}$ \\
\hline $\begin{array}{l}\text { Swedberg } \\
2010\end{array}$ & 677 & $\begin{array}{l}\text { Ivabradine } \\
\text { Placebo }\end{array}$ & 3268 & 3290 & $\begin{array}{l}5 \mathrm{mg} / 7.5 \mathrm{mg} \\
\text { twice a day }\end{array}$ & M 12 & D $0, M 12$ & $\mathrm{LVEF} \leq 35$ & $\begin{array}{l}\text { BB (89.5\%); ACE inhibitor (78.5\%); } \\
\text { MRA (60.0\%) }\end{array}$ \\
\hline
\end{tabular}


Table 2. Study characteristics of studies with HFrEF (Continued)

\begin{tabular}{|c|c|c|c|c|c|c|c|c|c|}
\hline $\begin{array}{l}\text { Tsutsui } \\
2019\end{array}$ & 146 & $\begin{array}{l}\text { Ivabradine } \\
\text { Placebo }\end{array}$ & 127 & 127 & $\begin{array}{l}2.5 \text { to } 7.5 \mathrm{mg} \\
\text { twice a day }\end{array}$ & W 52 & every $2 \mathrm{M}$ & LVEF $\leq 35$ & $\begin{array}{l}\text { ACE inhibitor (48.9\%); ARB (20.1\%); } \\
\text { ACE inhibitor and/or ARB (68.5\%); } \\
\text { MRA (77.6\%) }\end{array}$ \\
\hline
\end{tabular}

$\Sigma 9393$

$\Sigma 9337$

*Reported only as abstract.

** Initial dose $5 \mathrm{mg}$ twice a day; after 2 weeks with a heart rate of $60 / \mathrm{min}$ or higher: $7.5 \mathrm{mg}$ twice a day; if heart rate dropped below $50 / \mathrm{min}$ or other clinical symptoms of bradycardia: again $5 \mathrm{mg}$ twice a day; if symptoms did not improve: ivabradine treatment stopped.

${ }^{\star \star \star}$ According to the European Society of Cardiology (ESC) Clinical Practice Guideline on Acute and Chronic Heart Failure (Ponikowski 2016).

Abbreviations: $\mathrm{ns}=$ not specified; $\mathrm{Y}=$ year; $\mathrm{M}=$ month; $\mathrm{W}=$ week; $\mathrm{D}=$ day; $\mathrm{ACE}$ inhibitor = angiotensin-converting enzyme inhibitor; $\mathrm{ARB}=$ angiotensin $\mathrm{II}$ receptor blocker; $\mathrm{BB}=$ betablockers; $\mathrm{EF}=$ ejection fraction; $\mathrm{HFrEF}=$ heart failure with reduced ejection fraction; $\mathrm{IP}=$ interventional product; $\mathrm{LVEF}=$ left ventricular ejection fraction; $\mathrm{MRA}=$ mineralocorticoid receptor antagonist; $\mathrm{SC}=$ standard care

\section{Table 3. Study characteristics of studies with HFpEF}

\begin{tabular}{|c|c|c|c|c|c|c|c|c|}
\hline$R$ & $\begin{array}{l}\text { Number } \\
\text { of centres }\end{array}$ & Intervention & $\begin{array}{l}\text { Ivabra- } \\
\text { dine }\end{array}$ & $\begin{array}{l}\text { Place- } \\
\text { bo/SC }\end{array}$ & Dosage & $\begin{array}{l}\text { Duration } \\
\text { IP }\end{array}$ & $\begin{array}{l}\text { Timing } \\
\text { outcomes }\end{array}$ & $\begin{array}{l}\text { Ejection } \\
\text { fraction [\%] }\end{array}$ \\
\hline
\end{tabular}

$[n] \quad[n]$

Short-term treatment ( $<6$ months) with ivabradine

\begin{tabular}{|c|c|c|c|c|c|c|c|c|c|}
\hline $\begin{array}{l}\text { De Masi De } \\
\text { Luca 2013* }\end{array}$ & ns & $\begin{array}{l}\text { Ivabradine } \\
\text { Placebo }\end{array}$ & 53 & 58 & $\begin{array}{l}5 \mathrm{mg} / 7.5 \mathrm{mg} \text { twice a } \\
\text { day }\end{array}$ & ns & M 0, 3 & $E F \geq 50$ & ns \\
\hline Kosmala 2013 & 3 & $\begin{array}{l}\text { Ivabradine } \\
\text { Placebo }\end{array}$ & 30 & 31 & $5 \mathrm{mg}$ twice a day & W 1 & $\mathrm{D} 0,7$ & $\mathrm{LVEF} \geq 50$ & ns \\
\hline
\end{tabular}

Long-term treatment ( $\geq 6$ months) with ivabradine

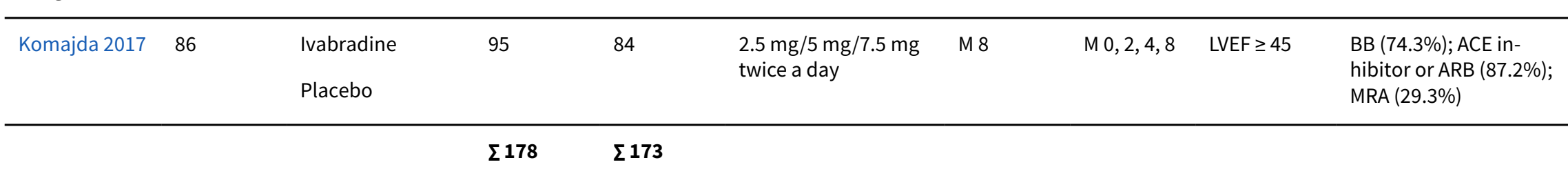

*Reported only as abstract.

** Initial dose $5 \mathrm{mg}$ twice a day; after 2 weeks with a heart rate of $60 / \mathrm{min}$ or higher: $7.5 \mathrm{mg}$ twice a day; if heart rate dropped below 50/min or other clinical symptoms of bradycardia: again $5 \mathrm{mg}$ twice a day; if symptoms did not improve: ivabradine treatment stopped.

${ }^{\star \star \star A}$ According to the European Society of Cardiology (ESC) Clinical Practice Guideline on Acute and Chronic Heart Failure (Ponikowski 2016). 
Abbreviations: $\mathrm{ns}=$ not specified; $\mathrm{M}=$ month; $\mathrm{W}=$ week; $\mathrm{D}=$ day; $\mathrm{ACE}$ inhibitor = angiotensin-converting enzyme inhibitor; $\mathrm{ARB}=$ angiotensin II receptor blocker; $\mathrm{BB}=$ beta- $\mathrm{blockers;}$ $\mathrm{EF}=$ ejection fraction; $\mathrm{IP}=$ interventional prodcut; $\mathrm{LVEF}=$ left ventricular ejection fraction; $\mathrm{MRA}=$ mineralocorticoid receptor antagonist; $\mathrm{SC}=\mathrm{standard}$ care 


\section{AP PEN DICES}

Appendix 1. Search strategy for randomised controlled trials

\section{CENTRAL}

\#1 Ivabradine

\#2 Procoralan

\#3 Corlanor

\#4 \#1 or \#2 or \#3

\#5 MeSH descriptor: [Heart Failure] explode all trees

\#6 ((heart or cardiac or myocard*) near/2 (fail* or insufficien* or decomp*))

\#7 \#5 or \#6

\#8 \#4 and \#7

\section{MEDLINE}

1. Ivabradine.tw.

2. Procoralan.tw.

3. Corlanor.tw.

4. 1 or 2 or 3

5. exp Heart Failure/

6. ((heart or cardiac or myocard $\left.{ }^{\star}\right)$ adj2 (fail ${ }^{\star}$ or insufficien ${ }^{\star}$ or decomp $\left.\left.{ }^{\star}\right)\right)$.tw.

7.5 or 6

8. 4 and 7

9. randomized controlled trial.pt.

10. controlled clinical trial.pt.

11. randomized.ab.

12. placebo.ab.

13. drug therapy.fs.

14. randomly.ab.

15. trial.ab

16. groups.ab.

17.9 or 10 or 11 or 12 or 13 or 14 or 15 or 16

18. exp animals/not humans.sh.

19. 17 not 18

20. 8 and 19

\section{EMBASE}

1. Ivabradine.tw. 
2. Procoralan.tw.

3. Corlanor.tw.

4. 1 or 2 or 3

5. exp heart failure/

6. ((heart or cardiac or myocard $\left.{ }^{\star}\right)$ adj2 (fail ${ }^{\star}$ or insufficien* or decomp $\left.{ }^{\star}\right)$ ).tw.

7.5 or 6

8. 4 and 7

9. random\$.tw.

10. factorial\$̣.tw.

11. crossover\$.tw.

12. cross over\$.tw.

13. cross-over\$.tw.

14. placebo\$.tw.

15. (doubl\$ adj blind\$).tw.

16. (singl\$ adj blind\$).tw.

17. assign\$.tw.

18. allocat\$.tw.

19. volunteer\$.tw.

20. crossover procedure/

21. double blind procedure/

22. randomized controlled trial/

23. single blind procedure/

24.9 or 10 or 11 or 12 or 13 or 14 or 15 or 16 or 17 or 18 or 19 or 20 or 21 or 22 or 23

25. (animal/ or nonhuman/) not human/

26. 24 not 25

27.8 and 26

\section{Web of Science}

\# 10 \#9 AND \#8

\# 9 TS=(random ${ }^{\star}$ or blind ${ }^{\star}$ or allocat ${ }^{\star}$ or assign* or trial $^{\star}$ or placebo* or crossover ${ }^{\star}$ or cross-over $\left.^{\star}\right)$

\# 8 \#7 AND \#4

\# 7 \#6 OR \#5

\# 6 TS=((heart or cardiac or myocard $\left.{ }^{\star}\right)$ near/2 $\left(\right.$ fail $^{\star}$ or insufficien ${ }^{\star}$ or decomp $\left.\left.{ }^{\star}\right)\right)$

\# 5 TS=Heart failure

\# 4 \#3 OR \#2 OR \#1

\# 3 TS=Corlanor

Ivabradine as adjuvant treatment for chronic heart failure (Review) 
\# 2 TS=Procoralan

\# 1 TS=Ivabradine

\section{US National Library of Medicine (clinicaltrials.gov)}

1. All studies

2. Chronic Heart Failure

3. Ivabradin*

4. Completed

5. Terminated

6. Unknown status

7. Interventional

8. Adult (18-64)

9. Older Adult (65+)

10. Interventional Clinic Trial

\section{WHO International Clinical Trials Registry Platform (ICTRP)}

1. All studies

2. Chronic Heart Failure

3. Ivabradin*

\section{Appendix 2. Economic evaluation search strategy}

\section{NHS Economic Evaluation Database}

\#1 Ivabradine

\#2 Procoralan

\#3 Corlanor

$\# 4 \# 1$ or \#2 or \#3

\#5 MeSH descriptor: [Heart Failure] explode all trees

\#6 ((heart or cardiac or myocard $\left.{ }^{\star}\right)$ near/2 (fail* or insufficien ${ }^{\star}$ or decomp $\left.{ }^{\star}\right)$ )

\#7 \#5 or \#6

\#8 \#4 and \#7

\section{MEDLINE Ovid}

1. Ivabradine.tw.

2. Procoralan.tw.

3. Corlanor.tw.

4. 1 or 2 or 3

5. exp Heart Failure/

6. ((heart or cardiac or myocard $\left.{ }^{\star}\right)$ adj2 (fail ${ }^{\star}$ or insufficien* or decomp $\left.\left.{ }^{\star}\right)\right)$.tw.

7.5 or 6 


\section{4 and 7}

\section{Economics/}

10. exp "costs and cost analysis"/

11. Economics, Dental/

12. exp economics, hospital/

13. Economics, Medical/

14. Economics, Nursing/

15. Economics, Pharmaceutical/

16. (economic\$ or cost or costs or costly or costing or price or prices or pricing or pharmacoeconomic\$).ti,ab.

17. (expenditure\$ not energy).ti,ab.

18. value for money.ti,ab.

19. budget\$.ti,ab.

20. or/9-19

21. ((energy or oxygen) adj cost).ti,ab.

22. (metabolic adj cost).ti,ab.

23. ((energy or oxygen) adj expenditure).ti,ab.

24. or $/ 21-23$

25. 20 not 24

26. letter.pt.

27. editorial.pt.

28. historical article.pt.

29. or/26-28

30. 25 not 29

31. exp animals/ not humans/

32. 30 not 31

33. bmj.jn.

34. "cochrane database of systematic reviews".jn.

35. health technology assessment winchester england.jn.

36. or/33-35

37.32 not 36

38. 37 and 8

39. limit 38 to ed $=20150101-20200320$

\section{Embase Ovid}

1 Ivabradine.tw.

2 Procoralan.tw. 
3 Corlanor.tw.

41 or 2 or 3

5 exp Heart Failure/

$6\left(\left(\right.\right.$ heart or cardiac or myocard*) adj2 (fail* or insufficien* or decomp $\left.\left.{ }^{\star}\right)\right)$.tw.

75 or 6

84 and 7

9 Health Economics/

10 exp Economic Evaluation/

11 exp Health Care Cost/

12 pharmacoeconomics/

139 or 10 or 11 or 12

14 (econom\$ or cost or costs or costly or costing or price or prices or pricing or pharmacoeconomic\$).ti,ab.

15 (expenditure\$ not energy).ti,ab.

16 (value adj2 money).ti,ab.

17 budget\$.ti,ab.

1814 or 15 or 16 or 17

1913 or 18

20 letter.pt.

21 editorial.pt.

22 note.pt.

2320 or 21 or 22

$2419 \operatorname{not} 23$

25 (metabolic adj cost).ti,ab.

26 ((energy or oxygen) adj cost).ti,ab.

27 ((energy or oxygen) adj expenditure).ti,ab.

2825 or 26 or 27

2924 not 28

30 animal/

31 exp animal experiment/

32 nonhuman/

33 (rat or rats or mouse or mice or hamster or hamsters or animal or animals or dog or dogs or cat or cats or bovine or sheep).ti,ab,sh.

3430 or 31 or 32 or 33

35 exp human/

36 human experiment/

3735 or 36 
3834 not (34 and 37)

3929 not 38

40 0959-8146.is.

41 (1469-493X or 1366-5278).is.

42 1756-1833.en.

4340 or 41 or 42

4439 not 43

45 conference abstract.pt.

4644 not 45

478 and 46

48 limit 47 to yr="2015 -Current"

\section{H I S T O R Y}

Protocol first published: Issue 4, 2018

Review first published: Issue 11, 2020

\section{CONTRIBUTIONS OF AUTHORS}

$\mathrm{CB}$ is the primary contact author for this review. CB co-ordinated the review. CB selected trials, extracted data, assessed the methodological quality of trials, was responsible for handling data in Review Manager 5, checked data entered into Review Manager 5, designed the metaanalyses, interpreted the results, drafted the review, revised the manuscript, and approved the final version. CB is the guarantor of this review.

CK selected trials, extracted data, assessed the methodological quality of trials, checked data entered into Review Manager 5 , interpreted the results, contributed important content to the drafting of the review, and approved the final version.

TB selected trials, extracted data, assessed the methodological quality of trials, checked data entered into Review Manager 5, contributed important content to the drafting of the review, and approved the final version.

NH designed the meta-analyses, contributed important content to the drafting of the review, and approved the final version.

GM provided support and guidance throughout the review, contributed important content to the drafting of the review, and approved the final version.

CS extracted data, contributed important content to the drafting of the review, and approved the final version.

VB selected trials, extracted data, assessed the methodological quality of trials, was responsible for handling data in Review Manager 5 , designed the meta-analysis, contributed important content to the drafting of the review, revised the manuscript, and approved the final version.

\section{DECLARATIONSOF INTEREST}

CB: none known.

CK: none known.

TB: none known.

$\mathrm{NH}$ : none known.

GM: none known.

CS: none known.

VB: none known. 


\section{SOURCES OF SUPPORT}

\section{Internal sources}

- No sources of support supplied

\section{External sources}

- This project was supported by the National Institute for Health Research (NIHR), via Cochrane Infrastructure funding to the Heart Group. The views and opinions expressed therein are those of the authors and do not necessarily reflect those of the Systematic Reviews Programme, NIHR, NHS, or the Department of Health and Social Care, UK

- This research project is supported by the START-Program of the Faculty of Medicine, RWTHAachen, Germany

\section{DIFFERENCES BETWEEN PROTOCOLANDREVIEW}

When we created the protocol, we did not distinguish between type of heart failure (heart failure with reduced ejection fraction (HFrEF) and heart failure with preserved ejection fraction (HFpEF)) per se, but planned subgroup analyses to assess these differences. The study selection process then identified both studies focusing exclusively on HFrEF or HFpEF. We then made the decision to distinguish between both conditions per se due to clinical differences between patient populations, as described in the Background section in detail.

We initially planned the following subgroup analyses for the investigation of statistical heterogeneity.

1. Dosage of ivabradine (e.g. limited to starting dosage of $5 \mathrm{mg}$ or increased dosage, based on resting heart rate).

2. Severity of heart failure (e.g. we distinguished between studies that included participants diagnosed with HFrEF, or participants diagnosed with HFpEF with a mid-range ejection fraction (HFmrEF) diagnosed with heart failure). For this subgroup analysis, we adopted the definitions provided by the European Society of Cardiology, and based the level of heart failure on the left ventricular ejection fraction (LVEF): a) HFrEF applies to participants with an LVEF < 40\%; b) HFpEF applies to participants with an LVEF $\geq 50 \%$; and c) HFmrEF applies to participants with an LVEF between 40\% and 49\% (Ponikowski 2016).

3. Optimal or suboptimal medical therapy for chronic heart failure (e.g. we also distinguished between participants receiving optimal or suboptimal medical therapy for chronic heart failure as recommended: angiotensin-converting-enzyme (ACE) inhibitors plus betablockers plus mineralocorticoid receptor antagonist (MRA)).

4. Duration of ivabradine treatment (short-term treatment ( $<6$ months) or long-term treatment ( $\geq 6$ months)).

Due to heterogeneity in participant characteristics (e.g. long- and short-term duration of ivabradine treatment), differences in the underlying condition (HFpEF and HFrEF), and heterogeneity in outcome definition and reporting in included studies, we were not able to perform subgroup analysis.

The following sensitivity analyses were initially planned:

1. 'Best-worst case' scenario: we assumed that all participants lost to follow-up in the ivabradine group had survived, had no serious adverse event, had not been hospitalised for heart failure, and had improved quality of life, defined as the group mean plus both one and two standard deviations of the group mean; and we assumed that all those with missing outcomes in the control group had died, had a serious adverse event, had been hospitalised for heart failure, and had reduced quality of life, defined as the group mean plus both one and two standard deviations of the group mean (Jakobsen 2014).

2. 'Worst-best case' scenario: we assumed that all those with missing outcomes in the control group had died, had a serious adverse event, had been hospitalised for heart failure, and had reduced quality of life, defined as the group mean plus both one and two standard deviations of the group mean; and we assumed that all participants lost to follow-up in the ivabradine group had survived, had no serious adverse event, had not been hospitalised for heart failure, and had improved quality of life, defined as the group mean plus both one and two standard deviations of the group mean (Jakobsen 2014).

Based on the limited evidence available for this Cochrane Review, sensitivity analysis was not feasible.

To maintain stringency, we decided to report all outcomes in a 'Summary of findings' table even though exercise capacity and economic costs were initially planned only for assessment and not for the 'Summary of findings' table.

Last, we rephrased the secondary outcome 'adverse events' more specifically ('rate of serious adverse events'), as serious adverse events is a stronger outcome which greatly increases the informative value of our review.

\section{N DEX TERMS}

\section{Medical Subject Headings (MeSH)}

Bias; Cardiovascular Agents [adverse effects] [economics] [*therapeutic use]; Cardiovascular Diseases [mortality]; Chemotherapy, Adjuvant; Chronic Disease; Exercise Tolerance [drug effects]; Heart Failure [ ${ }^{\star}$ drug therapy] [mortality]; Ivabradine [adverse effects] [economics] [*therapeutic use]; Placebos [therapeutic use]; Randomized Controlled Trials as Topic; Stroke Volume 


\section{MeSH check words}

Female; Humans; Male; Middle Aged 